\title{
Coping matters in psychosis : Bleuler's right
}

Citation for published version (APA):

Bak, M. L. F. J. (2004). Coping matters in psychosis : Bleuler's right. [Doctoral Thesis, Maastricht University]. Datawyse / Universitaire Pers Maastricht. https://doi.org/10.26481/dis.20040924mb

Document status and date:

Published: 01/01/2004

DOI:

10.26481/dis.20040924mb

Document Version:

Publisher's PDF, also known as Version of record

\section{Please check the document version of this publication:}

- A submitted manuscript is the version of the article upon submission and before peer-review. There can be important differences between the submitted version and the official published version of record.

People interested in the research are advised to contact the author for the final version of the publication, or visit the DOI to the publisher's website.

- The final author version and the galley proof are versions of the publication after peer review.

- The final published version features the final layout of the paper including the volume, issue and page numbers.

Link to publication

\footnotetext{
General rights rights.

- You may freely distribute the URL identifying the publication in the public portal. please follow below link for the End User Agreement:

www.umlib.nl/taverne-license

Take down policy

If you believe that this document breaches copyright please contact us at:

repository@maastrichtuniversity.nl

providing details and we will investigate your claim.
}

Copyright and moral rights for the publications made accessible in the public portal are retained by the authors and/or other copyright owners and it is a condition of accessing publications that users recognise and abide by the legal requirements associated with these

- Users may download and print one copy of any publication from the public portal for the purpose of private study or research.

- You may not further distribute the material or use it for any profit-making activity or commercial gain

If the publication is distributed under the terms of Article $25 \mathrm{fa}$ of the Dutch Copyright Act, indicated by the "Taverne" license above, 


\title{
Coping Matters in Psychosis
}

\author{
Bleuler's Right
}


Ein vielbesprochener Kriterium der Heilung ist die Krankheitseinsicht. Leute, die selber von ihren Wahnideen, von ithem Verhalten während des Anfalles als von krankhaften Erscheinungen sprechen, die begreifen, daß man sie so und so behandeln mußse, und gar noch dem Arzt oder der Anstalt dankbar sind, werden nicht ohne Grund leicht als geheilt angesehen, während das Gegenteil ein ziemlich sicheres Zeichen fortbestehender Krankheit ist.

(Eugen. Bleuler, $19 \rrbracket$, Dementia Praecox, oder Gruppe der Schizophrenien, p 211.)

(Heruitgave van orgineel, Arts \& Boeve Nijmegen 2001) 


\title{
Coping Matters in Psychosis
}

\section{Bleuler's Right}

\author{
PROEFSCHRIFT \\ ter verkrijging van de graad doctor \\ aan de Universiteit Maastricht, \\ op gezag van de Rector Magnificus, \\ Prof. mr. G.P.M.F. Mols
}

volgens het besluit van het College van Decanen,

in het openbaar te verdedigen

op vrijdag 24 september 2004 om 12.00 uur

door

Maarten Lucas Friedrich Joseph Bak

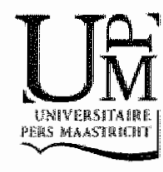




\section{Promotor}

Prof. dr. J.J. van Os

\section{Copromotores}

Dr. Ph.A.E.G. Delespaul

Dr. I. Myin-Germeys

\section{Beoordelingscommissie}

Prof. dr. F.R.J. Verhey (voorzitter)

Dr. M. van der Gaag (Rijksuniversiteit Groningen)

Prof. dr. M. Romme

Dr. L.R. Valmaggia (University of London)

Prof. dr. M. de Vries

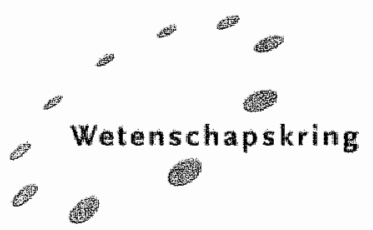

South-Limburg Mental Health Research and Teaching Network PhD Series

Unrestricted financial support for this thesis has kindly been provided by

Janssen Cilag

Lilly

Astra Zeneca 


\section{Contents}

1. Introduction

Defining schizophrenia

Continum of psychosis

Vulnerability stress model of psychosis

Cognitive models of psychosis

Insight and subjective experiences in psychosis

Perceived control with distress

Defining coping.

Coping with psychosis

Need for care with psychosis

Ains and method of this study

Outline of this dissertation

2. Description of Maastricht Assessment of Coping Strategies (MACS)

3. MACS-I: Maastricht Assessment of Coping Strategies

A brief instrument to assess coping with psychotic symptoms

4. MACS-II: Does coping enhance subjective control over psychotic symptoms?

5. Predictive value of "clinician recognised" and "clinician non-recognised" self-reported positive psychotic symptoms: a prospective general population study....

6. When does experience of psychosis result in need for care?

A prospective general population study.

7. Do different psychotic experiences differentially predict need for care in the general population?

8. General discussion: Coping matters in psychosis

9. Summary - Samenvatting

10. Appendix: Overview of coping research on psychosis

11. Dankwoord, CV en publicaties 

Chapter 1

Introduction 
Schizophrenia and the spectrum of psychotic disorders still poses problems of definition and delimitation for clinicians and researchers alike, while for patients with psychotic symptoms the pathway to care is often tortuous and difficult to find. Not only subjects reconised as patients with a psychotic disorder do suffer and need care. In the general population, people who suffer from psychotic experiences as delusons or hallucinations may be in need for care, and yet have difficulties to get in contact with services in order to receive the care they need. Alien and frightening experiences, the inability to make sense of these experiences, misunderstanding or misinterpreting the environment, and being stigmatised and misunderstood paradoxically constitute reasons for need for care as well as some of the main obstacles in obtaining it. People facing these experiences and the ensuing problems, develop so-called coping strategies. These coping strategies remain underresearched yet may disclose suitable avenues that aid in achieving personal recovery, facilitate the process of contacting health care professionals and clarify need for care through better understanding people or patients behaviour. Coping strategies arising in the context of psychosis are the central theme of this dissertation.

The introduction provides a short description of the continuum of psychosis, which means the natural distribution of psychotic experiences present in the general population throughout psychotic disorder and how it relates to the concept of schizophrenia. We will discuss the literature of coping with psychotic symptoms that are part of the schizophrenia syndrome and coping with psychotic experiences as part of the continuum of psychosis, and describe methods to assess it. Subsequently, a framework describing the relationship between psychotic experiences, symptoms and need for care is introduced.

\section{Defining schizophrenia}

After more than a century of research, the assessment of schizophrenia and its causes is still debated. The most widely accepted criteria for a diagnosis of schizophrenia are described in the fourth edition of the Diagnostic and Statistic Manual of Mental Disorders (DSM-IV) (American Psychiatric Association, 1994). "The essential features of schizophrenia are a mixture of characteristic signs and symptoms (both positive and negative) that have been present for a significant portion of time (or shorter if successfully treated), with some signs of the disorder persisting for at least 6 months". The characteristic signs and symptoms fall into two broad categories.

Positive symptoms reflect an excess or distortion of normal functions: distortions of inferential thinking (delusions), perception (hallucination), language and communication (disorganised speech) and disorganised or catatonic behaviour. Negative symptoms are restrictions within the normal range and intensity of mental functions: reduced emotional expression (affective 
flattening), reduced fluency and productivity of thought and speech (alogia) and reduced goal-directed behaviour (avolition).

A diagnosis of schizophrenia is assessed if at least two of the so-called Criteria A (1. delusions, 2. hallucinations, 3. disorganised speech, 4. grossly disorganised or catatonic behaviour, 5. negative symptoms) are present for at least one month except when treated adequately. These signs and symptoms should be associated with marked social and occupational dysfunction for a significantly long period (Criterion B). In addition, Criterion $C$ stipulates that attenuated symptoms of the prodromal and residual phases, together with the acute phase last for more than six months. Finally, the disturbance is not a schizo-affective disorder or a mood disorder with psychotic features and is not due to the direct physiological effects of a substance or a general medical condition (Criteria D and E) (American Psychiatric Association, 1994).

Scholars in the field have proposed to reduce the heterogeneity of the definition of schizophrenia by introducing subclasses based on clinical picture, outcome development, underlying pathology and factor analyses of the symptoms (Crow, 1985; Kuipers, 1992; Van Os, Jones, Sham, Bebbington, \& Murray, 1998). The most popular sub-classification is the positive and negative typology of schizophrenia. The positive type is characterised by hallucinations and delusion, an acute onset, episodic course with good prognosis and reaction to antipsychotic drugs. The pathophysiology is thought to involve neurochemical mechanisms (such as increased dopaminergic activity). The negative type, in contrast, represents symptoms as flat affect, alogia and avolition, intellectual and cognitive impairments, an insidious onset, a chronic and deteriorating course, and poor response to anti-psychotic drugs.

Apart from reducing heterogeneity by clustering patients into subclasses, related symptoms can be clustered into symptom dimensions or syndromes. The covariation of symptoms or symptom dimensions is usually assessed with factor analysis. The optimal factorial solution for psychotic symptoms from structured scales such as the Brief Psychiatric Rating Scale (BPRS) (Overall \& Gorham, 1962), yields not two but three factors (Johnstone, Connelly, Frith, Lambert, \& Owens, 1996; Lidd]e, Barnes, Morris, \& Haque, 1989; Peralta, Cuesta, \& Farre, 1997): the reality distortion syndrome (hallucinations and delusional experiences), the disorganisation syndrome (e.g. formal thought disorder, speech disorder, inappropriate affect) and the psychomotor poverty syndrome (e.g. poverty of content of speech, lack of energy and initiative, flat affect, cognitive impairments). It remains unclear whether those factors represent separate entities with different aetiologies (Murray, O'Callaghan, Casile, \& Lewis, 1992) or divergent expressions of the same aetiology.

Although the DSM-classification system has improved the communication between clinicians and researchers about the various psychotic disorders, contemporary diagnosis of schizophrenia based on classification systems as DSM (American Psychiatric Association, 1994) might be responsible for the 
standstill in scientific improvement (Bentall, 1990, 1992; van Praag, 1992). With no objective criteria present to confirm a psychotic diagnosis, clinical judgements of delusions, hallucinations, unintelligible speech and conceptual disorganisation are used (Heinssen, Perkins, Appelbaum, \& Fenton, 2002). Relevant aspects as intensity, frequency and duration of these phenomena, as well as general functioning and distress are ignored (Ustun, Chatterji, \& Andrews, 2002). A re-evaluation of the fundamental symptoms and an appraisal of how patients adapt to troublesome and distressing experiences has been proposed (de Vries, 1992).

\section{Continuum of psychosis}

Considering the range of possible constituent symptoms, none of which are prerequisite, a wide range of heterogeneous symptoms and illness courses are enclosed in the concept of schizophrenia. However, none of these symptoms are pathognomonic for a diagnosis of schizophrenia. For example, hallucinations and delusions are present in numerous other medical or psychiatric diagnoses, even in subjects who cannot be diagnosed as suffering from a psychiatric disorder, but do have halucinatory or delusional experiences (Asaad \& Shapiro, 1986; Peters, Day, McKenna, \& Orbach, 1999; Romme \& Escher, 1994; Verdoux, Maurice-Tison et al., 1998). Deseribing psychotic disorders from the perspective of a continuum seems more rational (Johns \& van Os, 2001; van Os, Verdoux, Maurice-Tison et al., 1999). It encompasses the range of non-illness related psychotic experiences to the diagnosis of schizophrenia

In medicine, dichotomous (present/absent) categorisation of illness, symptoms and syndromes is used traditionally (Rose, 1992). The DSM-IV is a reflection of this categorical approach to psychiatric nosology (American Psychiatric Association, 1994). Categorical research has been successful in clinical decision-making and facilitates research into the aetiology of a syndrome and the evaluation of treatment strategies. To enhance reliability, the categorical approach defines strict rules to integrate experiences and symptoms into syndrome "caseness" (subjects who are in need for care) by proposing inclusion and exclusion rules to decide upon the differential diagnosis (Delespaul, 1995). However, it is questionable whether dichotomous categorisation of psychosis should be preferred to a continuous categorisation.

Delusions, hallucinations and disordered speech or thoughts, are regarded as core features of psychosis, irrespective of whether these signs and symptoms do represent a diagnosis of schizophrenia. Hallucinations are defined as perceptions without the triggering of a perceptual organ. They may occur in any sensory modality and are perceived as distinct from the person's own thoughts (American Psychiatric Association, 1994). Hallucinations are widespread amongst various other psychiatric diagnoses. It appears that hallucinatory experiences are also prevalent throughout the general population (Johns \& van 
Os, 2001; Kendler, Gallagher, Abelson, \& Kessler, 1996; Romme \& Escher, 1994; Tien, 1991; van Os, Hanssen, Bijl, \& Ravelli, 2000; van Os, Hanssen, Bijl, \& Vollebergh, 2001; van Os, Verdoux, Bijl R.V., \& Ravelli, 1999). This indicates that, although hallucinatory experiences may be regarded as core symptoms of psychosis, these experiences are also related with an array of differential diagnoses and indeed may be part of normal psychic experiences. While there is a general consensus on the definition of hallucinations, defining a delusion is more difficult. DSM-IV defines delusions as:

"erroneous beliefs that usually involve a misinterpretation of perceptions or experiences" (American Psychiatric Association, 1994). The definition of delusions has changed during the past years. The previous definition in DSM-III-R was:

"a false personal belief based on incorrect inference about external reality and firmly sustained in spite of what everyone else believes and in spite of constitutes incontrovertible and obvious proof of evidence to the contrary. The belief is not one ordinarily accepted by other members of a person's culture." (American Psychiatric Association, 1987).

Although both definitions appear intuitively correct, differences point to relevant qualitative differences between delusions and other strongly held beliefs, e.g. that God exists. In delusions, the awareness of meaning undergoes a transformation described as a direct experience of meaning or interpretation of meaning (Jaspers, 1963). However, delusions may share more similarities than differences with "normal" beliefs (Birchwood \& Jackson, 2001).

Therefore, whether hallucinations and delusions should be considered as pathognomonic of schizophrenia is challenged (Asaad \& Shapiro, 1986; Bentall, 1990; Johns \& van Os, 2001; E. Peters et al., 1999; Romme \& Escher, 1994; van Os, Hanssen et al., 2000; van Os, Verdoux, Maurice-Tison et al., 1999; Verdoux, Maurice-Tison et al., 1998). As said before, delusions and hallucinations may be considered as extremes of a continuum that starts within normality and changes by the degree of conviction and the extent of preoccupation with the belief (Claridge, 1997; Strauss, 1969). Psychosis-like experiences that are prevalent in non-clinical, general population samples, show a true quantitative continuum or they are qualitatively different and therefore not directly related with disorders like DSM constructs of schizophrenia.

Two complementary approaches have been used to explore the range of psychotic phenomena in non-clinical populations. The first approach is based upon a "fully dimensional" model (Claridge, 1997; Claridge \& Beech, 1995). It takes "normality" as the reference point, and conceptualises psychosis as a dimensional trait ranging to clinical levels of psychosis. Deviance, here a psychotic disorder or schizophrenia, is represented in personality as health diversity (Claridge, 1994). The non-pathological counterpart of schizophrenia, 
often called schizotypy or psychosis proneness, is organised around a multiple factor model resembling the factor models of schizophrenia (Venables \& Bailes, 1994; Venables \& Rector, 2000). This model of a fully dimensional approach matches normal life experiences since "in the flow of experiences, based on the awareness that an experience has reached the level of delusion or hallucination grows ower time" (Delespaul, 1995). For example, "after a while someone realises that he thought his food was poisoned, so he must have been delusive". In retrospect, we draw a line and interpret slight changes that passed unnoticed when they occurred as the beginning of a new phase. It is not the intensity or frequency of psychotic experiences that define the transition to a psychotic state, but rather the concomitant distress and preoccupation that distinguish between presence or absence of disorder in the experiences ( $E$. Peters et al., 1999). This illustrates that in the moment-to-moment experience of subjects, the majority of the psychotic features are experienced in a continuum, ranging from normal to a clinically defined symptom (Delespaul, 1995).

A slightly different approach is the "quasi-dimensional" model (Johns \& van Os, 2001). This model takes the abnormal illness related symptom state as the reference point, and explores full-blown psychotic symptoms in both nonclinical and clinical populations. The psychotic disorder is viewed as the result of unique causal factors related to the disorder per se and/or the result of shared risk factors. General population studies - which are generally based on a quasi-dimensional model and use structured diagnostic interviews demonstrate that psychotic experiences and full-blown psychotic symptoms are quite common (van Os, Verdoux, Maurice-Tison et al., 1999). The Epidemiological Catchments Area study in the USA has reported a lifetime prevalence of hallucinations without clear organic causes in $10 \%$ of the men and $15 \%$ of the women (Tien, 1991). In the Eastern Baltimore Mental Health Survey, $10 \%$ of the subjects reported at least three paranoid symptoms and $5 \%$ experienced at least one hallucination during their life (Eaton, Romanoski, Anthony, $\&$ Nestadt, 1991). In about a quarter of the subjects $(28.4 \%)$ it was agreed that at least one interview item was related to a delusion or hallucination in the National Co-morbidity Survey (Kendler et al., 1996). However, clinicianassessed lifetime prevalence of narrow-defined psychosis -- presence of psychotic symptoms with presence of distress or general dysfunction -- was only $0.2 \%$. It rose to $0.7 \%$ for broadly defined psychosis syndrome, i.e. presence of positive symptoms only. In the Dutch NEMESIS study, also a general population study, $17.5 \%$ of the subjects report one or more CIDI defined true psychotic symptoms (van Os, Hanssen et al., 2000). The prevalence of lifetime DSM-III-R diagnosis of non-affective psychosis is $1.5 \%$ (van Os, Hanssen et al., 2001). In a birth cohort at the age of 26 years, lifetime prevalence of psychotic symptoms was high: $20.1 \%$ for delusions and $13.2 \%$ for hallucinations (Poulton et al., 2000). These results clarify that applying 
diagnostic information to the general population (the quasi-dimensional model) seems to constitute a valid strategy.

These approaches demonstrate that psychosis can be conceptualised as a continuous process, with changes in intensity and frequency of signs and symptoms as a result of continuous interaction and perception of stressful or non-stressful environmental influences.

\section{Vulnerability-stress model of psychosis}

Since decades, starting before the anti-psychotic drugs era, descriptions have been given of patients who remained symptom-free for some time. However, symptoms often re-emerged. In other words: patients remain 'vulnerable" (Bleuler, 1978). Several early studies have shown that psychosocial stress, generated by stressful life events, trigger or exacerbate psychotic symptoms in vulnerable individuals (Wing, 1992; Wing, Bennet, \& Denham, 1964). Psychiatric symptoms emerge whenever the level of stressors exceeds the individuals vulnerability threshold, with the latter being a stable characteristic. This dynamic equilibrium between vulnerability and the personal stressors is described in the vulnerability-stress model (Nuechterlein \& Dawson, 1984; Zubin \& Spring, 1977). The vulnerability-stress model is the foundation of contemporary psychiatry and yields many interest of contemporary research programmes. It assumes that subjects differ in their liability to develop schizophrenia or psychosis (Nuechterlein \& Dawson, 1984; Zubin \& Spring, 1977). The transition to psychosis is a result of personal and environmental stressors, mediated by various vulnerability factors.

The vulnerability-stress model is embedded in two basic observations. Irrespective of the actual working mechanism, schizophrenia has a genetic and a neurobiological base (Andreasen \& Carpenter, 1993). But environmental influences also contribute to the expression and course of psychotic disorders (wan Os \& Marcelis, 1998). If particular vulnerability factors could be determined, they could be used to identify individuals who are at risk for developing schizophrenia. Although the search for vulnerability markers has been extensive, it has been hampered by methodological shortcomings. The genetic predisposition is generally agreed upon. Psycho-social markers as marital status, social status and family support, as well as expressed emotion $(\mathrm{EE})$, are strongly associated with psychosis and schizophrenia development or maintenance (Bebbington \& Kuipers, 1994; Leff, Kuipers, Berkowitz, Vaughn, \& Sturgeon, 1983; Leff \& Vaughn, 1980; Marcelis, Navarro-Mateu, Murray, Selten, \& Van Os, 1998; Murray \& Van Os, 1998; Van Os et al., 1998). Psychological factors, such as theory of mind deficits, attribution bias or abnormal perception and biases in reasoning processes, have been described over the past 15 years and are considered to be factors of psychological 
vulnerability (Birchwood \& Jackson, 2001; Garety \& Freeman, 1999; Garety, Kuipers, Fowler, Freeman, \& Bebbington, 2001).

There is widespread agreement that a vulnerable predisposition of bio-psychosocial origin defines psychosis proneness; the onset of full-blown psychosis often follows life events, adverse environments, illicit drug use or periods of isolation. There are emotional changes and disruptions in the cognitive process of attention, perception or judgement and at onset its most prominent symptoms are delusions and hallucinations (Garety et al., 2001). Yet, the assessment of psychotic symptoms and a diagnosis of schizophrenia are based upon indirect observations: subjective experiences and the ratings of behavioural expressions. Here behaviour is defined as a (mal)adaptive action or set of actions of individuals interacting with their environment in pursuing personal goals. In fact, the utmost contribution of the vulnerability-stress model is the understanding that psychosis emerges from disturbed balance, as subjects with a diagnosis of psychosis react with more intense emotions to subjective appraisals of stress in daily life than normal controls (Myin-Germeys, Delespaul, \& deVries, 2000; Myin-Germeys, van Os, Schwartz, Stone, \& Delespaul, 2001). Subjects with psychosis appear more sensitive to daily stress (Myin-Germeys et al., 2001). However, it not possible the predict the individual disturbances in the balance between vulnerability and stressful events.

Although the word stress is widely used in general communication and research on stress has been extensive, there is no universally accepted definition of the concept. It refers to an affective state expressed as emotional and bodily sensations in response to external or internal events that are threatening or are perceived as threatening. Major life events such as death of a family member or recent unemployment, have been implicated as precipitating factors in illness (Dohrenwend \& Dohrenwend, 1974). Later, the attention shifted towards the impact of daily hassles or minor stressors on illness development (Nicolson, 1992). The subjective level of stress may vary as a function of the number and/or severity of life events or daily hassles and the individual differences in vulnerability to the impact of life stress (Birchwood \& Jackson, 2001). It is clear that stress is conceptualised as a dynamic process, that changes in intensity continuously.

The vulnerability-stress model takes into account that individuals respond to stressful situations or experiences, but may not develop any illness if certain "protective factors" or adaptation factors are present (Delespaul, 1995; Nuechterlein \& Dawson, 1984; Nuechterlein et al., 1994). These adaptation factors can be internal, e.g. effective coping abilities, or external, e.g. social/environmental such as a supportive family (Green, 1992). Assessment of successful or failing adaptation processes that characterize the illness directly in the biological substrate is hitherto impossible. It is even uncommon to incorporate adaptation processes during diagnostic assessment or evaluation. However, the study of coping with stressful events seems clinically relevant, 
because of the balance between stress and vulnerability, resulting in presence or absence of a disorder.

\section{Cognitive models of psychosis}

The cognitive models describe psychological factors involved in formation and maintenance of positive symptoms of psychosis. These models are based on thorough research and offer modes for intervention in daily practice, usually subsumed under the heading of cognitive behaviour therapy (CBT).

Two routes are described towards psychotic symptom formation and maintenance. One proceeds through a primarily cognitive distortion with a disturbed emotional pathway and the other through affective disturbances alone (Garety et al., 2001). Crucial to the first route is the notion that cognitive disturbances will lead to conscious anomalous experiences. During the prodromal phase of development of psychotic experiences, subjects do acknowledge unfamiliar cognitive and perceptual changes. At that time these experiences have not yet turned into psychotic symptoms. Emotional changes, that occur in direct response to the triggering event and the anomalous experiences, trigger a feedback loop and add to the cognitive appraisal of the experience. Salience or personal relevance is crucial in the process of psychotic symptom formation (Maher, 1988). A bias in the appraisal process contributes to a judgement that these confusing experiences have an external cause. Psychotic symptoms develop when the individual appraises experiences as externally caused and personally relevant. Such appraisals are formally identified as delusions and hallucinations.

There are consistent findings that emotions play a causal and maintaining role in many cases of delusions and hallucinations. The experience of emotion will start a search for meaning and understanding. Life events trigger disturbed affect, which in turn directly activates biased appraisal and maladaptive self/other schemata, leading to an externalising appraisal (i.e. delusion or hallucination) of the life event or disturbed affect (Garety et al., 2001). Psychotic beliefs may be more firmly held if they are consistent with distorted beliefs about the self, others and the world. Furthermore, people with psychosis tend to have poor self-esteem (Close \& Garety, 1998; Freeman et al., 1998). Low self-esteem develops in aversive social environments and history of traumatic experiences (Bebbington \& Kuipers, 1994; Mueser et al., 1998; van Os, Driessen, Gunther, \& Delespaul., 2000; Van Os et al., 1998). Residual psychotic symptoms, in hallucinations as well as in delusions, are more common in depressed people who often suffer from feelings of hopelessness and uncontrollability (Birchwood, Iqbal, Chadwick, \& Trower, 2000). Depression will contribute to the persistence of positive psychotic symptoms, through a feedback into the affective route, resulting in maladaptive appraisal of experiences. Consistent with these findings, hopelessness and uncontrollability 
are predictors for poor outcome, resulting in increased likelihood of "caseness" (Aguilar et al., 1997: Birchwood, Mason, MacMillan, \& Healy, 1993). Metacognitive beliefs, such as beliefs concerning the uncontrollability of one"s thoughts, will increase the distress caused by the psychotic experiences (Freman \& Garety, 1999). Besides depression, anxiety is also an important emotion that creates distress and contributes to the development of hallucinations and enhancement of delusional thoughts (Slade, 1976).

Figure 1. Cognitive model of positive psychotic symptoms of psychosis

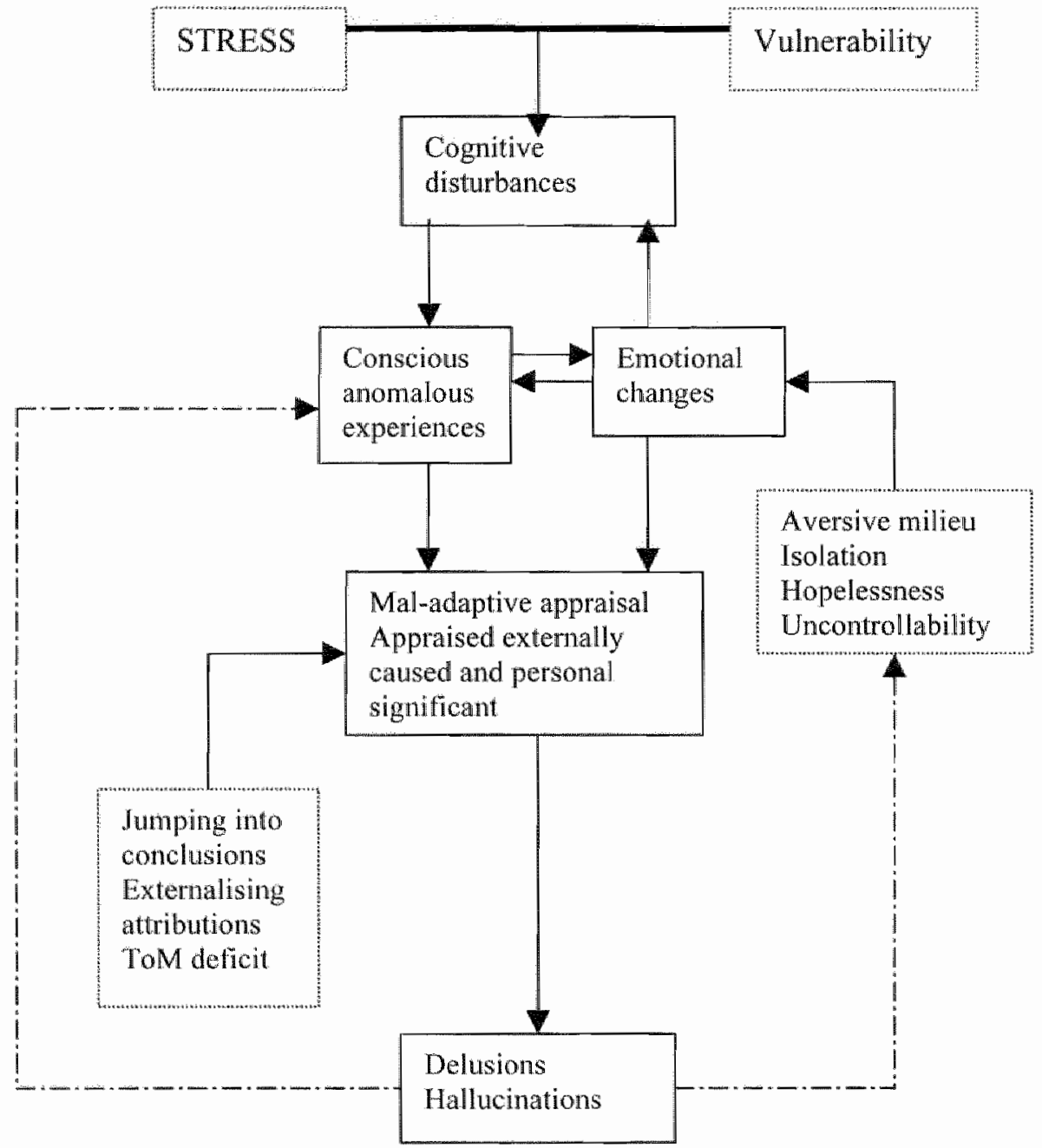

Reasoning biases such as jumping to conclusions, externalising attributional style and difficulties in understanding social situations and the intentions of others, are basic deficits that catalyse the maladaptive appraisal, with psychosis 
as a consequence (Garety \& Freeman, 1999). In general, subjects with psychosis use heuristic or probabilistic reasoning, in stead of logico-experimental reasoning for decision-making. When this reasoning process is hampered due to a data gathering bias, delusions and hallucinations may develop (Kingdon $\&$ Turkington, 1994). An example is the following case description:

A 26 old white male is convinced that his former girl-friend poisoned him by using "Voodoo" and therefore he feels very tired, weak and has lost his sexual drive. When she ended their relationship she held his head in her hands, which made him shiver and she said he would suffer for some years and no doctor would be able to help him. He asks regularly for a CT-scan, so we can discover where and what she put into his head. He does not accept the possibility that it is impossible that someone would poison him by putting hands on his head, that it is impossible to see a Voodoo derived brain abnormality on the CT-scan or that he mourns about the loss of his girlfriend. Even minor information in favour of confirmation of his beliefs is processed as proof that he is right, whereas clear contra-arguments are discarded. accompanied by statements that he is not taken seriously. He feels unable to do anything about his complaints, as he claims all his problems are due to the poisoning through "Voodoo". For that he seeks proof at the university library.

People tend to "jump to conclusions" as a data gathering bias, which decreases their problem-solving abilities. Reviewing the literature, Garety and Freeman concluded that "people with delusions show a tendency to seek less information to reach a decision, but they are able to use the appropriate information when it is presented to them" (Garety \& Freeman, 1999). This does not lead directly to errors, but may facilitate the early acceptance of incorrect hypotheses.

Secondly, they use an externalising attributional style, especially for negative events (Bentall, Kinderman, \& Kaney, 1994; Huq, Garety, \& Hemsley, 1988). This may result from a particular tendency to personalise - that is to blame people rather than situations when things go wrong. Three distinct attributional loci can be identified:

I) an internal locus - attributing events to oneself

II) an external-personal locus - attributing the event to identifiable others

III) external-situation locus - attributing the causes of events to situations or chance (Kinderman \& Bentall, 1996).

The external-personal locus and the external-situation locus are both related with development of suspiciousness.

A third cognitive bias found in psychoses that can result in psychotic symptom formation and maintenance, is the decreased ability to distinguish between external and internal stimuli, also found in autism spectrum disorder. Symptoms of schizophrenia reflect specific impairments in patients' ability to represent 
their own and other people's mental states, called meta-representation or Theory of Mind (ToM) deficit (Frith, 1992). Although ToM impairments in schizophrenia are less severe than in autism, they represent specific cognitive deficits (Pickup \& Frith, 2001). The cognitive deficit is probably caused by a disrupted relation between memory and perception. Memory traces are inadequately accessed. Therefore, the subject is unable to distinguish between relevant and irrelevant sensory information in this enviromment (Hemsley, 1994). This so-called lack of "theory of mind" (ToM) may result in deficiencies in normal social interaction with hampered ability for empathy, with an increased likelihood of psychosis development (Frith, Blakemore, \& Wolpert, 2000). Knowing what people think or recognising their emotional behaviour (non-verbal communication) is important in normal social interactions and a handicap in this function makes subjects prone to suspicious thoughts and leads to passivity experiences and third person auditory hallucinations (Birchwood \& Jackson, 2001).

As explained above, both emotional distress and cognitive dysfunctional schemata, that are closely related with emotional distress, contribute to the formation and maintenance of psychotic experiences or symptoms. It is suggested that secondary appraisals of illness (e.g. psychosis) influence engagement with treatment and adaptive behaviour (Garety et al., 2001). If it is the appraisal of a chronic mental illness, experiences of stigmatisation and humiliation may increase, which enhance development of depression (Birchwood, Meaden, Trower, Gilbert, \& Plaistow, 2000). Secondary appraisal of the experience of psychosis itself is defined as illness perception and defines the level of insight in psychosis. It may trigger a renewed emotion driven route to psychosis maintenance as mentioned above. It is argued that the forthcoming emotions are consequences of the psychotic experiences or symptoms themselves, expressed as distress or anxiety, low self-esteem and hopelessness in relation to specific delusional or hallucinatory experiences or symptoms, that launches a new loop of psychosis exacerbation. Safety behaviours will prevent the receipt of disconfirmatory evidence and consequently prevent change in psychotic beliefs (Freeman, Garety, \& Kuipers, 2001). These may be important factors related to the coping process.

\section{Insight and subjective experiences in psychosis}

Often, subjects with delusions or hallucinations are unaware of these experiences and deny the consequenses of these exeperience on their general functioning. In the literature about schizophrenia and schizophrenia spectrum disorders, subjects are often found to be unaware of their symptoms, the consequences of the disorder and the need for treatment (Amador et al., 1994; Amador, Strauss, Yale, \& Gorman, 1991; David et al., 1995). There are various mechanisms that may explain this lack of insight. It is often seen as a defence 
mechanism against the potentially devastating realisation of a person's illness or disstressing experiences. In its extreem form denial is a kind of self-deception that protects individuals from threats and involves exaggerated perceptions of control and self-efficacy. As will be argued later in this chapter, coping and defence mechanism will be distinguished at the level of conciousness of perceptions. Coping strategies are the conscious behavioural and cognitive actions, whereas defence mechanisms remain unconscious.

Variations in insight is an important issue in the assessment of subjects with a diagnosis of schizophrenia (Amador \& Gorman, 1998; McGorry \& McConville, 1999). Others, however, regard it as secondary (e.g. denial of the illness), and independent of the psychotic illness, acting as a defence mechanism against low self-esteem (McGlashan \& Carpenter, 1976). Evidence for this thesis comes from descriptive studies of psychological recovery from acute psychosis (McGlashan, 1975). The concept of lack of insight may therefore be somewhat simplistic and restrictive (Perkins \& Moodley, 1993). Individuals perspective, beliefs and values should be taken into account, as it may clinicians provide greater understanding of different models of illness, help-seeking and mental health service acceptability. From a cognitive psychological perspective, this implies that poor insight is the result of an overactivation of normal adaptive cognitive strategies to protect self-esteem (Amador et al., 1995; Amador et al., 1994; Amador \& Gorman, 1998). However, most experiences or symptoms that are part of a psychotic syndrome, are stress-related and force the subjects to adapt in various ways to the experience of stress, irrespective of whether they recognise the specific symptoms.

Lack of insight may also be viewed as misattribution, a form of cognitive error based on lack of information, systematic biases or idiosyncratic beliefs. Lack of insight is related to poor compliance (Bartko, Herczeg, \& Zador, 1988; Cuffel, Alford, Fischer, \& Owen, 1996; Fenton, Blyler, \& Heinssen, 1997), poor clinical outcome (Schwartz, 1998a; van Os et al, 1996), decreased social functioning (P. H. Lysaker, M. D. Bell, G. J. Bryson, \& E. Kaplan, 1998; van Os et al., 1996) and diminished response to vocational rehabilitation (Lysaker \& Bell, 1994). Insight is related to the level of positive psychotic symptoms, but not to negative symptoms, general psychopathology, global functioning or demographic characteristics (Schwartz, 1998b). Deficits in insight may result from cognitive impairments. The same phenomenological and neuropsychological characteristics occur in schizophrenia and neurological disorders (Amador \& Kronengold, 1998; Amador et al., 1991; David \& Cutting, 1994; P. H. Lysaker, M. D. Bell, G. Bryson, \& E. Kaplan, 1998). Other researchers have challenged the relation between insight and poor neuropsychological test performances (Cuesta \& Peralta, 1994; Cuesta, Peralta, Caro, \& de Leon, 1995; McEvoy et al., 1996). 


\section{Perceived control}

There is an extensive amount of research that identifies the key conditions of health behaviour and the negative impact of stress on health and health perception. The term health-related behaviour implies that illness-related information is understood (Lobban, Barrowclough, \& Jones, 2003) and that subjects are able to regulate physical and emotional distress to gain control over their disabilities (Leventhal et al., 1997). The perception of an enduring sense of control over important events in one's \ife contributes to well-being and general health status (Rodin \& Salovey, 1989; Rodin, Timko, \& Harris, 1985). The perception of control is related to socio-economic status (Bailis, Segall, Mahon, Chipperfield, \& Dunn, 2001; Pearlin \& Schooler, 1978; Rodin et al., 1985). Populations at risk of chronic illness often have a decreased socio-economic status and a decreased control perception (Helgeson, 1992; Skinner, 1996; Tennen, Affleck, Armeli, \& Carney, 2000). The perception of control comes from the individual history of success or failure in attaining one's goals. Individuals who experience repeated failure in their attempts to secure rewards or escape punishments, may develop the conviction that they are helpless (Seligman, 1975). This generalized expectation is an important determinant of coping in the face of hardships and perceived threats to health (Folkman, 1984). Coping with a situation, by altering the environment, changing the meaning of the situation, and/or managing one's emotions and behaviour, is an attempt to control it. If control refers to cognitive or behavioural efforts to deal with a stressful encounter, coping and control are regarded as synonymous. This is different from general and/or situational beliefs about control that influences cognitive appraisals of threat and challenge (Lazarus \& Folkman, 1984).

When negative events occur, both the stress that people experience and their persistence in seeking an adaptive response are likely to depend on their prior belief that they are able to control their lives (Lau \& Hartman, 1983; Matthews, 1982). Whether general, specific, illusory or realistic, one's belief in one's ability to control an event inlluences how that event is appraised and subsequently the elicited coping activity (Lazarus, DeLongis, Folkman, \& Gruen, 1985). Negative attributions about oneself or anomalous experiences, which will disturb the perception of control, define the coping process (Skinner, 1995, 1996; Skinner, Zimmer-Gembeck, \& Connell, 1998). Unravelling the concept of control perception with respect to its appraisal and coping functions, the pathways through which control perception affects the outcome of stressful events and short- and long-term adaptation will be better defined (Lazarus \& Folkman, 1984).

People strive for optimal perceived control through various adaptation processes, both at the conscious and at the unconscious level. Subjects suffering from psychotic symptoms adapt to the concomitant stress experience and should not be considered differently. According to the affective route of psychosis formation and maintenance, beliefs about the controllability of a situation may 
alter emotional experiences (Birchwood, Meaden et al., 2000; Freeman \& Garety, 1999; Freeman et al., 2001). Psychotic patients who experience control appear less disturbed by their symptoms and have a better prognosis (Breier \& Strauss, 1983; Falloon, 2000; Falloon \& Talbot, 1981). The underlying processes, when pursued consciously, could be considered as coping strategies.

\section{Defining coping}

Generally, psychotic symptoms and disorder generate some degree of distress. The study of people's responses to stressful and upsetting situations has generated a vast literature on a variety of overlapping concepts. The process of adaptation to stress is divided into two concepts: defence mechanisms and coping. Defence mechanisms and coping intend to diminish the negative impact of stress (Cramer, 2000; Somersfield \& McCrae, 2000). The central function of defence mechanisms is to keep the disturbing emotions or conflicts (expressed. as stress, anxiety) unconscious, to resolve the associated stress or anxiety. Defence mechanisms represent a trait adaptation to stress, as by definition they are rigid, compelled, reality distorting and undifferentiated (Haan, 1965). Although some overlap exists between defence mechanisms and coping, defence mechanisms are unconscious, non-intentional, dispositional, hierarchical and associated with pathology (Cramer, 2000, 2001). They are ordered along a hierarchical continum and differ in degree of maturity. The most adaptive are ranked on top of the hierarchy, the less adaptive, most immature defences at the bottom. It was Anna Freud who highlighted the fact that any given person has only a subset of favoured defence mechanisms (Waeldner, 1960). Persons with clinically assessed psychiatric symptoms are likely to use immature defences, whereas mature defence mechanisms are related with better mental health (Vaillant, Bond, \& Vaillant, 1986).

The coping concept has evolved out of the notion of defence mechanism and has distinct differences, although there is still disagreement about how strong the distinction is (Snyder \& Dinoff, 1999). Coping is conscious, intentional, flexible, reality oriented and differentiated. Central in the work on coping by Lazarus and colleagues is the idea that an individual confronted with a stressor appraises the situation and the possible responses. The transactional coping model of Lazarus focuses on the appraisal definition. (Lazarus, 1991, 1993, 2000; Lazarus \& Folkman, 1984). Appraisal is the (although not necessarily) conscious and immediate reaction to a stressor, while coping is the conscious, well targeted behavioural or cognitive adaptation process. In this model, a person uses two levels of appraisal:

I) primary appraisal; an individual evaluates whether the situation is potentially harmful, threatening, blocking a goal, etc, by determining if something is important or at risk. This is the 
cognitive evaluation of the stressful event and its importance for the person"s well-being.

II) secondary appraisal; the event is perceived as threatening or harmful, generating an examination of the available coping resources (Lazarus \& Folkman, 1984; Snyder \& Dinoff, 1999).

How people cope with various aspects of illness is one of the most widely studied topics in psychiatry and psychology. A multitude of researchers have come up with a wide range of variation in the definition of coping. Most researchers use a unidirectional, static, antecedent-consequence model (Carver, Scheier, \& Weintraub, 1989; Lazarus, 2000; Lazarus \& Folkman, 1984; Moos, 1988; Moos \& Schaeffer, 1993; Pearlin \& Schooler, 1978; Roth \& Cohen, 1986). In contrast to this model, the transactional model views the person and the environment in a dynamic, reciprocal, bi-directional relationship, which is conscious and intentional. Unfortunately, this process remains hypothetical, as there is no research method available for a direct observation of this process. According to this model, coping is understood as a process and assessed in the unfolding or flow of events. We shall adopt this transactional model as described by Lazarus and Folkman, with their definition of the coping process:

"Constantly changing cognitive and behavioural efforts to manage specific external and/or internal demands that are appraised as raxing or exceeding the resources of the person" (Lazarus \& Folkman, 1984).

Coping strategies are the resources an individual activates to maintain psychosocial adaptation during stressful periods; it encompasses cognitive and behavioural efforts to reduce or eliminate stressful situations and associated disturbing negative emotional reactions (Lazarus \& Folkman, 1984; Moos \& Schaeffer, 1993). Despite variation in definition by other researchers, coping research has agreed upon the following points (Folkman \& Moskowitz, 2000):

1. Coping has multiple functions, including but not limited to the regulation of distress and the management of problems causing distress.

2. Coping is influenced by the appraisal characteristics of the stressful context, including its controllability.

3. Coping is influenced by personality dispositions including optimism, neuroticism and extraversion.

4. Coping is influenced by social resources.

Coping in this sense refers to the cognitive and behavioural strategies with the specific intention to control or master the symptoms or to minimise the distress caused by them (Tarrier, 1992, p.152). Lazarus has described two coping dimensions, which are widely used in coping research: emotion-focused and problem-focused (Lazarus \& Folkman, 1984; Parker \& Endler, 1996). Problemfocused coping involves strategies that solve, re-conceptualise or minimise the effects of stressful situations. It is instrumental by nature: it identifies situation specific goals and gives the opportunity to experience situational mastery and 
control, by defining the problem, generating alternative solutions, weighing the alternatives in terms of their costs and benefits and choosing from them, by learning new skills, removing barriers, generating alternative solutions (Folkman \& Moskowitz, 2000; Lazarus \& Folkman, 1984).

Figure 2 Schema of transactional coping

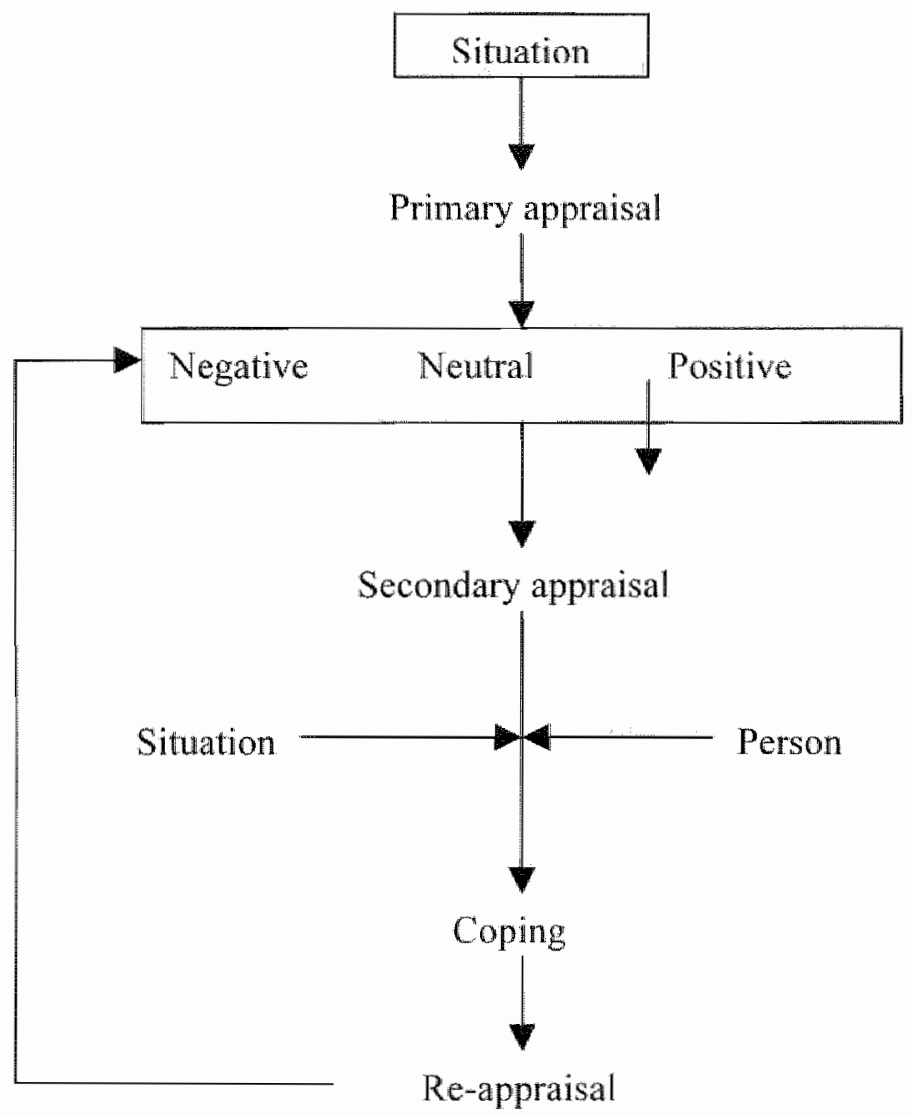

Emotion-focused coping, in contrast, are attempts at managing emotional responses to the stressor. This includes strategies like wishful thinking, seeking emotional support, social comparison or other conscious activities related to affect regulation.

An additional dimension in coping classification is approach-avoidance. Here the method of coping that people employ is emphasised (Moos \& Schaeffer, 1993). It centres around the coping with all kinds of stressors, ranging from 
seemingly small daily hassles to major traumas, and reflects at the processes that occur either at or below the level of awareness (Snyder \& Dinoff, 1999; Snyder \& Mann Pulver, 2001; Snyder \& Mann Pulvers, 2001). The approach strategy actively reduces distress, whereas avoidance coping is associated with reducing distress through escape strategies. The adaptive significance of approach versus avoidance coping strategies may depend on the controllability of the stressor that has to be faced (Folkman, 1992a; Roth \& Cohen, 1986).

The discrepancy between the two models is that the first approach of Lazarus emphasises the focus of coping: a person's orientation and activity in response to a stressor, whereas the second emphasises the method of coping that people employ; that is, whether a response entails primarily cognitive or behavioural efforts. It has been proposed that problem- and emotion-focused coping and the approach-avoidance dimension, should be integrated into one model with four basic categories of coping: cognitive approach, behavioural approach, cognitive avoidance, behavioural avoidance (Holahan, Moos, \& Schaeffer, 1996). The individual attitude toward a stressor is divided into approach and avoidance domains. In addition, each of these two domains is divided into categories that reflect cognitive and behavioural coping. Lazarus agrees with the approach/avoidance and cognitive/emotionall coping dimensions, with the restriction that appraisal is a necessary condition precipitating coping, since coping cannot be an unconscious process (Lazarus, 2000).

However, whether coping is entirely conscious is disputed by researchers. They do acknowledge the dynamic process of coping. But coping can be anticipatory, minimising distress before it occurs, or coping may be habitual as it includes automatic behaviours and thoughts (Coyne \& Gottlieb, 1996; Cramer, 2000; Snyder \& Dinoff, 1999; Snyder \& Mann Pulver, 2001). In these cases coping is unconscious. However, the transactional coping model limits coping to conditions of psychological distress, which requires mobilisation and excludes automatised behaviours and thoughts that do not require effort (Lazarus \& Folkman, 1984). In cognitive psychology it is assumed that negative automatic thoughts are basic to psychopathology formation (Beck, 1971; Beck \& Rector, 2000; Garety et al., 2001). This demonstrates the reciprocity of these strategies as cause and solution for psychopathology. Consequently, in therapy dysfunctional automatic and habitual patterns of responses have to be compensated (Coyne \& Gottlieb, 1996). However, anticipatory and habitual coping might be learned through specific coping training, in which coping will evolve from conscious to unconscious after some time (Tennen et al., 2000).

The effectiveness of coping is evaluated in terms of associations between coping and psychological distress, with the assumption that a negative association represents coping success. This ignores the inter-individual variation of success evaluation, which is based on personal goals and values. So stress reduction is not the generally appropriate indicator of successful outcome (Coyne \& Racioppo, 2000). Personal characteristics, history and circumstances 
determine distress perception, and the available coping options. The evaluation of the options is based on earlier use of coping and the perceived effectiveness in the past (Coyne \& Gottlieb, 1996). These subject characteristics and their history mediate the coping process and the automatic or habitual coping properties, which are not necessarily negative or pathological. Present coping questionnaires and assessment rely heavily on self-report, retrospective descriptions of standardised stressful situations and predefined coping repertoire. A dynamic assessment of the stressful encounters in prospective manner, without intervening in the coping process, is thought to be more appropriate, although rather difficult (Coyne \& Gottlieb, 1996; Coyne \& Racioppo, 2000; Stone et al., 1998; Tennen et al., 2000). The critique at the transactional coping definition focuses at two points: coping is delined as entirely conscious, and coping is dynamic, although the coping assessment lists that originate from the transactional coping research are rather static. Nevertheless, the transactional model offers the best definition of coping assessment given the dynamic relationship between psychotic symptoms and related experience of stress. Besides, the transactional coping definition is most widely used.

For years coping has been studied, but research in the realm of coping with psychotic symptoms is sparse. We shall give a short survey of the research on coping with psychosis.

\section{Coping with psychosis}

Both the transactional coping model and the cognitive model of psychosis development and maintenance emphasise the close relationship between a stressor and the subsequent appraisal of the stressor. Stressor and subsequent appraisal of it mediate the consequences of behaviour and/or cognition. As mentioned above, secondary appraisal of a distressful experience like psychosis is defined as illness perception and may trigger a renewed emotion-driven route to psychosis maintenance. This cognitive model of psychosis formation and maintenance follows the transactional coping model, in which the appraisal of experiences mediates the formation and maintenance of psychosis or, in terms of the transactional model, general psychopathology (Lazarus \& Folkman, 1984). Two levels of appraisal are crucial:

1) primary appraisal; an individual evaluates whether the situation is potentially harmful, threatening, blocking a goal, etc, by determining if something is important or at risk. This is the cognitive evaluation of the stressful event and how important it is to the persons well-being.

II) secondary appraisal; the event is perceived as threatening or harmful, generating an examination of the available coping resources (Lazarus \& Folkman, 1984; Snyder \& Dinoff, 1999). 
Therefore, it is straightforward to incorporate the transactional coping model into the cognitive model of psychosis. The secondary appraisal triggers the coping strategies, which define psychosis formation and maintenance. This synthesised model is also based on the vulnerability-stress-coping model, in which coping influences the personal balance between stress and various vulnerabilities that may give rise to need for care.

The Appendix (page 151) offers a summary of studies on coping with psychotic symptoms by subjects with a diagnosis of schizophrenia or any other psychotic diagnosis. Since the first studies by Falloon \& Talbot (1981), Breier \& Strauss (1983) and Cohen \& Berk (1985) it is generally accepted that coping serves to diminish threat experiences or other psychotic experiences or symptoms and augment controllability (Cohen \& Berk, 1985; Dittmann \& Schuttler, 1990; Rudnick, 2001; Solano \& Krauss Whitbourne, 2001). The studies on coping and schizophrenia or coping with psychotic symptoms of the last 20 years predictably vary in study population, method, assessment of coping type, and efficacy measurement. Most studies are descriptive and the assessment methods of coping are ambiguous. The instruments for the assessment of coping are not designed originally to study psychotic symptoms or stress due to psychosis, and they are unsuitable to assess the dynamic aspects of psychotic symptoms and their related coping process. Those scales assess general stress perception and management in subjects with a diagnosis of schizophrenia or suffering from another psychotic disorder. The subjects under study differ in phase of the illness and treatment setting. Therefore, understanding the results is complex and the conclusions are limited. Contemporary research is not definitive in clarifying the notion of Bleuler that personal abilities to cope with psychotic symptoms will determine onset of disorder. They rather describe how people who are troubled by psychotic symptoms, because of a diagnosis of schizophrenia, engage in a variety of coping strategies to eliminate distress.

However, there is tentative agreement on some important aspects of coping in subjects with a psychotic disorder, or a diagnosis of schizophrenia. These patients may experience greater and more prolonged stress than normal controls or non-psychotic disordered patients, due partially to inadequate social and problem-solving skills and less supportive social networks (Lukoff, Snyder, Ventura, \& Nuechterlein, 1984). Many patients with a diagnosis of schizophrenia seem to be deficient in the coping skills required to remedy the losses brought on by life events or to deal effectively with stressful relatives (Lukoff et al., 1984). Avoidant strategies or emotion-focused strategies are primarily used, especially at higher levels of distress or symptom severity (McDonald, Pica, McDonald, Hayes, \& Baglioni, 1998; Wiedl, 1992). Increased levels of distress - due to severity of symptoms - result in an augmented number of coping strategies, showing more flexibility and variability in the use of coping. At least $67 \%$ of the patients use one or more coping strategies to control or minimise distress (Breier \& Strauss, 1983; Carr, 1988; Falloon \& 
Talbot, 1981; Tarrier, 1987; Tarrier et al., 1993). Multiple coping strategies are more effective than one or no coping strategy at all (Boschi et al., 2000; Mueser, Valentiner, \& Agresta, 1997; Tarrier, 1987). Generally, one may conclude that decreased adaptive coping abilities lead to impaired social functioning in subjects with a diagnosis of schizophrenia (Meyer, 2001).

In coping research, problem-solving is the most effective coping strategy in terms of decrease of distress or enhanced perceived control (Bohnen, Nicolson, Sulon, \& Jolles, 1991; Folkman \& Moskowitz, 2000). Brenner et al. report that problem-solving is used three times more by patients with a diagnosis of schizophrenia compared to subjects with a neurotic disorder and normal controls. (Brenner, Boker, Muller, Spichtig, \& Wurgler, 1987). However, patients with a diagnosis of schizophremia who were chronically hospitalised and were compared with a group of out-patients, used more avoidant strategies or emotion-focused coping (Böker, Brenner, \& Wurgler, 1989; van den Bosch, van Asma, Rombouts, \& Louwerens, 1992; Wiedl, 1997). It has been argued that coping type and problem-solving strategies, determine whether subjects with a diagnosis of schizophrenia can be discharged or not.

The relationship between coping type and symptom type is unclear. Some studies show associations between specific symptoms and coping type (Muesen et al., 1997), or associations restricted to one symptom dimension (McDonald et al., 1998), whereas others have found no association (Rudnick, 2001; Tarrier, 1987). The number of coping strategies appear to be related to the severity of positive psychotic symptoms (Boschi et al., 2000; McDonald et al, 1998; Middelboe \& Mortensen, 1997; Mueser et al., 1997; Tarrier et al., 1993). More positive symptoms are associated with the use of more cognitive coping strategies (Wiedl, 1997). Severity of positive symptoms appears to be inversely proportional to active adaptive coping abilities (Meyer, 2001; Middelboe \& Mortensen, 1997). After some time, this results in less severe psychotic symptoms (Meyer, 2001). Negative symptoms seem to correlate with passive strategies and help-seeking behaviour (Mueser et al., 1997). Milder negative symptoms correlated positively with coping effectiveness (McDonald et al,, 1998). Affective symptoms, anxiety and depression, in subjects with schizophrenia, generate the most coping responses (Carr, 1988; Cohen \& Berk, 1985; Middelboe \& Mortensen, 1997). These coping responses are predominantly avoidant, passive and/or emotion-focused coping strategies. Poor cognitive functioning, as is consistently present in subjects with a diagnosis of schizophrenia, is associated with those avoidant, passive, emotion-focused coping styles (Pallanti, Quercioli, \& Pazzagli, 1997; van den Bosch \& Rombouts, 1997; Wilder-Willis, Shear, Steffen, \& Borkin, 2002). However, it is suggested that there is no association between cognitive deficits and avoidant coping strategies (van den Bosch et al., 1992).

The goal of coping is to decrease distress associated with a psychotic symptom and/or to enhance controllability. This might result in minimisation or 
disappearance of symptoms or may prevent full-blown psychosis. Little research has been conducted comparing subjects with a diagnosis of schizophrenia versus subjects without a diagnosis of schizophrenia but with positive psychotic symptoms and specific coping properties that may protect against disorder formation or maintenance. The number of coping strategies do not discriminate between the presence or absence of a diagnosis of schizophrenia (Carter, Mackinnon, \& Copolov, 1996). Subjects who claim to poses control over their voices, generate more selective listening and limitsetting coping. Subjects who cannot cope with the voices, predominantly use distraction, resulting in less perceived control and are much more likely to have a diagnosis of schizophrenia (Farhall \& Gehrke, 1997; Honig et al., 1998; Romme, Honig, Noorthoorn, \& Escher, 1992). At follow-up, active coping styles, which include problem-solving strategies, are not significantly related to reduction in severity of positive psychotic symptoms over time (Boschi et al., 2000).

Most remarkably, specific training of problem-solving strategies versus enhancement of other coping strategies (behavioural and social coping strategies) results in a decrease of problem-solving, but also in an increase of coping strategies (Tarrier et al., 1993). Recent studies on problem-solving training in subjects with a first psychotic episode of schizophrenia, show some promising results in relapse prevention and enhancement of treatment compliance (Andres, Pfammatter, Garst, Teschner, \& Brenner, 2000; Falloon, 2000; Leclere, Lesage, Ricard, Lecomte, \& Cyr, 2000; Medalia, Dorn, \& Watras-Gans, 2000). The possibilities of problem-solving training programmes are hampered by the cognitive deficits of subjects with psychosis and the limited applicability of acquired problem-solving strategies to daily life.

\section{Need for care with psychosis}

As outlined before, psychosis displays a continuum across the general population. The DSM classification system (American Psychiatric Association, 1994) is criticized because it does not account for the dimensional aspects of psychosis (van Os, Gilvarry et al., 2000; van Praag, 1992). However, identification of cases is necessary to assess whether someone is in need for care, for research purposes and for epidemiological population studies that are used for planning health services.

Despite the technological advances made in diagnostic criteria, discrepancies in prevalence rates between population surveys remain present (Regier et al., 1998). Studying subjects who have psychosis-like experiences without reaching the clinical threshold of being "in need of treatment", might clarify some of the puzzles surrounding the aetiology of psychosis (Claridge, 1997; Meehl, 1969; Venables, 1995; Venables \& Rector, 2000). It is questioned whether disorders in the community represent milder cases of essentially the same disorder or 
transient homeostatic responses to internal or external stimuli that do no represent true psychopathological disorders (Stefanis et al., 2002; van Os, Hanssen et al., 2001). To identify true psychopathological states we would need additional assessment of severity, impairment, co-morbidity and duration, which may define "caseness" (Regier, 2000; Regier et al., 1998). In DSM-IV, "caseness" (or need for care) is defined tautologically as: disturbances that "cause clinically significant distress or impairment" based on the clinicians judgement (Frances, 1998). Possibly many people with DSM-defined mental syndromes in the general population may have appropriate homeostatic responses that are neither pathological nor in need of treatment (Regier et al., 1998). In other words, they may display an array of more or less appropriate coping strategies.

Disorder definition depends on the elucidation of dysfunction in the individual that results in clistress or disability, whereas need for care depends on additional non-diagnostic factors such as the presence of social support and the availability of effective therapeutic options (Pincus, Zarin, \& First, 1998). Evaluation of functioning is the missing link between diagnosis and assessment of need for care. Problems in functioning make people seek treatment even when they do not meet diagnostic criteria of, for example, a psychotic disorder (Ustun et al., 2002; Ustun, Chatterji, \& Rehm, 1998). On the other hand, people will not seek treatment in case of a disorder according to diagnostic criteria, if their functioning is not hampered subjectively. Therefore, it is obvious that community cases are not milder per se (Ustun et al., 1998). From the perspective of dimensional distribution of psychotic symptoms throughout the general population, separate assessment of the level of distress and functioning in relation to need for care would be a more appropriate manner of assessing "cases" of psychotic disorder in community surveys, compared to a DSMdefined classification system that unites positive psychotic symptoms, distress and general dysfunction.

\section{Aims and method of this study}

In summary, analysis suggests that psychosis may be conceived of as a continuum (Johns \& van Os, 2001; van Os, Hanssen et al., 2000; van Os, Hanssen et al., 2001). A diagnosis of schizophrenia represents the most severe end of the spectrum of psychotic expressions, whereas halucinatory and delusional experiences without any need for care represent the other end of the spectrum. Case-finding in clinical settings skew samples towards subjects with need for care. The vulnerability-stress model and the cognitive model of psychosis assume that symptom-formation is a reaction to stress. The appraisal of stress by subjects suffering from cognitive biases and problems in metarepresentation leads to delusions and hallucinations (Garety et al., 2001). These psychotic symptoms are stressful and subjects attempt to face this distress 
through coping. Coping is thought to have some protective function against psychosis onset and psychosis exacerbation, through a behavioural and cognitive conscious adaptational process (Lazarus \& Folkman, 1984). In this dissertation, we merge the transactional coping model and the cognitive model of psychosis formation and maintenance. Coping is mediated by secondary appraisal according to the transactional coping model of Lazarus as well as the cognitive model of the formation or maintenance of delusions and hallucinations. Various coping strategies are each in their own way involved in psychotic symptom formation and maintenance. Perceived control achieved by coping efforts is rellated with better general health, improved quality of life and may reduce the development of need for care resulting from psychotic experiences. Thus, control is a suitable measure to assess effectiveness of coping.

This study has four main research questions:

I) is need for care associated with severity of psychotic symptoms?

II) are other factors associated with need for care in subjects with psychosis?

III) is need for care in subjects with psychosis associated with coping and specific coping strategies?

IV) are the various defined coping strategies protective at the level of single positive symptoms?

Given the continuum of psychosis and the fact that a diagnosis of schizophrenia is based on a heterogeneous set of experiences and symptoms, assessment of coping in relation to psychotic experiences and symptoms is impossible with the presently available coping scales. There is no scale available to assess distress and coping per experience or symptom in subjects. Therefore, the fifth research question of this study:

V) is a specifically designed coping list, the Maastricht Assessment of Coping Strategies (MACS) a reliable and valid scale in assessing coping strategies per symptom? 


\section{Outline of this dissertation}

Chapter 2 describes the rationale, development, and assessment rules of the Maastricht Assessment of Coping Strategies (MACS).

Chapter 3 addresses the reliability and validity of the MACS in patients with a diagnosis of schizophrenia (Bak et all., 2001a).

Chapter 4 examines the associations between subjective experience of control and the use of self-initiated coping strategies for psychotic symptoms in patients with a diagnosis of schizophrenia (Bak et al., 200l b).

Chapter 5 examines the predictive value of patient recognised and clinician recognised psychotic symptoms, testing the assumption that patient reports of psychosis are considered to be of questionable value given the frequent occurrence of "false" positives (patient recognised but not clinician recognised) (Bak, Delespaul et al., 2003).

Chapter 6 assesses differences in coping strategies and associated levels of perceived control over psychotic symptoms, in relation to need for care status (Bak, Myin-Germeys et al., 2003).

Chapter 7 studies the association between need for care and various psychotic symptoms, and the mediating influence of self-reported distress and previous history of psychotic symptoms (Bak et al., submitted for publication).

Chapter 8 summarises and discusses the main research findings, and attempts to integrate the results into a general framework. Finally, directions for future studies are suggested. 


\section{References}

Aguilar, E. J., Haas, G., Manzanera, F. J., Hernandez, J., Gracia, R., Rodado, M. J., \& Keshavan, M. S. (1997). Hopelessness and first-episode psychosis: a longitudinal study. Acta Psychiar Scand, 96(1), 25-30.

Amador, X., Flaum, M., Andreasen, N. C., Strauss, D. H., Yalle, S. A., Clark, S., \& Gorman, J. M. (1995). Awareness of illness in schizophrenia and mood disorders. Arch Gen Psychiatry, 51,826-836.

Amador, X. F., Flaum, M. Andreasen, N. C., Strauss, D. H., Yale, S. A, Clark, S. C., \& Gorman, J. M. (1994). Awareness of illness in schizophrenia and schizoaffective and mood disorders. Arch Gen Psychiatry, 51(10), 826-836.

Amador, X. F., \& Gorman, J, M. (1998). Psychopathologic domains and insight in schizophrenia. Psychiatr Clin North Am, 21(1), 27-42.

Amador, X.F., \& Kronengold, H. (1998). The Description and Meaning of Insight and Pschosis. In Amador X. F. \& D. A.S. (Eds.), Insight and Psychosis (pp. 15-32). New York: The Oxford University Press.

Amador, X. F., Strauss, D. H., Yale, S. A., \& Gorman, J. M. (1991). Awareness of illness in schizophrenia. Schizophr Bull, 17(1), 113-132.

American Psychiatric Association, A. (1987). DSM-III-R: Diagnostic and Statistical Manual of Mental Disorders. Washington, DC: APA.

American Psychiatric Association, A. (1994). DSM-IV: Diagnostic and Statistical Manual of Mental Disorders. Washinton DC.: APA.

Andreasen, N. C., \& Carpenter, W. T., Jr. (1993). Diagnosis and classification of schizophrenia, Schizophr Bull, 19(2), 199-214.

Andres, K., Pfammatter, M., Garst, F., Teschner, C., \& Brenner, H. D. (2000). Effects of a coping-orientated group therapy for schizophrenia and schizoaffective patients: a pilot study. Acta Psychiatr Scand, 101(4), 318-322.

Asaad, G., \& Shapiro, B. (1986). Hallucinations: theoretical and clinical overview. Am J Psychiatry, 143(9), 1088-1097.

Bailis, D. S., Segall, A., Mahon, M. J., Chipperfield, J. G., \& Dunn, E. M. (2001). Perceived control in relation to socioeconomic and behavioral resources for health. Soc Sci Med, 52(11), 1661-1676.

Bak, M., Delespaul, P., Hanssen, M., de Graaf, R., Vollebergh, W., \& van Os, J. (2003). How false are "false" positive psychotic symptoms? Schizophr Res, 62(1-2), $187-189$.

Bak, M., Myin-Germeys, I., Delespaul, P., Vollebergh, W., De Graaf, R., \& Van Os, J. (submitted for publication). Do different psychotic experiences differentially predict need for care in the general population?

Bak, M., Myin-Germeys, I., Hanssen, M., Bijl, R., Vollebergh, W., Delespaul, P., \& van Os, J. (2003). When does experience of psychosis result in a need for care? A prospective general population study. Schizoph Bull, 29(2), 349-358.

Bak, M., Van Der Spil, F., Gunther, N., Radstake, S., Delespaul, P., \& Van Os, J. (2001a). Maastricht Assessment of Coping Strategies (MACS-I): a brief instrument to assess coping with psychotic symptoms. Acta Psychiatr Scand, $103(6), 453-459$.

Bak, M., Van Der Spil, F., Gunther, N., Radstake, S., Delespaul, P., \& Van Os, J. (200lb). MACS-II: does coping enhance subjective control over psychotic symptoms? Acta Psychiatr Scand, I03(6), 460-464. 
Bartko, G., Herczeg, I., \& Zador, G. (1988). Chincal symptomatology and drug compliance in schizophrenic patients. Acta Psychiatr Scand, 77(1), 74-76.

Bebbington, P. \& Kuipers, L. (1994). The predictive utility of expressed emotion in schizophrenia: an aggregate analysis. Psychol Med, 24(3), 707-718.

Beck, A. T. (1971). Cognition, affect, and psychopathology. Arch Gen Psychiotry. 24(6), 495-500.

Beck, A. T., \& Rector, N. A. (2000). Cognitive therapy of schizophenia: a new therapy for the new millennium. Am $J$ Psychother, 54(3), 291-300.

Bentall, R. (1990). Reconstructing Schizophrenia. London: Routledge.

Bentall, R. (1992). The Classification of Schizophrenia. In K. D.J. (Ed.), Schizophrenia. An Overview and Practical Handbook. (pp. 23-44). London: Chapman \& Hill.

Bentall, R. P., Kinderman, P.y \&aney, S. (1994). The self, atributional processes and abnormal beliefs: towards a model of persecutory dellusions. Behov Res Ther: 32(3), 331-341.

Birchwood, M., Iqbal, Z., Chadwick, P., \& Trower, P. (2000). Cognitive approach to depression and suicidal thinking in psychosis. 1. Ontogeny of post-psychotic depression. BrJ Pychiatry, $177,516-521$.

Birchwood, M., \& Jackson, C. (2001). Schizophrenia. Hove: psychology Press.

Birchwood, M., Mason, R., MacMillan, F., \& Healy, J. (1993). Depression, demoralization and control over psychotic illness: a comparison of deprassed and non-depressed patients with a chronic psychosis. Psychol Med, 23(2), 387395.

Birchwood, M., Meaden, A., Trower, P., Gilbert, P., \& Plaistow, J. (2000). The power and omnipotence of voices: subordination and entrapment by voices and significant others. Psychol Med, 30(2), 337-344.

Bleuler, M. (1978). The schizophrenic disorders, long-term patient and family studies . (S. M. Clemens, Trans.). New Haven, CT: Yale University Press.

Bolmen, N., Nicolson, N., Sulon, J., \& Jolles, J. (1991). Coping style, trait anxiety and cortisol reactivity during mental stress. I Psychosom Res, 35(2-3), 141-147.

Böker, W., Brenner, H. D., \& Wurgler, S. (1989). Vulnerability-linked deficiencies, psychopathology and coping behaviour of schizophrenics and their relatives. Br.J Psychiatry Supp/(5), 128-135.

Boschi, S., Adams, R. E., Bromet, E. J., Lavelle, J. E., Everet, E., \& Galambos, N. (2000). Coping with psychotic symptoms in the early phases of schizophrenia. Am J Orthopsychiatry, 70(2), 242-252.

Breier, A., \& Strauss, J. S. (1983). Self-control in psychotic disorders. Arch Gen Psychiatry, 40(10), 1141-1145.

Brenner, H. D., Boker, W., Muller, J., Spichtig, L., \& Wurgler, S. (1987). On autoprotective efforts of schizophrenics, neurotics and controls. Acta Psychiar Scand $75(4), 405-414$.

Carr, V. (1988). Patients" techniques for coping with schizophrenia: an exploratory study. Br.J Med Psychol. 6I(Pt 4), 339-352.

Carter, D. M., Mackinnon, A., \& Copolov, D. L. (1996). Patients" strategies for coping with auditory hallucinations. I Nerv Ment Dis, 184(3), 159-164.

Carver, C. S., Scheier, M. F., \& Weintraub, J. K. (1989). Assessing coping strategies: a theoretically based approach. J Pers Soc Psychol, 56(2), 267-283.

Claridge, G. (1994). Single indicator of risk for schizophrenia: probable fact or likely myth? Schizophr Bull, 20(1), 15 $1-\llbracket 68$. 
Claridge, G. (1997). Schizotypy; implications for illmess and health. Oxford: Oxford University Press.

Claridge, G., \& Beech, T. (1995). Fully and quasi-dimensional constructions of schizotypy. In A. Raine \& T. Lencz \& S. A. Mednick (Eds.), Schizotypal Personality. (pp. 192-216). Cambridge: Cambridge University Press.

Close, $\mathbb{H}$., \& Garety, P. (1998). Cognitive assessment of voices: further developments in understanding the emotional impact of voices. Br J Clin Psychol, 37(Pt 2), 173-188.

Cohen, L. J., \& Berk, L. A. (1985). Personal coping styles of schizophrenic outpatients. Hosp Community Psychiatry, 36(4), 407-410.

Coyne, J. C., \& Gottlieb, B. H. (1996). The mismeasure of coping by checklist. J Pers, $64(4), 959-991$.

Coyne, J. C., \& Racioppo, M. W. (2000). Never the Twain shall meet? Closing the gap between coping research and clinical intervention research. Am Psychol, 55(6), $655-664$.

Cramer, P. (2000). Defence machanisms in psychology today. American Psychologist, $55(6), 637-646$.

Cramer, P. (2001). The unconscious status of defense mechanisms. Am Psychol, 56(9), $762-763$.

Crow, T. J. (1985). The two-syndrome concept: origins and current status. Schizophr Bull, $/ 1(3), 471-486$.

Cuesta, M. J., \& Peralta, V. (1994). Lack of insight in schizophrenia. Schizophr Bull, 20(2), 359-366.

Cuesta, M. J., Peralta, V., Caro, F., \& de Leon, J. (1995). Is poor insight in psychotic disorders associated with poor performance on the Wisconsin Card Sorting Test? Am J Psychiatry, 152(9), 1380-1382.

Cuffel, B. J., Alford, J., Fischer, E. P., \& Owen, R. R. (1996). Awareness of illness in schizophrenia and outpatient treatment adherence. $J$ Nerv Ment Dis, 184(11), $653-659$.

David, A., van Os, J., Jones, P., Harvey, I., Foerster, A., \& Fahy, T. (1995). Insight and psychotic illness. Cross-sectional and longitudinal associations. $\mathrm{Br} J$ Psychiatry, 167(5), 621-628.

David, A. S., \& Cutting, J. (1994). The Neuropsycholoy of Schizophrenia. Hillsdale, NJ: Erlbaum.

de Vries, M. (1992). Experiencing psychopathology. Cambridge, England: Cambridge University Press.

Delespaul, P. A. E. G. (1995). Assessing Schizophrenia in Daily Life: The Experience Sampling Method. Unpublished PhD Thesis, Maastricht University, Maastricht.

Ditmann, I., \& Schuttler, R. (1990). Disease consciousness and coping strategies of patients with schizophrenic psychosis. Acta Psychiar Scand, 82(4), 318-322.

Dohrenwend, B. S., \& Dohrenwend, B. P. (1974). Stressfut LifeEvents: Their nature and Effects. New York: Wiley.

Eaton, W. W., Romanoski, A., Anthony, J. C., \& Nestadt, G. (1991). Screening for psychosis in the general population with a self-report interview. $J$ Nerv Ment Din, $179(11), 689-693$. 
Falloon, I. R. (2000). Problem solving as a core strategy in the prevention of schizophrenia and other mental disorders. Awst $N Z$ J Psychowy, 34 Srppl, S185-190.

Falloon, I. R., \& Talbot, R. E. (1981). Persistent auditory hallucinations: coping mechanisms and implications for management. Psychol Med, 11(2), 329-339.

Farhall, J., Gehrke, M. (1997). Coping with hallucinations: exploring stress and coping framework. $\mathrm{Br} J$ Clin Psychol, 36(Pt 2), 259-261.

Fenton, W. S., Blyler, C. R., \& Heinssen, R. K. (1997). Determinants of medication compliance in schizophrenia: empirical and clinical findings. Schizoph" Bull. $23(4), 637-651$.

Folkman, S. (1984). Personal control and stress and coping processes: a theoretical analysis. J Pers Soc Psychol, 46(4), 839-852.

Folkman, S. (1992). Making the case for coping. In B. N. Carpenter (Ed.). Personal Coping: theory, research and application. (pp. 31-46). New York.: Praeger.

Folkman, S., \& Moskowitz, J. T. (2000). Positive affect and the other side of coping. Am Psychol, 55(6), 647-654.

Frances, A. (1998). Problems in defining clinical significance in epidemiological studies. Afch Gen Psychiary, 55(2), 119.

Freeman, D., \& Garety, P. (1999). Worry, worry processes and dimensions of delusions: an exploratory investigation of a role for anxiety processes in the maintenance of delusional distress. Behorvioural and Cognitive Psychotherapy, 27, 47-62.

Freeman, D., Garety, P., Fowler, D., Kuipers, E., Dunn, G., Bebbington, P., \& Hadley, C. (1998). The London-East Anglia randomized controlled trial of cognitivebehaviour therapy for psychosis. IV: Self-esteem and persecutory delusions. $B t^{\circ}$ $J$ Clin Psychol, 37(Pt 4), 415-430.

Freeman, D., Garety, P. A., \& Kuipers, E. (2001). Persecutory delusions: developing the understanding of belief maintenance and emotional distress. Psychol Med, $31(7), 1293-1306$.

Frith, C. (1992). The Cognitive Newropsycholoy of Schizophrenia. Hillsdale, Na: Erlbaum.

Frith, C. D., Blakemore, S., \& Wolpert, D. M. (2000). Explaining the symptoms of schizophrenia: abnormalities in the awareness of action. Brain Res Bram Res Rev, $3 l(2-3), 357-363$.

Garety, P. A., \& Freeman, D. (1999). Cognitive approaches to delusions: a critical review of theories and evidence [see comments]. BrJ Clin Psychol, 38(P1 2), $113-154$.

Garety, P. A., Kuipers, E., Fowler, D., Freeman, D., \& Bebbington, P. E. (2001). A cognitive model of the positive symptoms of psychosis. Psychol Med, 3/(2), $189-195$.

Green, M. F. (1992). Information processing in schizophrenia. In K. D.J. (Ed.), Schizophrevia: an overview and practical handbook. London: Chapman \& Hall.

Haan, N. (1965). Coping and defense mechanisms related to personality inventories. Jourmal of Consuling Psychology, 29, 373-378.

Heinssen, R. K., Perkins, O., Appelbaum, P. S., \& Fenton, W. S. (2002). Informed consent in early psychosis research: National Institute of Mental Health workshop, Nowember 15, 2000. Schizophr Bull, 4, 571-584. 
Helgeson, V. S. (1992). Moderators of the relation between perceived control and adjustment to chronic illness. J Pers Soc Psychol, 63(4), 656-666.

Hemsley, D. R. (1994). A cognitive model for schizophrenia and its possible neural basis. Acta Pychiatr Scand Suppl, 384, 80-86.

Holahan, C. J., Moos, R. H. \& Schaeffer, J. A. (1996). Coping, Stress Resistance and Growth: Conceptualizing Adaptive Functioning. In M. Zeidner \& N. S. Endler (Eds.). Hawdbook of Coping (pp. 24-43). New York.: J. Wiley \& Sons.

Honig, A., Romme, M. A., Ensink, B. J., Escher, S. D., Pennings, M. H., \& deVries, M. W. (1998). Auditory hallucinations: a comparison between patients and nompatients. J Nerv Men Dis, 186(10), 646-651.

Huq, S. F., Garety, P. A., \& Hemsley, D. R. (1988). Probabilistic judgements in deluded and non-deluded subjects. $Q$ J Exp Psychol [A], 40(4), 801-812.

Jaspers, K. (1963). General Psychopathology. Manchester: Manchester University Press.

Johns, L. C., \& van Os, J. (2001). The continuity of psychotic experiences in the general population. Clin Psychol Rev, 21(8), 1125-1141.

Johnstone, E. C., Connelly, d., Frith, C. D., Lambert, M. T., \& Owens, D. G. (1996). The nature of 'transient' and 'partial' psychoses: findings from the Northwick Park "Functional' Psychosis Study. Psychol Med, 26(2), 361-369.

Kendler, K. S., Gallagher, "T. J., Abelson, J. M., \& Kessler, R. C. (1996). Lifetime prevalence, demographic risk factors, and diagnostic validity of nonaffective psychosis as assessed in a US community sample. The National Comorbidity Survey. Arch Gen Psychiatry. 53(11), 1022-1031.

Kinderman, P., \& Bentall, R. (1996). A new measure of causal locus: The internal, personal and situational attributions for negative events. Personality and Individual Differences, 20,261-264.

Kingdon, D. G., \& Turkington, D. (1994). Cognitive-behavioural therapy of schizophrenia. London: Hove, UK: Pychology Press.

Kuipers, T. (1992). Stille Waters (Silent Waters). Utrecht University, Utrecht.

Lau, R. R., Hartman, K. A. (1983). Common sense representations of common illnesses. Health Psychol, 2, $167-185$.

Lazarus, R. S. (1991). Emotion and adaptation. Londton.: Oxford University Press.

Lazarus, R. S. (1993). Coping theory and research: past, present, and future. Psychosom Med. $55(3), 234-247$.

Lawarus, R. S. (2000). "Toward a better research on stress and coping. American Psychologist, 55(6), 665-673.

Lazarus, R. S., Delongis, A., Folkman, S., \& Gruen, R. (1985). Stress and adaptational outcomes. The problem of confounded measures. Am Psychol, 40(7), 770-785.

Lazarus, R. S., \& Folkman, S. (1984). Stress, Appraisal and Coping. New York: Springer Verlag.

Lecletc, C., Lesage, A. D., Ricard, N., Lecomte, T., \& Cyr, M. (2000). Assessment of a new rehabilitalive coping skills module for persons with schizophrenia. Am $J$ Orhopsychiary, $70(3), 380-388$.

Leff, J., Kuipers, L., Berkowitz, R., Vaughn, C., \& Sturgeon, D. (1983). Life events, relatives expressed emotion and maintenance neuroleptics in schizophrenic rolapse. Psychol Med, 13(4), 799-806. 
Leff, $J$, \& Vaughn, C. (1980). The interaction of life events and relatives' expressed emotion in schizophrenia and depressive neurosis. Br J Psychiony, 136, 146153.

Leventhal, H., Benjamin, Y., Brownlee, S., Diefenbach, M., Leventhal, E. A., PatrickMiller, L., \& Robitaille, C. (1997). Illness representations; theoretical foudations. In K. L. Petrie \& J. Weinman (Eds.), Perceptions of Health and Ilness (pp. 19 - 47). London: Harwood Academic Publishers.

Liddle, P. F., Barnes, T. R., Morris, D., \& Haque, S. (1989). Three syndromes in chronic schizophrenia. Br J Psychiatry Suppl(7), 119-122.

Lobban, F., Barrowclough, C., \& Jones, S. (2003). A review of the role of illness models in severe mental illness. Clin Psychol Rev, 23(2), 171-196.

Lukoff, D., Snyder, K., Ventura, J., \& Nuechterlein, K. H. (1984). Life events, familial stress, and coping in the developmental course of schizophrenia. Schizophr Bull, $10(2), 258-292$.

Lysaker, P., \& Bell, M. (1994). Insight and cognitive impaiment in schizophrenia. Performance on repeated administrations of the Wisconsin Card Sorting Test. $J$ Nerv Ment Dis, 182(11), 656-660.

Lysaker, P. H., Bell, M. D., Bryson, G., \& Kaplan, E. (1998). Neurocognitive function and insight in schizophrenia: support for an association with impairments in executive function but not with inpairments in global function. Acta Psychiar Scand, 97(4), 297-301.

Lysaker, P. H., Bell, M. D., Bryson, G. J., \& Kaplan, E. (1998). Insight and interpersonal function in schizoplurenia. J Nerv Ment Dis, 186(7), 432-436.

Maher, B. A. (1988). Anamalous experience and delusional thinking: the logic of explanations. In T. F. Oltmans \& B. A. Maher (Eds.), Delusional beliefs (pp. 15 - 33). New York: Wiley.

Marcelis, M., Navarro-Mateu, F., Murray, R., Selten, J. P., \& Van OS, J. (1998). Urbanization and psychosis: a study of 1942-1978 birth cohorts in The Netherlands. Psychol Med, 28(4), 871-879.

Matthews, L. A. (1982). Human services during economic depression: how Michigan is coping. N Engl J Hum Serv, 2(2), 22-30.

McDonald, E. M., Pica, S., McDonald, S., Hayes, R. L., \& Baglioni, A. I., Jr. (1998). Stress and coping in early psychosis. Role of symptoms, self-efficacy, and social support in coping with stress. Br J Psychiatry Suppl, 172(33), 122-127.

McEvoy, J. P., Hartman, M., Gottlieb, D., Godwin, S., Apperson, L. J., \& Wilson, W. (1996). Common sense, insight, and neuropsychological test performance in schizophrenia patients. Schizophr Bull, 22(4), 635-641.

McGiashan, T. H. (1975). Integration and sealing-over. Arch Gen Psychiciry, 32, 12691272 .

McGlashan, T. H., \& Carpenter, W. T. (1976). Postpsychotic depression in schizophrenia. Arch Gen Psychiarty, 33, 231-239.

McGorry, P. D., \& McConville, S. B. (1999). Insight in psychosis: an elusive target. Compr Psychiatry, 40(2), 131-142.

Medalia, A., Dorn, H., \& Watras-Gans, S. (2000). Treating problem-solving deficits on an acute care psychiatric inpatient unit. Psychiatry Res, 97(1), 79-88.

Meehl, P. E. (1969). Schizotaxia, schizotypy, schizophrenia. American Psychologist, $17,827-838$ 
Meyer, B. (2001). Coping with severe mental illness: relations of the Brief COPE with symptoms, functioning and well-being. Journal of Psychopathology and Behavioural Assessment, 23(4).

Middelboe, T., \& Mortensen, E. L. (1997). Coping strategies among the long-term mentally ill: categorization and clinical determinants. Acta Psychiatr Scand, $96(3), 188-194$.

Moos, R. H. (1988). [Coping: concepts and measuring procedures]. Z Psychosom Med Psychoanal, 34(3), 207-225.

Moos, R. H., \& Schaeffer, J. A. (1993). Coping resources and processes: Current concepts and measures. In L. Goldberger \& S. Breznitz (Eds.), Handbook of stress: Theoretical and clinical aspects. (Vol. 2nd edition, pp. $234-257$ ). New York: Free Press.

Mueser, K. T., Goodman, L. B., Trumbetta, S. L., Rosenberg, S. D., Osher, C., Vidaver, R., Auciello, P., \& Foy, D. W. (1998). Trauma and posttraumatic stress disorder in severe mental illness. $J$ Consult Clin Psychol $66(3), 493-499$.

Mueser, K. T., Valentiner, D. P., \& Agresta, J. (1997). Coping with negative symptoms of schizophrenia: patient and family perspectives. Schizophr Bull, 23(2), 329339.

Murray, R. M., O'Callaghan, E., Castle, D. J., \& Lewis, S. W. (1992). A neurodevelopmental approach to the classification of schizophrenia. Schizophr Bull, 18(2), 319-332.

Murray, R. M., \& Van Os, J. (1998). Predictors of outcome in schizophrenia. I Clin Psychopharmacol, 18(2 Suppl 1), 2S-4S.

Myin-Germeys, I., Delespaul, P. A., \& deVries, M. W. (2000). Schizophrenia patients are more emotionally active than is assumed based on their behavior. Schizophr Bull, 26(4), 847-854.

Myin-Germeys, I., van Os, J., Schwartz, J. E., Stone, A. A., \& Delespaul, P. A. (2001). Emotional reactivity to daily life stress in psychosis. Arch Gen Psychiatry, $58(12), 1137-1144$.

Nicolson, N. (1992). Stress, coping and cortisol dynamics in daily life. In M. de Vries (Ed.), The experience of psychopathology: Investigating mental disorders in their natural settings. (pp. 219 - 232). Cambridge: Cambridge University Press.

Nuechterlein, K. H., \& Dawson, M. E. (1984). A heuristic vulnerability/stress model of schizophrenic episodes. Schizophr Bull, 10(2), 300-312.

Nuechterlein, K. H., Dawson, M. E., Ventura, J., Gitlin, M., Subotnik, K. L., Snyder, K. S., Mintz, J., \& Bartzokis, G. (1994). The vulnerability/stress model of schizoplurenic relapse: a longitudinal study. Acta Psychiarr Scand Suppl, 382, $58-64$.

Overall, J. E. \& Gorham, D. (1962). The Brief Psychiatric Rating Scale. Psychological Reports, $10,799-812$.

Pallanti, S., Quercioli, L., \& Pazzagli, A. (1997). Relapse in young paranoid schizophrenic patients: a prospective study of stressful life events, P300 measures, and coping. Am J Psychiatry. 154(6), 792-798.

Parker, J. D., \& Endler, N. S. (1996). Coping and Defense: A Historical Overview. In M. Zeidner \& N. S. Endler (Eds.), Handbook of Coping (pp. 3-23). New York: John Wiley \& Sons. 
Pearlin, L. 1., \& Schooler, C. (1978). The structure of coping. I Heath Sod Behat, $19(1), 2-21$.

Peralta, V., Cuesta, M. J., \& Farre, C. (1997). Factor structure of symptoms in functional psychoses. Biol Psychiaty, 42(9), 806-815.

Perkins, R. E., \& Moodley, P. (1993). Perception of problems in psychiatric inpatients: denial, race and service usage. Soc Psychiatry Psychiatr Epidemiol, 28(4), 189193.

Peters, E., Day, S., McKenna, I., \& Orbach, G. (1999). Delusional ideation in religious and psychotic populations. BrJ J Clin Psychol, 38(Pt 1), 83-96.

Pickup, G. I., \& Frith, C. D. (2001). Theory of mind impaiments in schizophrenia: symptomatology, severity and specificity. Psychol Med, 3/(2), 207-220.

Pincus, H. A., Zarin, D. A., \& First, M. (1998). "Clinical significance" and DSM-IV. Arch Gen Psychiatry, 55(12), 1145; discussion 1147-1148.

Poulton, R., Caspi, A., Moffitt, T. E., Cannon, M., Murnay, R., \& Harrington, H. (2000). Children's self-reported psychotic symptoms and adult schizophrenitorm disorder: a 15-year longitudinal study. Arch Gen Psychiony, 57(11), 10531058.

Regier, D. A. (2000). Community diagnosis counts. Arch Gen Psychiatry, 57(3), 223224.

Regier, D. A., Kaelber, C. T., Rae, D. S., Farmer, M. E., Knauper, B., Kessler, R. C. \& Norquist, G. S. (1998). Limitations of diagnostic criteria and assessment instruments for mental disorders. Implications for research and policy. Arch Gen Psychiatry, 55(2), 109-115.

Rodin, J., \& Salovey, P. (1989). Health psychology. Amm Rev Psychol, 40, 533-579.

Rodin, J., Timko, C., \& Harris, S. (1985). The construct of control: Biological and psychological correlates. In M. P. Lawton \& G. L. Maddox (Eds.), Ammal peview of gerontology and gerratrics. (pp. 3-55). New York: Springer.

Romme, M., \& Escher, S. (1994). Hearing voices. BMJ, 309(6955), 670.

Romme, M. A., Honig, A., Noorthoorn, E. O., \& Escher, A. D. (1992). Coping with hearing voices: an emancipatory approach. Br. JPsychiary, 161,99-103.

Rose, G. (1992). The Strategy of Preventive Medicine. Oxford" Oxford University Press.

Roth, S., \& Cohen. L. J. (1986). Approach, avoidance, and coping with stress, Anzerican Psychologist, 41, 813-819.

Rudnick, A. (2001). The impact of coping on the trelation between symptoms and quality of life in schizophrenia. Psychiany, 64(4), 304-308.

Schwartz, R. C. (1998a). Insight and illness in chronic schizophrenia. Compr Psychiatry. 39(5), 249-254.

Schwartz, R. C. (1998b). The relationship between insight, illness and treatment outcome in schizophrenia. Psychiatr $Q, 69(1), 1-22$.

Seligman, M. E. (1975). Helplessness: On depression, development and health. San Fransisco: Freeman.

Skinner, E. A. (1995). Perceived control (Vol. 8). Thousand Oaks: Sage Publications.

Skimner, E. A. (1996). A guide to constructs of control. J Pers 5 oc Psychol, $7 /(3), 549$. 570.

Skinner, E. A., Zimmer-Gembeck, M. I., \& Connell, J. P. (1998). Individual differences and the development of perceived control. Monogy" Soc Res Child Dev, 63(2-3), $1-220$. 
Slade, P. D. (1976). An investigation of psychological factors involved in the predisposition to auditory hallucinations. Psychol Med, $6(1), 123-132$.

Snyder, C. R., \& Dinoff, B. L. (1999). Coping: Where Have You Been? In C. R. Snyder (Ed.), Coping. The Psychology of What Works (pp. 3-20). New York: Oxford University Press.

Snyder, C. R., \& Mann Pulver, K. (2001). Copers Coping with Stress. In C. R. Snyder (Ed.), Coping with Stress (pp. 285-302). New York: The Oxford University Press.

Snyder, C. R. \& Mann Pulvers, K. (2001). Dr. Seuss, the Coping Machine and "Oh the Places You'll Go". In C. R. Snyder (Ed.), Copingwith Stress (pp. 3-29). New York: The Oxford University Press.

Solano, N. H., \& Krauss Whitbourne, S. (2001). Coping with schizophrenia: Patterns in later adulthood. Int. J. Aging and Human Development, 53(1), 1-10.

Somersfield, M. R., \& MoCrae, R. R. (2000). Stress and coping research: methodological challenges, theoretical advances and clinical applications. American Psychologist, 55(6), 620-625.

Stefanis, N. C., Hanssen, M., Smirnis, N. K., Avramopoulos, D. A., Evdokimidis, I. K., Stefanis, C. N., Verdoux, H., \& Van, O. J. (2002). Evidence that three dimensions of psychosis have a distribution in the general population. Psychol Med, 32(2), 347-358.

Stone, A. A., Schwartz, J. E., Nealle, I. M., Shiffman, S., Marco, C. A., Hickcox, M., Paty, J., Porter, L. S., \& Cruise, L. J. (1998). A comparison of coping assessed by ecological momentary assessment and retrospective recall. $J$ Pers Soc Psychol, 74(6), 1670-1680.

Strauss, J. S. (1969). Hallucinations and delusions as points on continua function. Rating scale evidence. Arch Gen Psychiatry, 27(5), 581-586.

Tarrier, N. (1987). An investigation of residual psychotic symptoms in discharged schizophrenic patients. Br J Clin Psychol, 26(Pt 2), 141-143.

Tarrier, N. (1992). Management and modification of residual positive psychotic symptoms. In M. Birchwood \& N. Tarrier (Eds.), Innovations in psychological management of schizophrenia. (pp. 147-169). Chichester: John Wiley \& Sons Litd.

Tarrier, N., Sharpe, L., Beckett, R., Harwood, S., Baker, A., \& Yusopoff, L. (1993). A trial of two cognitive behavioural methods of treating drug-resistant residual psychotic symptoms in schizophrenic patients. II. Treatment- specific changes in coping and problem-solving skills. Soc Psychiatry Psychiatr Epidemiol, $28(1), 5-10$.

Tennen, H., Affleck, G., Armeli, S., \& Carney, M. A. (2000). A daily process approach to coping. Linking theory, research, and practice. Am Psychol, 55(6), 626-636.

Tien, A. Y. (1991). Distributions of hallucinations in the population. Soc Psychiatry Psychiatr Epidemiol, 26(6), 287-292.

Ustun, T. B., Chatterii, S., \& Andrews, G. (2002). International classifications and the diagnosis of mental disorders: Strengths, limitations and future perspectives. In M. Mai \& W. Gaebel \& J. J. López-Ibor \& N. Sartorius (Eds.), Psychiatric Diagnosis and Classifications (pp. 25 - 46). Chichester: J. Wiley \& Sons.

Ustun, T. B., Chatterji, S., \& Rehm, J. (1998). Limitations of diagnostic paradigm: it doesn't explain "need". Arch Gen Psychiatry, 55(12), 1145-1146; discussion $1147-1148$. 
Vaillant, G. E., Bond, M., \& Vaillant, C. O. (1986). An empirically validated herarchy of defence mechanisms. Arch Gen Psychiany, 43(8), 786-794.

van den Bosch, R. J., \& Rombouts, R. P. (1997). Coping and cognition in schizophrenia and depression. Compr Psychiary. 38(6), 341-344.

van den Bosch, R. J., van Asna, M. J., Rombouts, R. \& Louwerens, I. W. (1992). Coping style and cognitive dysfunction in schizophrenic patients. $B r^{*} J$ Psychiatry Suppl(18), 123-128.

van Os, I., Driessen, G., Gunther, N., \& Delespaul, P. (2000). Neighbourhood variation in incidence of schizophrenia. Evidence for person-environment interaction. $\mathrm{Br}$ J Psychiatry, 176, 243-248.

van Os, I., Fahy, T. A., Jones, P., Harvey, I., Sham, P., Lewis, S., Bebbington, P., Toone, B., Williams, M., \& Murray, R. (1996). Psychopathological syndromes in the functional psychoses: associations with course and outcome. Psychol Med, 26(1), 161-176.

van $\mathrm{O}_{\mathrm{s}}, \mathfrak{J}_{.,}$Gilvarry, C., Bale, R., van Horn, E., Tattan, T., White, 1., \& Murray, R. (2000). Diagnostic value of the DSM and ICD categories of psychosis: an evidence-based approach. UK 700 Group. Soc Psychiary Psychiat Epidemiol. $35(7), 305-311$.

van Os, J., Hanssen, M., Bijl, R. V., \& Ravelli, A. (2000). Strauss (1969) revisited: a psychosis continuum in the general population? Schizophr Res, 45(1-2), 11-20.

van Os, J., Hanssen, M., Bijl, R. V., \& Vollebergh, W. (2001). Prevalence of psychotic disorder and community level of psychotic symptoms: an urban-rural comparison. Arch Gen Psychiatry, 58(7), 663-668.

Van Os, J., Jones, P., Sham, P., Bebbington, P., \& Murray, R. M. (1998). Risk factors for onset and persistence of psychosis. Soc Psychiatyy Psychiatr Epidemiol, 33(12), 596-605.

van Os, J., \& Marcelis, M. (1998). The ecogenetics of schizophrenia: a review. Schizophr Res, $32(2), 127-135$.

van Os, I., Verdoux, H., Bijl R.V., \& Ravelli, A. (1999). Psychosis as an extreme of continuous variation in dimensions of psychopathology. In H. Hafner \& W. Gattaz (Eds), Search for the Canses of Schizophrenia. (Vol. 4, pp. 59-79). Berlin: Springer.

van Os, J., Verdoux, H., Maurice-Tison, S., Gay, B., Liraud, F., Salamon, R., \& Bourgeois, M. (1999). Self-reported psychosis-like symptoms and the continum of psychosis. Soc Psychiary Psychiatr Epidemiol, 34(9), 459-463.

van Praag, H. M. (1992). "Make-Believes" in Psychiatry or the Perils of Progrexs. NewYork: Brunner Mazel.

Venables, P. H. (1995). Schizotypal status as a developmental stage in studies of risk for schizophrenia. In A. Raine \& T. Jencz \& S. A. Mednick (Eds.), Schizorypical Personaliry. (pp. 107-134). Cambridge, NY: Cambridge University Press.

Venables, P. H., \& Bailes, K. (1994). The structure of schizotypy, its relation to subdiagnoses of schizophrenia and to sex and age. Br J Clin P.sychol, 33(Pt 3), $277-294$.

Venables, P. H., \& Rector, N. A. (2000). The content and structure of schizotypy: a study using confirmatory factor analysis. Schizophr Bull, 26(3), 587-602.

Verdoux, H., Maurice-Tison, S., Gay, B., Van Os, J., Salamon, R., \& Bourgeois, M. L. (1998). A survey of delusional ideation in primary-care patients. Psychol Med, $28(1), 127-134$. 
Waeldner, R. (1960). Basic theory of psychoonalysis. New York: International Universities Press.

Wiedl, K. H. (1992). Assessment of coping with schizophrenia. Stressors, appraisals, and coping behaviour. Br.J Psychiatry Stuppl(18), 114-122.

Wiedl, K. H. (1997). Coping-oriented therapy with schizophrenic patients: General guidelines, starting points and issues of evaluation. In H. D. Brenner \& W. Bokker \& R. Genner (Eds.), Towards a comprehensive therapy for schizophrenia. (pp. 209-227). Seattle, Hogrefe \& Huber,.

Wilder-Willis, K. E., Shear, P. K., Steffen, J. J., \& Borkin, J. (2002). The relationship between cognitive dysfunction and coping abilities in schizophrenia. Schizophr Res, 55(3), 259-267.

Wing, J. (1992). Differential diagnosis of schizophrenia. In L. D. Kavanagh (Ed.), Schizophrenia: An overview and practical handbook. London: Chapman \& Hall.

Wing, J., Bennet, D. H., \& Denham, J. (1964). The industrial rehabilitation of longstay schizophrenic patients (Medical Research Council Memo). London: HMSO.

Zubin, J., \& Spring, B. (1977). Vulnerability-a new view of schizophrenia. $J$ Abnorm Psychol, 86(2), 103-126. 


\section{Chapter 2}

Maastricht Assessment of Coping Strategies (MACS) 


\section{General aspects about coping assessment}

Actual coping is a phenomenon that can be noticed by introspection or by observation, and it includes internal events as well as overt actions (Schwarzer \& Schwarzer, 1996 ). Concepts of coping consists of three ingredients: (I) coping does not need to be a completed "successful" act, but the effort has to be made; (II) this effort does not need to be expressed in actual behaviour, but can be clirected to cognitions as well; and (III) a cognitive appraisal taxing the situation is a prerequisite of coping attempts (Schwarzer \& Schwarzer, 1996). Because cognitive coping and appraisal can be mutual confounders, coping refers to what an individual thinks or does to manage an emotional encounter (Lazarus, 1991). Reduction of distress is not the immediate goal of coping. In fact, freedom from distress is conspicuously absent from current conceptualisations of psychological well-being, which suggests that selfacceptance, personal growth in life and autonomy are better markers for effective functioning (Ryff \& Keyes, 1995). The aspects of individual psychological well-being, self-ecceptance and autonomy is conceptualiased in the assessment of perceived control and serves as a measurement of coping efficacy.

Assessment of coping strategies depends basically on self-report. Self-report of the stressful encounter and coping strategies narrow questionnaires to behaviours and cognitions within the subject's awareness. The more time has elapsed, the more people tend to refer to the most recent situation and perceived stress and towards the dispositional accounts of their own behaviour (Moore, Sherrod, Liv, \& Underwood, 1979; Porter \& Stone, 1995; Stone, Greenberg, Kennedy-Moore, \& Newman, 1991). The limitations and disadvantages of self report data are problems of memory, the desire of subjects to present themselves in a positive light, language ambiguity and the use of verbal reports as an ego defence. Personal characteristics, history and circumstances determine whether people report circumstances as stressful or not in their recent lives, what options were available to cope with. Furthermore the meaning, function and effectiveness of particular coping responses shift across persons and situations (Coyne \& Gottlieb, 1996). Coping is as dynamic as stress perception, mutually interactive in time and determining at the level of self-awareness and self-report properties. One cannot obtain observations on stress and coping without facing the ubiquitous and vexing problem of method variance (Lazarus \& Folkman, 1984).

This has severe implications for measuring coping, as it determines which method is used for coping measurement, and what the shortcomings are of measuring by checklist or an whatever alternative method. Gathering information about the circumstances that generate stressful experiences and the complex contingencies linking person and situational variables and coping over time is preferred before drawing conclusions about coping abilities and effectiveness (Coyne \& Gottlieb, 1996; Gottlieb \& Gignac, 1996). A generic 
coping instrument that could be applied to many different coping contexts, will lose the richness and domain specificity of coping (Gottlieb \& Gignac, 1996). And gathering data by checklist will threaten the ecological validity of coping (Delespaul, 1995; Coyne \& Gottlieb, 1996; Coyne \& Racioppo, 2000).

Much of the problems related with self-report assessment would be solved by the use of a semi-structured interview, as it might preserve rather than obscure crucial differences how subjects attempted to deal with different stressful circumstances at different times (Coyne \& Gottlieb, 1996; Coyne \& Racioppo, 2000 ) and would delimit the phases of action and the associated shift in goals and actions more profoundly (Folkman, 1992b). Finally, semi structured interviews could serve as a basis for consensual rating of coping effectiveness (Coyne \& Gottlieb, 1996; Coyne \& Racioppo, 2000). The existing coping scales use a narrow, incomplete and distorted concept of coping (Coyne \& Gottlieb, 1996). They disregard variability and dynamics of coping (Marco, Neale, Schwartz, Shiffman, \& Stone, 1999; Stone et al., 1998). In addition, most items are prone to information bias, they are not designed for measuring coping at symptom level, and they do not allow the report of simultaneously used coping strategies. Finally, administering the scales of the scales is often time consuming.

\section{Description}

The Maastricht Assessment of Coping Strategies (MACS) is designed to measure coping strategies and comprises coping asssessment in subjects with a single psychotic experience to psychotic disorders, like schizophrenia, schizoaffective disorder, schizophreniform disorder, psychotic depression, etc. The argument of assessing coping strategies per symptom is found in the expected qualitative and quantitative differences in coping strategies per symptom. For example Carr and colleagues studied coping in severe mental patients (Carr, 1988). Depressive symptoms generated more coping strategies than positive or negative symptoms. Although, it is still debated whether the number or the quality of coping strategies are more associated with good outcome (Mueser ef al., 1997).

\section{Rationale}

The goal of the Maastricht Assessment of Coping Strategies (MACS) is to assess coping for separate symptoms, using a new instrument tailored and validated in people suffering from psychotic experiences or any kind of psychotic disorder, in particular schizophrenia. The scale has to be applied easily, for both clinicians and subjects. The scale respects the attention and concentration problems of subjects with diagnosis of schizophrenia. The MACS covers both symptom dimensions and coping domains in a comprehensive way. 
Coping domains - Carr's list of coping domains was adopted.

Behavioural coping strategies: Distraction, Physical change, Task performance, Indulgence and Specific activities.

Social coping:

Cognitive coping:

Medical:

Symptomatic coping:
Externalisation and lsolation.

Suppression, Shifted attention and Problem solving.

Help seeking, Prescribed drugs, and Non-prescribed drugs. For a better description actual psychotropic and substance use as coping strategy, we split medication use in three categories.

behaviour and cognitions with the intention to decrease inconvenience but resulting in an increased expression of illness related behaviour. This in turns, leads to an external manifestations of psychopathology.

Symptom dimensions - The item dimensions were selected from the Brief Psychiatric Rating Scale (BPRS) (Overall \& Gorham, 1962), Positive And Negative Symptom Scale (PANSS) Kay, Fiszbein, \& Opler, 1987; Kay, Opler, \& Lindenmayer, 1989), Present State Examination (PSE) (Wing, Nixon, Mann, \& Leff, 1977) and Subjective Experience of Negative Symptoms (SENS) (Selten, Sijben, van den Bosch, Omloo-Visser, \& Warmerdam, 1993). A prerequisite for coping assessment by consequence of the coping definition is that subjects need at least some awareness and have the posibility to communicate about their experiences that activate coping. Therefore, some cognitive and negative symptoms, like abstract thinking, had to be excluded. In addition, if experiences are denied or not acknowledged, coping awareness is assumed to be absent. In accordance with the lack of insight in psychosis discussion, denial of symptoms may be understood as a defence mechanism. As has been stated in chapter one, defence mechanisms are unconscious efforts to adapt to distress.

The item definitions cover as comprehensive as possible all the six symptom dimensions. This resulted in thirteen psychotic symptoms (MACS-13 version), grouped a priori in 6 dimensions: (I) positive symptoms (passivity experiences, unusual thought content and hallucinations), (II) negative symptoms (blunted affect, emotional withdrawal, self-neglect and lack of initiative), (III) depressive symptoms (depressive mood and anxiety), (IV) cognitive symptoms (poor attention, concentration and disorientation), (V) hostility (hostility) and (VI) euphoria (euphoria). 


\section{Method}

The MACS assesses coping per symptom or experiences that are viewed as symptoms belonging of a psychotic disorder. Only symptoms or experiences that are recognized as such, can be rated. The symptom definition is read aloud to the subject. This is told in general, first. Then the symptom definition is read in a more personal way to the subject, by referring to the question whether the subject is recognising that particular symptom. Subsequently, the subject for each symptom using a 7-point Likert-scale rates subjective distress levels. Often, people spontaneously report the ways they adapt to the distressing experience or symptom. If not, such a report is cued. Verbatim responses are written down and coping is coded afterwards by the interviewer using Carr's five main types and fourteen categories (Carr, 1988). Several coping strategies can be used to cope with a symptom. People are urged to be extensive and include all the behavioural, emotional and cognitive actions in response to their experienced distress. We used this open strategy (spontaneously mentioned strategies) to avoid information bias. After the coping strategie assessment the subject is asked to rate the level of perceived control over the experience or symptom. The objective of control perception is the measurement of subjective coping effectiveness. The subject gives a rating on 7-point Likert scale, ranging from no control to maximum control perception.

See for MACS-13 and -24 http://www.macsinfo.homestead.com/index.html. 


\section{MACS - Thirteen item version}

\section{Passivity experiences.}

Some people experience thoughts and feelings or perform actions, which they do not regard as strange to them or as foreign to themselves. Thoughts might be read or brought in by others.

Sometimes they are convinced that other people can read their thoughts without even being near.

Regarding the experience that people might read your thoughts or bring thoughts into your head, or that your thoughts are beard by others, or that you perform actions, which you do not regard as out of character or that others know a lot about you $I$ would like to ask the following questions.

- Have you had at least one of these experiences?

How distressing are these experiences? How troublesome are these experiences?

- In what ways do you influence or change these experiences? Nanne everything you do.

- Are you able to influence or change these experiences in such a way that you obtain control over the experience?

- (Can you) Express the amount of control?

\section{Unusual thoughts.}

Some people are convunced that others want to harm or hurt them, that others control what they think or do, or they are convinced to possess special gifts or powers.

Regarding the experience that you might be conwinced or know that other people want to harm or hurt you, that they want to control your thoughts or your actions, or you are convinced to possess special gifts or powers, I would like to ask the following questions.

$>$ Have you had at least one of these experiences?

How distressing are these experiences? How troublesome are these experiences?

In what ways do you intluence or change these experiences? Name everything you do.

$>$ Are you able to influence or change these experiences in such a way that you obtain control over the experience?

- (Can you) Express the amount of control?

\section{Disorganisation.}

Sometimes our thoughts are slow. It takes a while before one is able to produce an answer. At other times thoughts may be last. We answer questions quickly. Sometimes so many thoughts are within our head that we have a lot to think about and it is diffeult to answer. Thoughts are disordered. But at other times it feels as if we have no thoughts. Our head seems empty.

Regarding the experience that your thoughts might be slowed down or disordered, I would like to ask you the lollowing questions.

Hawe had at least one of these experiences?

How distressing are these experiences? How troublesome are these experiences?

In what ways do you influence or change these experiences? Name everything you do.

- Are you able to influence or change these experiences in such a way that you obtain control over the experience?

$>$ (Can you) Express the amount of control'? 


\section{Hallucinations.}

Sometimes people hear, see, smell, taste or feel sensations of which other people state that they do not experience that sensation. But for them the experience is realistic.

Regarding the experience that you might hear, see, smell, taste or feel sensations of which other people state that they do not experience that sensation, I would like to ask you the following questions.

Have you had at least one of these experiences?

How distressing are these experiences? How troublesome are these experiences?

$>$ In what ways do you influence or change these experiences? Name everything you do.

(Can you) Express the amount of control?

\section{Hostility.}

Sometimes we notice that we become easily irritated, agitated or angry. We might have troubles cooperating with other people.

Regarding the idea or feeling that you might be casily irritated, agitated or angry or that you have the experience it is difficult to cooperate with other people, I would like to ask you the following questions.

- Have you had at least one of these experiences?

\% How distressing are these experiences? How troublesome are these experiences?

In what ways do you influence or change these experiences? Name everything you do.

$\$$ (Can you) Express the amount of control?

\section{Blunted affect.}

Sometimes we experience a lot of emotions, like being in love or angry. At other moments we experience very little or no emotions. Some events seem to be experienced indifferently, as if we lost our emotions.

Regarding the experience it might be troublesome to express or show your emotions, I would like to ask you the following questions.

$>$ Have you had at least one of these experiences?

- How distressing are these experiences? How troublesome are these experiences?

In what ways do you influence or change these experiences? Name everything you do.

- (Can you) Express the amount of control?

\section{Lack of intiative.}

To start with activities, one must experience the need or urge to do anything.

Regarding the experience you undertake very little or no activities by yoursell, I would like to ask you the following questions.

Have you had at least one of these experiences?

How distressing are these experiences? How troublesome are these experiences?

In what ways do you influence or change these experiences? Name everything you do.

$>$ (Can you) Express the amount of control? 
8. Emotional withdrawidi.

Sometimes we do not ned much social contact with other people, we prefer to be alone. At other times however we need to be around people and actively go out to meet other people.

Regarding the expericnoe you might not need much social contacts with other people, you prefer to be by yoursel, I would like to ask you the following questions.

- Have you had at least one of these experiences?

- How distrosing are these experiences? How troublesome are these experiences?

In what ways do you influence or change these experiences? Name everything you do.

(Can you) Express the amount of control?

\section{Self-neglect.}

Sometimes we have attention for our hygiene. We make sure we bath regularly and take care of ourselves. Clothing looks orderly. However at other limes or periods we have little attention for self-care. We seldom take a shower, we look shabby, and usually the clothing is dirty.

Regarding the experience your self-care has decreased, I would like to ask you the following questions.

Have you had at least one of these experiences?

How distressing are these experiences? How troublesome are these experiences?

7 In what ways do you influence or change these experiences? Name everything you do.

$>$ (Can you) Express the amount of control?

\section{Depressive mood.}

Sometimes we experience happiness due to circumstances or events that happen. We may enjoy them a lot. At other times we are not able to enjoy those pleasurable events at all, we experience little or no happy emotions, we are down. We feel hopeless.

Regarding the experience that you might not enjoy any of those pleasurable events at all or you experience little or no happy emotions, you are down. I would like to ask you the following questions.

- Have you had at lesst one of these experiences?

- How distressing are these experiences? How troublesome are these experiences?

In what ways do you influence or change these experiences? Name everything you do.

$>$ (Can you) Express the amount of control?

\section{Anxiety}

Sometimes we experience tension of anxiety, noticing palpitations, tremor, shivering, sweating and being restless.

Regarting the experience that you might experience tension or anxiety, noticing palpitations, tremor, shivering, sweating and being restless, I would like to ask you the following questions.

Have you had a least one of these experiences?

How distressing are these experiences? How troublesome are these experiences?

In what ways do you influence or change these experiences? Name everything you do.

(Can you) Express the amount of control? 
12. Poor attention.

With daily activities we need good concentration and attention, otherwise we cannof follow what is happening or complete the task or work properly.

Regarding the experience that your attention or concentration might deteriorate, w would like to ask you the following questions.

- Have you had at least one of these experiences?

- How distressing are these experiences? How troublesome are these experiences?

$>$ In what ways do you influence or change these experiences? Name everything you do.

- Are you able to influence or change these experiences in such a way that you obtain control over the experience? Can you express the amount of control?

\section{Euphoria.}

There may be episodes in our life that one is feeling too happy or optimistic, acconding to the situation. Sometimes we experience unusual excessive energy, during which we ate very active. Your thoughts and speech are faster of tempo.

Regarding the too happy or optimistic feelings, with speeding up of your thoughts and speech behaviour, with at feeling of excessive energy, I would like to ask you the following questions.

Have you had at least one of these experiences?

How distressing are these experiences? How troublesome are these experiences?

In what ways do you influence or change these experiences? Name everything you do. (Can you) Express the amount of control? 


\section{MACS-list of coping strategles with the various coping domains.}

\section{A. Behovior conmol:}

Each change towards non-social behavior not resulting from medical care and not the result of psychopathology. There are 5 mechanisms of behavior control:

Distraction/relaxation* switching the center of attention from the individual and the symptoms to an external cause.

- Physical changes: changes in the amount and sort of body positions, in which the focus of attention remains the individual, itself, in particular, the body. For this there are 3 options: passive behavior, heightened activities, change of posture.

- Indulgence: behavior focused on simple needs, mostly orally: eating, smoking, drinking coffee, drinking alcohol, etc...

Tasks: activitues focused on the production of the essential work or duties

Non-specific activities: Behavior that leads to lessening the burden of the symptoms, by executing generall affairs that can be specified by the subject.

\section{B. Social:}

Every change of behavior that has the direct intention and/or effect to change the amount op personal contact. The two possibilities are increasing or decreasing the amount of interpersonal contact.

Socialization: increasing contact social interaction with other people

$>$ Isolation: decreasing contact or social interaction with other people

C. Cognitive control:

This regards some selective changes focusing on the thoughts and perceptions in particular. We recognize three mechanisms.

$>$ Suppression: suppression of the symptoms, narrowing the attention.

Shifting attention: choosing a different focus of attention as a diversion.

Problem solving: talking back to the voices, expressing yourself dismissing thoughts, "reality testing", etc...

\section{Medical care:}

Medical care is sought within the medical conmunity.

$>$ Help seeking: within Medicare.

- Prescription medication: use of medication as prescribed by a doctor.

Non-prescribed sources: use of drugs, alcohol abuse or non-prescribed medication.

\section{E. Symptomatic behavior"}

Each form of behavior with the intention to decrease inconvenience but resulting in an increased expression of illness related behavior leading the external manifestations of the psychopathology to increase rather than decrease or cured. A paranoid person caries a knife for self protective reasons, someone who hears woices act upon them, someone who lacks initiative stays in bed or at home. 


\section{References}

Carr, V. (1988). Patients' techniques for coping with schizophrenia: an exploratory study. Br.J Med Psychol. 6I(Pt 4), 339-352.

Coyne, J. C., \& Gottlieb, B. H. (1996). The mismeasure of coping by checklist. J Pers, 64(4), 959-991.

Coyne, J. C., \& Racioppo, M. W. (2000). Never the Twain shall meet? Closing the gap between coping research and clinical intervention research. Am Psychol, 55(6), 655-664.

Delespaul, P. A. E. G. (1995). Assessing Schizophrenia in Daib Life: The Experience Sampling Method. Unpublished PhD Thesis, Mastricht University, Maastricht.

Folkman, S. (1992). Reply to Stone and Kennedy-Moore. In H. S. Friedman (Ed.), Hostility, coping and health. Washington, DC,: American Psychological Association.

Gottlieb, B. H., \& Gignac, M. A. (1996). Content and domain specificity of coping among family caregivers of persons with dementia. Joumal of Aging Studies, $10,137-155$.

Kay, S. R., Fiszbein, A., \& Opler, L. A. (1987). The positive and negative syndrome scale (PANSS) for schizophrenia. Schizoph Bull, 13(2), 261-276.

Kay, S. R., Opler, L. A., \& Lindenmayer, J. P. (1989). The Positive and Negative Syndrome Scale (PANSS): rationale and standardisation. Br J Psychiatry Suppl(7), 59-67.

Lazarus, R. S. (1991). Emotion and adaptation. London.: Oxford University Press.

Lazarus, R. S., \& Folkman, S. (1984). Stress, Appraisal and Coping. New York: Springer Verlag.

Marco, C. A., Neale, J. M., Schwartz, J. E., Shiffman, S., \& Stone, A. A. (1999). Coping with daily events and short-term mood changes: an unexpected failure to observe effects of coping. J Consult Clin Psychol, 67(5), 755-764.

Moore, B., Sherrod, D., Liv, T., \& Underwood, B. (1979). The dispositional shift in attention over time. Journal of Personality and Social Psychology. 15, 553569.

Mueser, K. T., Valentiner, D. P., \& Agresta, J. (1997). Coping with negative symptoms of schizophrenia: patient and family perspectives. Schizophr Bull, 23(2), 329. 339.

Overall, J. E., \& Gorham, D. (1962). The Brief Psychiatric Rating Scale. Psychological Reports, 10,799-812.

Porter, L., \& Stone, A. A. (1995). Are there really gender differences in coping?: A reconstruction of previous data and results from daily study. Jourval of Social and Clinical Psychologr, 14.

Ryff, C. D., \& Keyes, C. L. (1995). The structure of psychological well-being revisited. Journal of Personality and Social Psychology, 69, 719-727.

Schwarzer, R., \& Schwarzer, C. (1996). A critical survey of coping instruments. In M. Zeidner \& N. S. Endler (Eds.), Handbook of coping (pp. 107-132). New York. john Wiley \& Sons, inc.

Selten, J. P., Sijben, N. E, van den Bosch, R. J., Omloo-Visser, J., \& Warmerdam, H. (1993). The subjective experience of negative symptoms: a self-rating scale. Compr Psychiatry, 34(3), 192-197. 
Stone, A. A., Greenberg, M. A., Kennedy-Moore, E, \& Newman, M. G. (1991). Selfreport, situation-specific coping questionnaires: what are they measuring? $J$ Pers Soc Psychol, 61(4), 648-658.

Stone, A. A., Schwartz, J. E., Neale, J. M., Shiffman, S., Marco, C. A., Hickcox, M., Paty, J., Porter, L. S. \& Cruise, L. I. (1998). A comparison of coping assessed by ecological momentary assessment and retrospective recall. I Pers Soc Psychol, 74(6), 1670-1680.

Wing, J. K., Nixon, J. M., Mann, S. A., \& Leff, J. P. (1977). Reliability of the PSE (ninth edition) used in a population study. Psychol Med, 7(3), 505-516. 


\section{Chapter 3}

MACS - I: Maastricht Assessment of Coping Strategies: A brief instrument to assess coping with psychotic symptoms

Bak, M., van der Spil, F., Gunther, N., Radstake, S., Delespaul, P., \& van Os, J. (2001). Maastricht Assessment of Coping Strategies (MACS-1): a brief instrument to assess coping with psychotic symptoms. Acta Psychiatr Scand, $103(6), 453-459$. 


\section{Abstract}

Objective: To examine the reliability of a brief instrument to assess coping with symptoms by patients with psychotic illness.

Method: A semi-structured interview (MACS) was developed to assess the amounts of distress, control and coping in relation to psychotic symptoms. Two raters interviewed twenty-three symptomatic but stable patients with a diagnosis of chronic schizophrenia on two separate occasions. Case managers were also interviewed.

Results: Both the number of coping strategies used for different groups of symptoms, and the amount of coping used in different domains of coping strategies could be assessed reliably between interviewers (intraclass correlation coefficients range: 0.90 to 0.97 ) and between interview sessions (ICC's range: 0.75 to 0.80 ). Reliability with case managers, however, was low.

Conclusion: The MACS may be a reliable and useful instrument to assess coping in relation to subjective experience of distress by and control over psychotic symptoms,

Keywords: psychosis, schizophrenia, coping, treatment. 


\section{Introduction}

Individuals with a diagnosis of schizophrenia have to cope on a daily basis with the stress generated by their symptoms. Coping is defined as "the person's cognitive and behavioural efforts to manage the internal and extemal demands of the person-enviromment transaction that is appraised as taxing or exceeding the person's resources" (Lazarus \& Folkman, 1984). Coping is the result of a dynamic relationship between the person and the environment that proceeds over time and is mediated by cognitive appraisal processes. Many studies have demonstrated that coping strategies are used by patients who experience difficulties in dealing with the amount of stress generated by symptoms (Böker et al., 1989; Brenner et al., 1987; Carter et al., 1996; Dittmann \& Schuttler, 1990; Falloon \& Talbot, 1981; Farhall \& Gehrke, 1997; Frederick \& Cotanch, 1995; Hatfield, 1989; Kumar, Thara, \& Rajkumar, 1989; Lee, Lieh-Mak, Yu, \& Spinks, 1993; Middelboe \& Mortensen, 1997; Mueser et al., 1997; Romme et al., 1992; Semple et al., 1999; Takai, Uematsu, Kaiya, Inoue, \& Ueki, 1990; Thurm \& Haefner, 1987; Wahass \& Kent, 1997). Coping strategies can be the specific target of psychological interventions but are also self-initiated by patients, enhancing the degree of symptom control and thereby reducing the level of distress (Jenner, van de Willige, \& Wiersma, 1998; Tarrier et al., 1993; Wykes, Parr, \& Landau, 1999).

Given the clinical importance of coping strategies, a brief instrument to aid assessment of distress, coping and control associated with symptoms would be useful in clinical practice. For example, for the planning of coping enhancement therapy it is important to have knowledge about the degree of coping in relation to symptoms and type of strategies used. Although a number of peer-reviewed coping questionnaires exist, these were developed for other, non-psychotic populations (Eriksen, Olff, \& Ursin, 1997; Moos, 1988). Other questionnaires mentioned in the literature appear too lengthy and time consuming for use in clinical practice (Wiedl, 1992). Carr (1988) identified over 350 coping strategies elicited in a sample of patients with a diagnosis of schizophrenia which fell into five basic categories: behavioural, social, cognitive, care-related and symptomatic strategies. We wished to develop an instrument that can reliably assess the number of coping strategies used for symptoms of psychosis, as well as the type of coping strategy used, in relation to the degree of subjective distress by and control over psychotic symptoms.

\section{Method}

Construction of the MACS. (hitp:/Www.macsinfo.homestead.com/index.html)

Thirteen core symptoms of schizophrenia were chosen based on the BPRS, PANSS, PSE and the SENS (Kay et al., 1987; Overall \& Gorham, 1962; Selten, Gernaat, Nolen, Wiersma, \& van den Bosch, 1998; Wing, Cooper, \& Sartorius, 1974). These 13 symptoms were a priori grouped, according to the already 
mentioned psychometric scales, as i) positive symptoms (passivity experiences, unusual thought content, hallucinations), ii) negative symptoms (blunted affect, emotional withdrawal, self-neglect, lack of initiative), iii) depressive symptoms (depressive mood, anxiety), iw) cognitive symptoms (poor attention, disorientation ), v) hostility (hostility) and vi) euphoria (euphoria). On the basis of the stem questions taken from the original instruments, the interviewer first described the symptom to the patient in a general way, as if other people might suffer from that specific symptom too. The interviewer then asked the patient whether this symptom might have been present in the last week, again repeating the same description and asking follow-up questions to clarify if necessary. If the patient indicated the symptom had been present, the patient was asked: (i) to indicate on a seven-point Likert scale the degree of distress associated with the symptom, (ii) to name all the strategies used to alleviate distress with symptoms and (iii) to indicate on a seven-point Likert scale the degree of control experienced over the symptom. The coping strategies were assessed by asking standard questions about what the patient did or thought when faced with the symptom. All the strategies mentioned by the patient were scored in one of five domains of coping, based on the work by Carr (1988). This method ensured that we gathered the most important, self-initiated coping strategies used by the patient. On the basis of extensive pilot interviews, definitions had been prepared for these five domains and their subcategories (see http://www.macsinfo.homestead.com/index.html), and examples were given for different symptoms so as to guide the interviewer. The five domains of coping consisted of: (i) behavioural, (ii) social, (iii) cognitive, (iv) care and (v) symptomatic. The first four domains had $5,2,3$ and 3 subcategories respectively, and the last consisted only of one item (see hitp://www.macsinfo.homestead.com/index.html), so that patients' descriptions of coping mechanisms could be scored under any of 14 different items.

\section{Interviews}

Two clinical interviewers, one a clinical psychologist and the other a psychiatrist, studied the definitions and examples of coping described above before starting joint interviews. The two raters separately rated coping mechanisms described by the patient (interview one and two). After one week (maximum of ten days), the interview with the same patient was repeated jointly by both interviewers (interview three and four).

If in clinical practice case managers already have adequate knowledge about how their patients cope with symptoms, the case for a specific assessment instrument would be less compelling. Therefore, a fifth interview was conducted with the (clinical) case manager of the patient, using the same procedure and as near the time of the second interview as possible (allowing for assessment of reliability with the second patient interview). The case manager was asked by one of the interviewers to indicate the estimated degree of distress 
by and control over any symptom, and to describe coping strategies on the part of the patient. Patient inclusion criteria were: DSM-IV diagnosis of schizophrenia according to the psychiatrist responsible for treatment, some degree of symptoms but not in need of in-patient treatment, and no recent (last six months) changes in housing, medication or responsible medical officer.

\section{Analyses}

\section{Domains of coping}

In order to examine patterns of correlation between the 14 different types of coping, a principal component factor analysis followed by varimax rotation was carried out, retaining factors with at least unity eigenvalues and retaining variables with a loading of at least 0.5 on one of the identified factors.

\section{Number of coping strategies by symptom group}

The data were analysed with STATA, version 6 (34). A data file was constructed in which each of the 21 patients included in the study contributed six observations: one for each of the six symptom groups described above. For each of the six symptom groups, the total number of coping strategies mentioned was calculated. For example, the positive symptom group consisted of three items as described above. A patient could indicate that he was using distraction and suppression for hallucinations (2 coping mechanisms), withdrawal for persecutory delusions ( 1 coping mechanism), and medication for passivity experiences ( 1 coping mechanism). This patient would thus have a coping score of $4(2+1+1)$ for positive symptoms. As there were 6 symptom groups and 21 patients, each interview would generate $6 \times 21=126$ coping strategy scores. In order to assess the test-retest reliability between the two interviewers both at the first and the second interview, and the reliability between the two interviewers and the case manager, intraclass correlations for coping strategy scores were calculated. In order to assess within rater (testretest) reliability, intraclass correlations were calculated between the first and the second interview of the same rater. In the same fashion, scores for the mean amount of distress and control were calculated for each of the six symptom groups in each patient, and compared both between interviewers and interview occasions.

In order to estimate the reliability in measuring the unobserved factors "distress" and "control", Cronbach's alpha was calculated using the distress and control ratings in each patient for each of the thirteen symptoms. Cronbach's alpha measures how well a set of items (or variables) measures a single unidimensional latent construct. When data have a multidimensional structure, Cronbach's alpha will usually be low. 


\section{Number of coping strategies by coping type}

Similar to the procedure described above for number of coping strategies by symptom group, a data file was constructed in which each of the 21 patients included in the study contributed five observations: one for each of the five domains of coping described below. The same intraclass correlations coefficients were calculated as described in the section on the number of coping strategies by symptom group.

\section{Results}

\section{Sample}

Twenty-three white patients, bom in the Netherlands, with a DSM-IV diagnosis of schizophrenia according to their psychiatrist provided written informed consent. Of the 23 subjects $15(65.2 \%)$ were male and $8(34.8 \%)$ female. The mean age was 38.5 years (SD 10.7), and the mean age of first contact with a mental health service 24.4 years (SD 7.3). Most subjects lived alone (69.6\%), and were single $(78.9 \%)$.

\section{Interviews}

Of the 23 patients, 2 were only interviewed once. One person thought the interview was too difficult and in another case the limit of ten days between the first and second interview was exceeded, because the patient forgot the appointment for the interview two times. The case managers of all 23 patients were interviewed. All the analyses were performed in the group of 21 individuals with complete data at all interviews.

\section{Dowains of coping}

Factor analysis of the individual patient scores on each of the 14 coping types (ie the number of times a patient had indicated the use of a particular coping type) revealed a interpretable pattern of correlation yielding five factors explaining $71 \%$ of the variance. The coping mechanisms distraction, problem solving and help-seeking clustered together in an active problem solving coping factor; the coping mechanisms prescribed medication, non-prescribed substances, and physical change clustered together in a passive illness" behaviour coping factor; the coping mechanisms shifted attention, socialisation, task performance and indulgence clustered together in an active problem avoiding coping factor; the coping mechanisms isolation, non-specific activities and suppression clustered together in a passive problem avoiding coping factor, and the fifth factor was one on which only symptomatic behaviour loaded. 


\section{Coping}

As there were 13 symptoms, 14 coping mechanisms and 21 patients, the maximum possible number of coping strategies for the whole study sample that could be elicited was 3822 . The total number of coping strategies elicited in all 21 patients was 361 and 309 at the first rating for the first and the second rater respectively, 283 and 293 at the second interview by the two raters, and 275 in the case manager interview. Thus, patients (and their case managers) indicated presence of coping in less than $10 \%$ of rateable instances of coping. These percentages differed between the different categories of coping strategies. In the symptomatic behaviour coping factor, coping was indicated around $20 \%$ of the time both in patient and case manager interviews. In the active problem solving coping factor, coping was elicited around $10 \%$ of the time in both patient interviews and case management interviews. Conversely, in the passive illness behoviour coping factor, coping was indicated around $4 \%$ of the time.

The mean coping score (number of coping mechanisms described per symptom group - see above) was around 2.5 and did not differ significantly between the five interview occasions

Table 1. Mean coping per symptom group and per coping domain at five interview occasions

\begin{tabular}{lllll}
\hline Interview\# & $\begin{array}{l}\text { Mean coping per } \\
\text { symptom group (SD) }\end{array}$ & $\begin{array}{l}\text { Obser- } \\
\text { vations* }\end{array}$ & $\begin{array}{l}\text { Mean coping per } \\
\text { coping domain (SD) }\end{array}$ & $\begin{array}{l}\text { Obser- } \\
\text { vations** }\end{array}$ \\
\hline 1 & $2.87(2.74)$ & 126 & $3.44(3.17)$ & 105 \\
2 & $2.25(2.50)$ & 126 & $2.70(2.95)$ & 105 \\
3 & $2.18(2.83)$ & 126 & $2.62(2.26)$ & 105 \\
4 & $2.45(2.42)$ & 126 & $2.94(2.50)$ & 105 \\
5 & $2.33(2.72)$ & 126 & $2.79(2.97)$ & 105 \\
$\begin{array}{l}\text { Test for } \\
\text { differences } \\
\text { in means }\end{array}$ & $\mathrm{F}=1.33, \mathrm{df}=4,625, \mathrm{P}=0.26$ & $\mathrm{~F}=1.43, \mathrm{df}=4,520, \mathrm{P}=0.22$ \\
\hline
\end{tabular}

\footnotetext{
\$ Interviewer 1,1 st interview, 2 =interviewer 1,2 nd intorvien; $3=$ was manager;

$4=$ Interviewer 2,1 si intarview; $5=$ Interviewer 2,2 nd interview.

* Each of the 21 individuals contributed 6 observations: one for each smptom group

* Each of the 21 individuals contributed 5 observations: on for each coping domain
}

The same held when coping scores were compared separately in each of the six symptom groups. Patients, however, varied widely in diversity of coping strategy, the total number of coping mechanisms per patient ranging from around 2 to around 30 at all five interviews occasions (mean over all five interviews: $14.5, \mathrm{SD}=6.5$ ). Only one patient indicated no use of any coping strategy at three of the five interview sessions.

Cronbach's alpha for the measurement of the internal scale reliability for distress and control was satisfactory at all three measurement occasions, somewhat more so at the second than at the first measurement session (Table 2). 
Table 2. Cronbach" atpha at he three measurement occasions

\begin{tabular}{lll}
\hline & $\begin{array}{l}\text { Cronbach's alpha } \\
\text { Distress }\end{array}$ & $\begin{array}{l}\text { Cronbach's alpha } \\
\text { Control }\end{array}$ \\
\hline First interview & 0.68 & 0.62 \\
Second interview & 0.86 & 0.82 \\
Case Manager & 0.80 & 0.60 \\
\hline
\end{tabular}

The intraclass correlation coefficients for distress and control as indicated by the patients were high between the first and the second interview, but low between case managers and patients (Table 3 ).

Table 3. Intraclass correlation coefficients for distess and control $(95 \%$ confidence intervals between brackets)

\begin{tabular}{|c|c|c|c|c|}
\hline 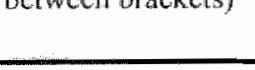 & \multicolumn{2}{|c|}{ Patient second interview } & \multicolumn{2}{|c|}{ Case Manager* } \\
\hline & Distress & Control & Distress & Control. \\
\hline $\begin{array}{l}\text { Patient first } \\
\text { interview }\end{array}$ & $\begin{array}{l}0.85 \\
(0.78-0.89)\end{array}$ & $\begin{array}{l}0.75 \\
(0.64-0.82)\end{array}$ & -- & -- \\
\hline $\begin{array}{l}\text { Patient second } \\
\text { interview }\end{array}$ & & - & $\begin{array}{l}0.64 \\
(0.48-0.74)\end{array}$ & $\begin{array}{l}0.45 \\
(0.22-0.62)\end{array}$ \\
\hline
\end{tabular}

\section{Number of coping strategies per symptom group and coping type.}

The intraclass correlation coefficients for number of coping strategies were high between the two interviewers, slightly lower within interviewers at different occasions, and lowest between case managers and interviewers (table 4).

Table 4. Intraclass corellation coefticients for number of coping mechanisms per symptom group, indicating the test-retest reliability between first and second interview (1-3 and 2-4) and interrater reliability between the two raters during first interview session (1-2) and second interview session (3-4). The correlation between the second interview session of each rater and the case-manager is indicated by $3-5$ and $\mathbf{4}-5$. (95\% confidence intervals between brackets)

\begin{tabular}{l|llll} 
& 2 & 3 & 4 & 5 \\
\hline 1 & $0.97(0.96-0.98)$ & $0.80(0.71-0.86)$ & & \\
2 & & $0.75(0.65-0.83)$ & \\
3 & & $0.90(0.85-0.93)$ & $0.53(0.33-0.67)$ \\
4 & & & $0.61(0.44-0.72)$
\end{tabular}

1=nterviewer 1 , Ist interwiew; $2=$ =nterwiewer 2.1 st interview; $3=$ nnterwiewer 1 , 2nd interview; 4 Interviewer

2. 2nd interview; $5=$ case manager. 
A similar pattern was seen for the number of coping strategies by coping type, with poor reliability between interviewers and case managers (Table 5).

Table 5. Intraclass comelation coefficienis for number of coping mechanisms per coping strategy indicating the test-retest rellability between first and second interview $(1-3$ and $2-4)$ and interrater reliability between the two raters during first interview session (1-2) and second interview session $(3-4)$. The correlation between the second interview session of each rater and the case-manager is indicated by $3-5$ and $45 .(95 \%$ confidence intervals between brackets)

\begin{tabular}{l|llll} 
& $\mathbf{2}$ & $\mathbf{3}$ & $\mathbf{4}$ & $\mathbf{5}$ \\
\hline $\mathbf{1}$ & $0.95(0.93-0.97)$ & $0.77(0.66-0.84)$ & & \\
2 & & & $0.77(0.67-0.85)$ & \\
3 & & & $0.93(0.90-0.95)$ & $0.52(0.30-0.68)$ \\
4 & & & $0.59(0.39-0.72)$
\end{tabular}

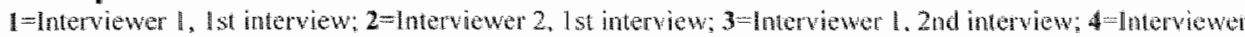
2. 2 nd inderview; 5 =case manager.

\section{Discussion}

Almost all patients indicated use of coping in dealing with symptoms, as reported before by Breier and Strauss (1983). The results of this investigation suggests that the number of coping strategies that patients indicate they use for the different symptoms of psychosis can be assessed reliably. The same appears to hold for the degree to which patients are using a specific coping strategy rather than another. Mental health professionals involved in the care of patients have low levels of agreement with patients regarding degree of distress by and control over symptoms experienced by patients, and the number and type of coping strategy used by patients.

Rather than trying to elicit an extensive list of different coping mechanisms in the way, for example, psychopathology interviews are conducted, coping strategies as reported by the patient were recorded. For this subjective approach was specifically chosen for several reasons. First, the MACS investigates coping in relation to subjective reports of distress and control experience with symptoms. Second, any subsequent intervention involving coping enhancement should arguably build on what the patient is conscious of and perceive as helpful to increase control experience, rather than what the interviewer may perceive "objectively". The fact that intraclass correlation coefficients between the first and the second interviews were satisfactory as a measure of test-retest reliability, suggests that the level of subjective reporting has sufficient "repeatability" for assessment with an instrument like the MACS. Furthermore, even though objective markers may be more reliable, their validity can be uncertain (Amador et al., 1994). 
Retrospective reports over the last week do not adequately capture the momentby-moment coping efforts. Retrospective reports may be more subject to distortion based on participants' beliefs about their coping styles, flowing from subjective self-awareness (Delespaul, 1995). Again, however, it can be argued that only such personal beliefs about recovery processes should be the starting point of therapy in clinical practice.

In rating the number and type of included coping strategies, we relied heavily on the study by Carr (1988). The results of the factor analysis, however, suggests that the included coping strategies yield clinically relevant domains of coping. The contrast between active and passive coping strategies is arguably a useful one from the clinical point of view (Boschi et al., 2000; Somersfield \& McCrae, 2000).

The sample size was rather small. However, analyses were carried out at the level of symptom experiences and coping strategies by number and type, resulting in reasonably precise estimates of reliability. The patient sample represented a very selected group among the total population of patients with psychosis, limiting the generalisability of the findings. More data are needed in patients with, for example, a first psychotic episode or an acute exacerbation.

The interview was conducted by trained clinicians, so as to reduce the likelihood of patients reporting coping in relation to non-symptomatic experiences. The procedure used to elicit the symptoms in the MACS was new, albeit based as much as possible on established instruments such as the BPRS and, again, conducted by trained clinicians to avoid misclassification. In a preliminary investigation of the concurrent validity of the psychopathological measures (part of ongoing work to be published in full in a later report), we examined correlations with the Montgomery-Asberg Rating Scale for depression (MADRS; (Montgomery \& Asberg, 1979) and the Peters et al Delusion Inventory (PDI; (E. Peters et al., 1999) with three added items on hallucinations (Bak, Radstake, \& Van Os, 1999), which were administered concurrently with the MACS. Total scores of the MADRS of the 21 patients correlated strongly with the MACS depressive symptom distress score (Pearson cortelation coefficients of 0.73 and 0.80 for first and second interview respectively), and the PDI total score correlated strongly with the positive symptom distress score (Pearson correlation coefficients of 0.65 and 0.61 respectively). Thus, although not all symptom groups were examined alongside previously validated instruments, these results do suggest concurrent vallidity.

\section{Conclusion}

The results suggest that it is possible to reliably assess the diversity of coping strategies per symptom group and type of coping strategy in patients with psychosis. Change in coping strategy by type or number may constitute a useful outcome for evaluation in clinical practice and treatment trials. In addition, 
mental health professionals may not be fully aware of dimensions of distress and control in relation to symptoms and the self-initiated coping strategies that their patients use. Routine assessment of coping may result in improved awareness of these subjective domains by the patient as well as the care-giver and thus contribute to improved communication with respect to symptom management. Although further work is needed, the current report suggests that the MACS may be adequate for this purpose. 


\section{References}

Amador, X. F., Flaum, M., Andreasen, N. C., Strauss, D. H., Yale, S. A., Clark, S. C., \& Gorman, J. M. (1994). Awareness of illness in schizophrenia and schizoaffective and mood disorders. Arch Gen Psychiatry, 51(10), 826-836.

Bak, M. Radstake, S, \& Van Os, J. (1999). Consultatie aan huisartsen ter detectie wan zorgmijdende mensen met een psychose. $M G v, 12,1281-1289$.

Böker, W., Brenner, H. D., \& Wurgler, S. (1989). Vulnerability-linked deficiencies, psychopathology and coping behaviour of schizophrenics and their relatives. Br J Psychiatry Suppl(5), 128-135.

Boschi, S., Adarns, R. E., Bromet, E. J., Lavelle, J. E., Everett, E., \& Galambos, N. (2000). Coping with psychotic symptoms in the early phases of schizophrenia. Am J Orthopsychiatry, 70(2), 242-252.

Breier, A., \& Strauss, J. S. (1983). Self-control in psychotic disorders. Areh Gen Psychiatry, 40(10), 1141-1145.

Brenner, H. D., Boker, W., Muller, J., Spichtig, L., \& Wurgler, S. (1987). On autoprotective efforts of schizophrenics, neurotics and controls. Acta Psychiatr Scand, 75(4), 405-414.

Carr, V. (1988). Patients' techniques for coping with schizophrenia: an exploratory study. BrJ Med Psychol, 61(Pt 4), 339-352.

Carter, D. M., Mackinnon, A., \& Copolov, D. L. (1996). Patients' strategies for coping with auditory hallucinations. J Nerv Ment Dis, 184(3), 159- 164.

Delespaul, P. A. E. G. (1995). Assessing Schizophremia in Daily Life: The Experience Sampling Method. Unpublished PhD Thesis, Maastricht University, Maastricht.

Dittmann, J., \& Schuttler, R. (1990). Disease consciousness and coping strategies of patients with schizophrenic psychosis. Acta Psychiatr Scand, 82(4), 318-322.

Eriksen, H. R., Olff, M., \& Ursin, H. (1997). The CODE: a revised battery for coping and defense and its relations to subjective health. Scand J Psychol, 38(3), 175182.

Falloon, L. R., \& Talbot, R. E. (198I). Persistent auditory hallucinations: coping mechanisms and implications for management. Psychol Med, //(2), 329-339.

Farhall, J., \& Gehrke, M. (1997). Coping with hallucinations: exploring stress and coping framework. BrJ Clin Psychol, 36(Pt 2), 259-261.

Frederick, J., \& Cotanch, P. (1995). Self-help techniques for auditory hallucinations in schizophrenia. 1ssues Ment Health Nurs, 16(3), 213-224.

Hatlield, A. B. (1989). Patients' accounts of stress and coping in schizophrenia [see comments]. Hosp Community Psychiatry. 40(11), 1141-1145.

Jenner, J. A., van de Willige, G., \& Wiersma, D. (1998). Effectiveness of cognitive therapy with coping training for persistent auditory hallucinations: a retrospective study of attenders of a psychiatric out-patient department. Acta Psychiatr Scand, 98(5), 384-389.

Kay, S. R., Fiszbein, A., \& Opler, L. A. (1987). The positive and negative syndrome scale (PANSS) for schizophrenia. Schizoph Bull, 13(2), 261-276.

Kumar, S., Thara, R., \& Rajkumar, S. (1989). Coping with symptoms of relapse in schizophrenia. Eur Arch Psychiatry Newrol Sci, 239(3), 213-215.

Lazarus, R. S., \& Folkman, S. (1984). Stress, Appraisal and Coping. New York: Springer Verlag. 
Lee, P. W., Lieh-Mak, F., Yu, K. K., \& Spinks, J. A. (1993). Coping strategies of schizophrenic patients and their relationship to outcome. Br J Psychiofry, 163 , $177-182$.

Middelboe, T., \& Mortensen, E. L. (1997). Coping strategies among the long-term mentally ill: categorization and clinical determinants. Acfa Psychiatr Soand. 96(3), 188-194.

Montgomery, S. A., \& Asberg, M. (1979). A new depression scale designed to be sensitive to change. BrJ Psychiatry, 134, 382-389.

Moos, R. H. (1988). [Coping: concepts and measuring procedures]. Z Psychosom Med Psychoamal, 34(3), 207-225.

Mueser, K. T., Valentiner, D. P., \& Agresta, J. (1997). Coping with negative symptoms of schizophrenia: patient and family perspectives. Schizophr Bull, 23(2), 329. 339.

Overall, J. E., \& Gorham, D. (1962). The Brief Psychiatric Rating Scale. Psychological Reports, 10,799-812.

Peters, E., Day, S., McKenna, J., \& Orbach, G. (1999). Delusional ideation in religious and psychotic populations. Br J Clin Psychol, 38(Pt 1), 83-96.

Romme, M. A., Honig, A., Noorthoorn, E. O., \& Escher, A. D. (1992). Coping with hearing voices: an emancipatory approach. BrJ Psychiatry. 161,99-103.

Selten, J. P., Gernaat, H. B., Nolen, W. A., Wiersma, D., \& van den Bosch, R. J. (1998). Experience of negative symptoms: comparison of schizophrenic patients to patients with a depressive disorder and to normal subjects. Am J Psychiatry, $155(3), 350-354$.

Semple, S. J., Patterson, T. L., Shaw, W.S., Grant, I., Moscona, S., \& Jeste, D. V. (1999). Self-perceived interpersonal competence in older schizophrenia patients: the role of patient characteristics and psychosocial factors. Acta Psychiatr Scand, 98, 384-389.

Somersfield, M. R., \& McCrae, R. R. (2000). Stress and coping research: methodological challenges, theoretical advances and clinical applications. American Psychologist, 55(6), 620-625.

Takai, A., Uematsu, M., Kaiya, H., Inoue, M., \& Ueki, H. (1990). Coping styles to basic disorders among sehizophrenics. Acta Psychiatr Scand, 82(4), 289-294.

Tarrier, N., Sharpe, L., Beckett, R., Harwood, S., Baker, A., \& Yusopoff, L. (1993). A trial of two cognitive behavioural methods of treating drug-resistant residual psychotic symptoms in schizophrenic patients. II. Treatment- specific changes in coping and problem-solving skills. Soc Psychiatry Psychiat Epidemiol, $28(1), 5-10$.

Thurm, I., \& Haefner, H. (1987). Perceived vulnerability, relapse risk and coping in schizophrenia. An explorative study. Eur Arch Psychiatry Neurol Sci. 237(1), 46-53.

Wahass, S., \& Kent, G. (1997). Coping with auditory hallucinations: a cross-cultural comparison between western (British) and non-western (Saudi Arabian) patients. J Nerv Ment Dis, 185(11), 664-668.

Wiedl, K.H. (1992). Assessment of coping with schizophrenia. Stressors, appraisals, and coping behaviour. Br J Psychiatry Suppl(18), 1]4-122.

Wing, J. K., Cooper, J. E., \& Sartorius, N. (1974). The measurement and classificatoin of psychiatric symptoms. London: Cambridge University Press. 
Wykes, T., Parr, A. M., \& Landau, S. (1999). Group treatment of auditory hallucinations. Exploratory study of effectiveness. Br J Psychicatry, 175, 180185. 


\section{Chapter 4}

\section{MACS - II. \\ Does coping enhance subjective control over psychotic symptoms?}

Bak, M., van der Spil, F., Gunther, N., Radstake, S., Delespaul, P., \& van Os, J. (2001). MACS-II: does coping enhance subjective control over psychotic symptoms? Acta Psychiatr Scand, 103(6), 460-464. 


\section{Abstract \\ Objective:}

Associations between subjective experience of control and the use of selfinitiated coping strategies were examined in patients with psychotic symptoms. Method: Twenty-three patients were interviewed to assess (i) the subjective experience of distress with and controll over symptoms and (ii) the coping strategles used.

Results: There was a positive association between coping type and control (OR $=1.07,95 \% \mathrm{Cl}: 1.03-1.12)$. Active coping strategies had the strongest association with experience of control (active problem solving: $\mathrm{OR}=1.41$ 95\% Cl: 1.18-1.68; active problem avoiding: $\mathrm{OR}=1.4595 \% \mathrm{CI}: 1.18-1.68)$. Symptomatic coping was negatively associated with control $(\mathrm{OR}=0.40,95 \% \mathrm{Cl}$ : $0.30-0.55$ ), but was the most frequently used strategy. Depressive symptoms were associated with the highest number of coping strategies.

Conclusion: Coping strategies differ in the degree and direction of associated subjective control, and symptoms differ in the degree with which coping is mobilised. Assessment of coping strategies may be usefull as a prelude to psychological therapy.

Keywords: psychosis, schizophrenia, subjective experience, coping, treatment. 


\section{Introduction}

The systematic application of coping strategies in treatment settings can be an important therapeutic tool (Tarrier, 1992), providing patients with psychotic illness a means to gain control over their symptoms (Böker et al., 1984; Brenner et al., 1987; Dittmann \& Schuttler, 1990; Middelboe \& Mortensen, 1997; Semple et al., 1999; Takai et al., 1990). Breier and Strauss (1983) studied coping mechanisms in a self-control framework, and found that almost all patients reported attempts to gain control over their symptoms using different coping strategies. It has been suggested that self-initiated coping strategies enhance control over psychotic symptoms (Brenner et al., 1987; Lazarus \& Folkman, 1984), but it remains uncertain to what extent self-initiated coping strategies are effective in alleviating symptoms. Some studies suggest that the quality of coping is determined more by the number of coping mechanisms than the type of coping (Mueser et al., 1997; Pallanti et al., 1997; Tarrier, 1987). Falloon and Talbot (1981), however, reported that patients who were the least handicapped by their symptoms used fewer coping strategies, but that consistency of used coping strategies was more important. Other work suggests that especially cognitive coping strategies contribute preferentially to attributions of control over symptoms (Tarrier et al., 1993). More recent work stressed the importance of active versus passive coping strategies in dealling with psychotic symptoms (Boschi et al., 2000).

We wished to investigate to what extent self-initiated coping strategies were associated with subjective experience of control over psychotic symptoms. In addition, the degree to which associations differed as a function of coping type or number of coping mechanisms was investigated per symptom.

\section{Material and Method}

The patient sample and instruments have been described in the companion paper (Bak et al., 2001, chapter 3). Of the five interviews described in the companion paper, the second interview by MB (who developed the instrument) was a priori chosen and used for the current analyses. Data were available for 21 patients.

\section{Analyses}

Analyses were conducted with the STATA statistical program (Statacorp, 2001). A data file was constructed in which each of the 21 patients included in the study contributed $14 \times 13=182$ observations: one for each of the different combinations of 14 original coping mechanisms and 13 original symptoms of the MACS (see companion paper, chapter 3). This was the most detailed level of analysis possible as the MACS assesses for each different symptom whether or not an individual uses any of the 14 coping strategies. Thus, for each of these 182 combinations patients could have a score of either 0 (indicating they did not 
use the coping strategy for the symptom) or $\mathbb{1}$ (indicating they did use the coping strategy for the symptom). After construction of the file, the symptoms were regrouped into 6 classes and coping strategies into five classes based on the factor analysis described in the companion paper, retaining the format of 182 ( $=14$ coping strategies $x 13$ symptoms) binary coping scores per individual. In this file, containing 21 subjects $\times 182=3822$ observations, the binary coping variable was the dependent variable, and control the independent variable. Interactions were fitted with coping type and type of symptom and assessed by likelihood ratio tests.

Effect sizes were expressed as odds ratios (OR) from the logistic regression model of the binary coping outcome. As observations were clustered within individuals, the CLUSTER and ROBUST options were used in the STATA logistic regression analyses. The CLUSTER option combined with the ROBUST option allows for the use of observations which are not independent within clusters (in this case: within individuals) and obtains the Huber/White/Sandwich estimator of variance instead of the traditional variance estimator. These procedures result in standard errors that are adjusted for clustering within persons.

Only observations were included of presence or absence of coping strategy that were associated with presence of a symptom, resulting in $n=1820$ out of 3822 maximum observations (inclusion of all observations regardless of presence of symptom would have resulted in associations merely reflecting presence or absence of symptoms).

\section{Results.}

Descriptive statistics of the sample are given in the companion paper (Bak et al., 2001).

\section{Coping in relation to coping type and type of symptom}

Both coping type and type of symptom had effects on the number of coping strategies. Symptomatic coping was by far the most prevalent strategy, whereas passive illness behowiour was the least frequent (Table 1). In the logistic regression analysis, the odds of using symptomatic coping were nearly 10 times higher than use of the passive illness behoviour strategy, whereas the odds of active problem solving, passive problem avoiding and active problem avoiding were around 2-3 times higher. The variation in the number of coping strategies used varied less with type of symptom (Table 2). The odds of using coping strategies were around 2 times higher with depressive symptoms and lowest for symptoms of euphoria, hostility and negative symptoms. The effects of coping type and type of symptom were independent of each other (assessed by entering both together in the logistic regression equation). 
Table 1. Amount of coping by coping domain given the presence of a psychotic sumptom.

\begin{tabular}{|c|c|c|c|c|}
\hline Coping group & Coping mechanism & \%present & $\begin{array}{l}\text { OR }(95 \% \text { Chy level of } \\
\text { coping sirategy }\end{array}$ & $\begin{array}{l}\text { OR ( } 95 \% \text { Clin) level } \\
\text { of coping grous }\end{array}$ \\
\hline \multirow[t]{3}{*}{$\begin{array}{l}\text { Passive illness } \\
\text { behaviour }\end{array}$} & $\begin{array}{l}\text { Non-prescribed } \\
\text { substances }\end{array}$ & $3.85 \%$ & $1 *$ & \multirow{3}{*}{$I^{*}$} \\
\hline & Prescribed medication & $6.92 \%$ & $\begin{array}{l}1.86 \\
(0.92,3.78)\end{array}$ & \\
\hline & Physical change & $10.77 \%$ & $\begin{array}{l}3.02 \\
(1.32,6.89)\end{array}$ & \\
\hline \multirow[t]{3}{*}{$\begin{array}{l}\text { Active problem } \\
\text { solwing }\end{array}$} & Distraction & $26.15 \%$ & $\begin{array}{l}8.85 \\
(3.62 .21 .66)\end{array}$ & \multirow{3}{*}{$\begin{array}{c}3.33 \\
(1.98,5.61)\end{array}$} \\
\hline & Problem solving & $26.92 \%$ & $\begin{array}{l}9.21 \\
(3.53,24.03)\end{array}$ & \\
\hline & Wllelp seeking & $8.46 \%$ & $\begin{array}{l}2.3 .1 \\
(0.65,8.21)\end{array}$ & \\
\hline \multirow[t]{3}{*}{$\begin{array}{l}\text { Passive problem } \\
\text { avoiding }\end{array}$} & Isolation & $9.23 \%$ & $\begin{array}{l}2.54 \\
(0.86,7.52)\end{array}$ & \multirow{3}{*}{$\begin{array}{c}1.77 \\
(0.90,3.50)\end{array}$} \\
\hline & Non-specific activities & $10.00 \%$ & $\begin{array}{l}2.78 \\
(0.81,9.48)\end{array}$ & \\
\hline & Suppression & $16.92 \%$ & $\begin{array}{l}5.09 \\
(2.29,11.33)\end{array}$ & \\
\hline \multirow[t]{4}{*}{$\begin{array}{l}\text { Active problem } \\
\text { avoiding }\end{array}$} & Shifted attention & $14.62 \%$ & $\begin{array}{l}4.28 \\
(1.63,11.21)\end{array}$ & \multirow{4}{*}{$\begin{array}{c}1.98 \\
(1.04,3.75)\end{array}$} \\
\hline & Socialisation & $18.46 \%$ & $\begin{array}{l}5.66 \\
(2.00,16.03)\end{array}$ & \\
\hline & Task performance & $13.85 \%$ & $\begin{array}{l}4.02 \\
(1.01,15.97)\end{array}$ & \\
\hline & Indulgence & $6.15 \%$ & $\begin{array}{l}1.64 \\
(0.45,5.93)\end{array}$ & \\
\hline Symptomatic & $\begin{array}{l}\text { Symptomatic } \\
\text { behayiour }\end{array}$ & $42.31 \%$ & $\begin{array}{l}18.33 \\
(6.50,51.73)\end{array}$ & $\begin{array}{c}9.48 \\
(4.09,21.95) \\
\end{array}$ \\
\hline Total & & $15.33 \%$ & & \\
\hline
\end{tabular}

For example, the sixth row relates to "help seeking" Out of 130 possible instances of coping through help seeking for 13 possible symptoms in 21 persons, individuals indicated the use of coping in $8.46 \%$. In comparison, the proportion in the baseline category "use of non-prescribed substances" was muel lower (3.85\%). The odds ratio of these two probabilities is 2.31 (column 4), indicating that paticuts are 2.31 tinnes more likely to cope through help-seeking than through non-prescribed substances.

\$95\% confidence interval; interval not inchding unity indicates statistical significance "Reference category

Table 2. Amount of coping by symptom domain given the presence of a psychotic symptom.

\begin{tabular}{lllllll}
\hline Symptoms & \multicolumn{1}{l}{$\begin{array}{l}\text { Present } \\
\text { (percentage) }\end{array}$} & total & OR (95* CI 1 group level \\
\hline Euphoria & 9 & $(10.71)$ & 84 & $1^{*}$ & \\
\hline Hostility & 20 & $(11.90)$ & 168 & 1.13 & $(0.54,2.34)$ \\
\hline Negative & 60 & $(12.24)$ & 490 & 1.16 & $(0.72,1.88)$ \\
\hline positive & 64 & $(15.76)$ & 406 & 1.56 & $(0.94,2.60)$ \\
\hline Cognitive & 53 & $(16.46)$ & 322 & 1.64 & $(0.94,3.75)$ \\
\hline Depressive & 73 & $(20.86)$ & 350 & 2.20 & $(1.29,3.75)$ \\
\hline Total & 279 & $(15.33)$ & 1820 & & & \\
\hline
\end{tabular}

First row relates to coping for symptoms of euforia. Out of 84 possible instances of coping for cuphoria will 14 different coping domains in 21 persons, individuals indicated the use of coping in $10.71 \%$. Totst numbers differ because symptom donains represent regrouping of variable numbers of symptoms.

th $95 \%$ confidence interval: interval not inchuing unity indicates statistical significance teference category 
Table 3. Associations between coping and control (odds ratio from logistic regression over seven levels of controly, stratified by type of coping strategies and coping group.

\begin{tabular}{|c|c|c|c|}
\hline Canng grom & Coping mechanism & $\begin{array}{l}\text { OR } 195 \text { CI } \\
\text { all lewel o: } \\
\text { ind widua mecharism }\end{array}$ & $\begin{array}{l}\text { OR }(95 \% \text { Cly }) \\
\text { al level of } \\
\text { coping group }\end{array}$ \\
\hline \multirow[t]{3}{*}{$\begin{array}{l}\text { Fussive ithess } \\
\text { behaviour }\end{array}$} & $\begin{array}{l}\text { Non-prescribed } \\
\text { subshuncess }\end{array}$ & $5.75(0.60,55.01)$ & \multirow{3}{*}{$1.25(1.03,1.45)$} \\
\hline & Prescribed medicalion & $1.34(1.11,1.60)$ & \\
\hline & Phystcal change & $1.26(1.04,1.54)$ & \\
\hline \multirow{3}{*}{$\begin{array}{l}\text { Active problem } \\
\text { solving }\end{array}$} & Distructiont & $1.06(0.90,1.26)$ & \multirow{3}{*}{$1.42(1.26,1.60)$} \\
\hline & Problem solving & $1.52(1.14,2.01)$ & \\
\hline & Help seeking & $1.21(0.93,1.58)$ & \\
\hline \multirow{3}{*}{$\begin{array}{l}\text { Passive problem } \\
\text { awoiding }\end{array}$} & Isolation & $1.51(0.99,2.28)$ & \multirow{3}{*}{$1.19(1.04,1.36)$} \\
\hline & Non-specille activitios & $1.17(0.87 .1 .57)$ & \\
\hline & Suppression & $1.30(1.01,1.68)$ & \\
\hline \multirow{4}{*}{$\begin{array}{l}\text { Aclive problem } \\
\text { avoiding }\end{array}$} & Shifled attention & $1.61(1.18,2.21)$ & \multirow{4}{*}{$1.30(1.06,1.58)$} \\
\hline & Socialisation & $0.99(0.82,1.20)$ & \\
\hline & Tusk performance & $1.17(0.95,1.44)$ & \\
\hline & Indulgenice & $1.37(1.07 .1 .74)$ & \\
\hline Symptomatic & $\begin{array}{l}\text { Symptomat ic } \\
\text { behaviour }\end{array}$ & $0.40(0.30,0.55)$ & $0.40(0.30,0.55)$ \\
\hline
\end{tabular}

I $95 \%$ confidene interval: interval not including unity indicates stastical significance

\section{Coping and control}

There was a positive and significant association between coping and control (OR control over seven levels: $1.07,95 \% \mathrm{CI}: 1.03,1.12$ ), which remained after adjustment for coping type and type of symptom $(\mathrm{OR}=1.09,95 \% \mathrm{CL}: 1.03$, 1.15). However, there was a significant interaction between control and the 14 different coping strategies in their effects on coping (likelihood ratio test: $\chi^{2}=108.47, \mathrm{df}=13, P<0.0001$ ).

Stratified analyses revealed that the associations between coping and control were very large and positive in the case of all non-symptomatic coping strategies, especially the active problem solving and active problem avoiding strategies, but negative in the case of symptomatic coping (Table 3 ).

Although not significant at conventional alpha, there was a very large effect size for use of non-prescribed substances (OR=5.75, 95\% Cl: $0.60,55.01)$. The effect of control was not modified by type of symptom (likelihood ratio test: $\left.\chi^{2}=3.01, \mathrm{df}=5, P=0.70\right)$.

\section{Discussion}

As reported in previous studies, we found that people with a diagnosis of schizophrenia reported the use of a diversity of coping strategies to experience control over their symptoms (Andres et al., 2000; Carr, 1988; Farhall \& Gehrke, 1997; Jenner et al., 1998; Romme et al., 1992; Wahass \& Kent, 1997). In 
addition, this study quantified some of the relations between coping and control in a useful way.

Patients who experienced control over symptoms especially used active, mostly cognitive, coping strategies. These results are in line with earlier studies showing that indiwiduals with a diagnosis of schizophrenia who felt they coped better with stress and symptoms used more active cognitive coping strategies (Andres et al., 2000; Tarrier \& Turpin, 1992) and to some degree care-related coping strategies and behavioural coping strategies. The finding that active cognitive coping favoured control was allso shown by Pallanti and colleagues in a young group of patients with a first episode of schizophrenia. Cognitive coping strategies, especially problem-focused styles reduced relapse rates and shortened the duration of hospitalisation (Andres et al., 2000; Pallanti et al., 1997). We found that problem solving was the most frequently reported coping mechanism among the different coping strategies after symptomatic coping strategies. Although passive illness behaviour was the least frequently used coping strategy, it did contribute significantly to experience of control over symptoms, including self-medication with non-prescribed substances and prescribed medications. Patients who used their medication regularly reported a significantly better subjective response to medication in a previous study (Garavan et al., 1998). In contrast, however, Marley and colleagues (Marley, 1998) reported in another study that the majority of subjects placed little emphasis on medication as a cause of feeling better. Our data in addition confirm previous suggestions that a small group of patients is having recourse to non-prescribed substances as a means of self-medication for psychotic symptoms (Blanchard et al., 1999; Buckley, 1998; Krystal, D'Souza, Madlonick, \& Petrakis, 1999). The clinical implication is that it is important to assess to what degree self-medication serves to enhance subjective control over psychotic symptoms before treatment of substance misuse is included in the treatment plan.

Symptomatic coping strategies negatively influenced control experience. This suggests that the outward manifestations of psychopathology serve to augment feelings of being out of control, and confirms earlier results reported by Carr (1988). The fact that this was the most frequently used coping strategy makes it clinically relevant, as a large proportion of feelings of being out of control may be attributable to this type of dysfunctional coping.

The MACS assesses coping strategies separately for different symptoms. Depressive symptoms were associated with the highest number of coping strategies followed by cognitive symptoms, positive symptoms, negative symptoms, and hostility and euphoria. We are unaware of previous reports analysing the number of coping strategies in psychotic illness as a function of symptoms. Coping strategy enhancement therapy and symptom management programmes typically focus on positive symptoms, although the implicit goal of such techniques is to reduce anxiety and depression associated with symptoms 
rather than just reduction of the positive symptoms themselves (Falloon \& Talbot, 1981; Romme et al., 1992; Tarrier, 1992; Tarrier et al, 1993). People with a diagnosis of schizophrenia very often suffer with depressive symptoms (Marley, 1998) and depressive symptoms have the strongest effects on subjective need for care, quality of life and service satisfaction (Bak et al., 1999, van Os et al. 1999). The fact that depressive symptoms generated more coping on the part of the patient is in agreement with these earlier findings, and implies that coping enhancement for depressive symptoms can have an important impact on many patient outcomes.

The above results should be viewed in the light of several potential limitations. The study group was rather small, 21 subjects. The limited number of subjects should lead to caution in interpreting the result of the factor analysis of coping strategies, as these analyses typically need at least 10 subjects for each included variable. The symptom and coping groupings used in the current study nevertheless had face validity.

The cross-sectional study design also introduces limitations. Thus, although it is logical to assume that coping results in more control over symptoms, it cannot be excluded that experience of control enhances the use of coping strategies or the reporting of more coping strategies. However, such a mechanism cannot explain the negative association between symptomatic coping and control.

Coping and experience of symptom control are dynamic entities with withinand between day fluctuations that cannot be captured by a cross-sectional instrument. However, the data (described in the companion article) showed good correlation of coping and control experience between the first and second interviews. The dynamic and reciprocal interactions between distress, coping and control also could not be studied within this design. A more detailed, longitudinal study is necessary to study simultaneously the different paths between these variables.

The study group was homogeneous, but cannot be considered representative of all patients with a diagnosis of schizophrenia. The subjects were all living outside hospital and not in need of hospital care. They all were able to communicate well and had their illness for quite a long time.

Whilst accepting the above-mentioned limitations, we feel that the results nevertheless suggest that the systematic study of coping in clinical settings may be useful in giving direction to coping enhancement therapies in individuals who experience distress caused by psychotic symptoms. 


\section{References.}

Andres, K., Pfammatter, M., Garst, F., Teschner, C., \& Brenner, H. D. (2000). Effects of a coping-orientated group therapy for schizophrenia and schizoaffective patients: a pilot study [In Process Citation]. Acta Psychiatr Scand 10/(4), 31.8 322.

Bak, M., Radstake, S., \& Van Os, J. (1999). Consultatie aan huisartsen ter detectie van zorgmijdende mensen met een psychose. $M G v, 12,1281-1289$.

Bak., M., Van Der Spil, F., Gunther, N., Radstake, S., Delespaul, P., \& Van Os, I. (2001). Maastricht Assessment of Coping Strategies (MACS-1): a brief instrument to assess coping with psychotic symptoms. Acta Psychat Scand, $103(6), 453-459$.

Blanchard, J. I., Squires, D., Henry, T., Horan, W. P., Bogenschutz, M., Lauriello, J., \& Bustillo, J. (1999). Examining an affect regulation model of substance abuse in schizophrenia. The role of traits and coping. J Nerv Ment Dis, $187(2), 72-79$.

Böker, W., Brenner, H. D., Gerstner, G., Keller, F., Muller, J., \& Spichtig, L. (1984). Self-healing strategies among schizophrenics: attempts at compensation for basic disorders. Acta Psychiatr Scand, 69, 373-378.

Boschi, S., Adams, R. E., Bromet, E. J., Lavelle, J. E., Everett, E., \& Galambos, N. (2000). Coping with psychotic symptoms in the early phases of schizophrenta. Am J Orthopsychiatry, 70(2), 242-252.

Breier, A., \& Strauss, J. S. (1983). Self-control in psychotic disorders. Arch Gen Psychiatry, 40(10), $1141-1145$.

Brenner, H. D., Boker, W., Muller, J., Spichtig, L., \& Wurgler, S. (1987). On autoprotective efforts of schizophrenics, neurotics and controls. Acta Psychiatp. Scand, 75(4), 405-414.

Buckley, P. F. (1998). Substance abuse in schizophrenia: a review. I Clin Psychiamy, 59(Suppl 3), 26-30.

Carr, V. (1988). Patients' techniques for coping with schizophrenia: an exploratory study. BrJ Med Ps)chol, 6I (Pt 4), 339-352.

Dittmann, J., \& Schuttler, R. (1990). Disease consciousness and coping strategies of patients with schizophrenic psychosis. Acra Psychiatr Scand, 82(4), 318-322.

Falloon, I. R., \& Talbot, $\mathbb{R}$. E. (1981). Persistent auditory hallucinations: coping mechanisms and implications for management. Psycho/ Med, //(2), 329-339.

Farhall, J., \& Gehrke, M. (1997). Coping with hallucinations: exploring stress and coping framework. Br.J Clin Psychol, 36(P॥2), 259-261.

Garavan, J., Browne, S., Gervin, M., Lane, A., Larkin, C., \& O'Callaghan, E. (1998). Compliance with neuroleptic medication in outpatients with schizophrenia; relationship to subjective response to neuroleptics; attitudes to medication and insight. Compr Psychiatry, 39(4), 215-219.

Jenner, J. A., van de Willige, G., \& Wiersma, D. (1998). Effectiveness of cognitive therapy with coping training for persistent auditory hallucinations: a retrospective study of attenders of a psychiatric out-patient department. Acta Psychiatr Scand, $98(5), 384-389$.

Krystal, J. H., D'Souza, D. C., Madonick, S., \& Petrakis, 1. L. (1999). Toward a rational pharmacotherapy of comorbid substance abuse in schizophrenic patients. Schizophr Res, 35 Suppl, S35-49.

Lazarus, R. S., \& Folkman, S. (1984). Stress, Appraisal and Coping New York: Springer Verlag. 
Marley, J. A. (1998). People matter: client-reported interpersonal interaction and its impact on symptoms of schizophrenia. Soc Work, 43(5), 437-444.

Middelboe, T. Mortensen, E. L. (1997). Coping strategies among the long-term mentally ill: categorization and clinical determinants. Acta Psychatr Scand, $96(3), 188-194$.

Mueser, K. T., Valentiner, D. P., \& Agresta, J. (1997). Coping with negative symptoms of schizophrenia: patient and family perspectives. Schizophr Bull, 23(2), 329339.

Pallanti. S., Quercioli, L., \& Pazzagli, A. (1997). Relapse in young paranoid schizophrenic patients: a prospective study of stressful life events, P300 measures, and coping. Am J Psychiary, 154(6), 792-798.

Romme, M. A., Honig, A., Noorthoorn, E. O., \& Escher, A. D. (1992). Coping with hearing voices: an emancipatory approach. Br I Psychiatry, 161, 99-103.

Semple, S. J., Patterson, T. L., Shaw, W. S., Grant, I., Moscona, S., \& Jeste, D. V. (1999). Self-perceived interpersonal competence in older schizophrenia patients: the role of patient characteristics and psychosocial factors. Acta Psychiatr Scand, 98, 384-389.

Statacorp. (2001). Statistical Software: release 7.: College Station, TX: Stata Corporation.

Takai, A., Uematsu, M., Kaiya, H. Inoue, M. \& Ueki, H. (1990). Coping styles to basic disorders among schizophrenics. Acta Psychiatr Scand, 82(4), 289-294.

Tarrier, N. (1987). An investigation of residual psychotic symptoms in discharged schizophrenic patients. Br J Clin Psychol, 26(Pt 2), 141-143.

Tarrier, N. (1992). Management and modification of residual positive psychotic symptoms. In M. Birchwood \& N. Tarrier (Eds.), Innovations in psychological management of schizophrenia. (pp. 147-169). Chichester: John Wiley \& Sons Ltd.

Tarrier, N., Sharpe, L., Beckett, R., Harwood, S., Baker, A., \& Yusopoff, L. (1993). A trial of two cognitive behavioural methods of treating drug-resistant residual. psychotic symptoms in schizophrenic patients. II. Treatment- specific changes in coping and problem-solving skills. Soc Psychiany Psychiatr Epidemiol, $28(1), 5-10$

Tarrier, N., \& Turpin, G. (1992). Psychosocial factors, arousal and schizophrenic relapse. The psychophysiological data. Br J Psychiatry, 161, 3-11.

Van Os, J., Gilvarry, C., Bale, R., Van Hom, E., Tattan, T., White, I., \& Murray, R. (1999). A comparison of the utility of dimensional and categorical representations of psychosis. UK 700 Group. Psychol Med, 29(3), 595-606.

Wahass, S., \& Kent, G. (1997). Coping with auditory hallucinations: a cross-cultural comparison between westem (British) and non-western (Saudi Arabian) patients. J Nerw Ment Dis, 185(11), 664-668. 


\section{Chapter 5}

\section{Predictive value of "clinician recognised" and "clinician non-recognised" self-reported positive psychotic symptoms: a prospective general population study.}

Bak, M., Delespaul, P., Hanssen, M., de Graaf, R., Vollebergh, W., \& van Os, J. (2003). How false are "false" positive psychotic symptoms? Schizophr Res, 62(1-2), 187-189.

Bak, M., Delespaul, P., Hanssen, M., de Graaf, R., Vollebergh, W., \& van Os, J. (2004). Voorspellende waarde van door clinici erkende en niet-erkende positieve psychotische symptomen: een rospectieve studie in de algemene bevolking. Tijdschrift voor Psychiatrie. 46 (5), $285-293$. 


\section{Abstract}

Introduction. A paradox present in literature is that self-reports of positive psychotic symptoms are considered to be of questionable value, but these selfreports do hold important prognostic validity in longitudinal cohort research. This paradox is studied here in a prospective setting.

Method. A risk set of 4081 subjects with no previous history of psychotic disorder was interviewed with the Composite International Diagnostic Interview (CIDI) at baseline and again 3 years later (T2). A Non Recognised Symptom (NRS) was defined as self-reported psychotic symptom (CIDI) at baseline, but rejected by the clinician after reassessment of the symptom at baseline. A Recognised Symptom (RS) was defined as a confirmed symptom by the clinician after reassessment at baseline.

Results. Not only RS, but also NRS were robust predictors of psychotic disorder development at $\mathrm{T} 2$ (respectively $\mathrm{OR}=46.5,95 \% \mathrm{CI}: 4.6-238.9$ and $\mathrm{OR}=27.5$, 95\%Cl: 4.5-123.4). The Positive Predictive Value (PPV) for RS was 11\% (95\% CI: $10 \%-12 \%)$ and for NRS 5\% (95\% CI: 4\%-5.3\%). However, in the group of NRS relative risks and predictive values were only elevated if the subject had additional self-reports of "sub-clinical psychosis-like experiences" (PPV $=10 \%, 95 \%$ CI: $1 \%-19 \%)$.

Conclusion. Clinical evaluation of self-reported psychotic symptoms alone is not enough to guarantee maximum sensitivity to predict future psychotic disorder development. Self-reported experiences in combination with clinicianassessed psychotic symptoms will obtain better results than on either one alone. 


\section{Introduction}

Secondary prevention of psychosis focuses at decreasing the duration of untreated psychosis (DUP) (Larsen et al., 2001; McGorry, 2000). Reduction of DUP depends on early recognition of psychotic symptoms and correct interpretation of subjective states in the general population. Attenuated, brief, or limited psychotic symptoms as well as schizotypical signs and symptoms are used as key variables to identify possible cases of psychosis (Carr et al., 2000; Chapman, Chapman, Kwapil, Eckblad, \& Zinser, 1994; Chapman, Edell, \& Chapman, 1980; Kwapil, Miller, Zinser, Chapman, \& Chapman, 1997; Phillips, Yung, \& McGorry, 2000). Recent population-based studies showed that selfreported positive symptoms of psychosis strongly predict the development of psychotic disorder in both the short and the long term (Hanssen, Bak M., Bijl, Vollebergh, \& Os, 2002; Poulton et al., 2000). Such findings seemingly contradict the conventional wisdom that the use of diagnostic assessment scales, which rely on self-report (Eaton, Neufeld, Chen, \& Cai, 2000), is problematic because of the frequent generation of false, not clinician recognised positive symptoms and, by consequence, false clinical diagnoses (Andrews, 2000; Brugha, Jenkins, Taub, Meltzer, \& Bebbington, 2001; Cooper, Peters, \& Andrews, 1998; Robins et al., 1988; Wittchen, 1994). The Composite International. Diagnostic Interview (CIDI) is a widely used instrument that assesses symptoms and construes diagnosis in the general population, but is essentially based on self-report (Eaton et al., 2000). The value of self-reported psychotic symptoms assessed through the CIDI psychosis section is disputed (Anthony et al., 1985; Cooper \& Collacott, 1994; Helzer et al., 1985). Selfreported psychotic experiences in children appears to result in a robust predictive value (up to $25 \%$ ) at the development of a psychotic disorder 16 years later (Poulton et al., 2000). Given the i) doubts about the value of selfreported psychotic symptoms because of the high proportion that is rejected after clinical evaluation, whereas ii) prospective studies have shown the high prognostic validities of self-report of psychotic experiences, we combine i) and ii) in a prospective study the prognostic value self-reported psychotic experiences and clinical assessed psychotic symptoms.

\section{Method}

Sample

This study is part of the Netherlands Mental Health Survey and Incidence Study (NEMESIS), a longitudinal study of the prevalence, incidence, course and consequences of psychiatric disorders in the Dutch general population. The local ethics committee approved the study proposal. Subjects were contacted at three points in time, namely 1996 (hereafter: baseline), 1997 (hereafter: T1) and 1999 (hereafter: T2) (Bijl, Ravelli, \& van Zessen, 1998; Bijl, van Zessen, Ravelli, de Rijk, \& Langendoen, 1998). A multistage, stratified, random 
sampling procedure was used to identify the sample. First, ninety municipalities were sampled randomly. Addresses from private households were randomly selected. The individual with the most recent birthday and aged between 18-64 years was asked to participate. Individuals living in institutions, including individuals residing in psychiatric hospitals were not included in the sampling frame. All subjects received an introductory letter from the Minister of Health. A total of 7076 subjects were enlisted at baseline. The response rate was 69.7 percent. No difference in psychiatric morbidity based on the GHQ-12 (General Health Questionnaire, 12 items) was found between responders and nonresponders (Bijl, Ravelli et al., 1998; Bijl, van Zessen et al., 1998). At T1, 5618 subjects participated for the second time; at T2, 4848 subjects participated.

\section{Instruments}

The sample was interviewed at home with the Composite International Diagnostic Interview (CIDI) version 1.1 (Smeets \& Dingemans, 1993) at all three measurements. The CIDI generates DSM-III-R diagnoses, but was in essence a self-report instrument (Eaton et al., 2000). Trained non-clinical interviewers interviewed respondents by reading out questions in a standardised way and record respondents' answers without interpretation. The CIDI used for each separate item (symptom) the same format. After training this format enabled lay interviewers to assign the presence or absence of a symptom. Previous research showed that the psychosis section of the CIDI was sensitive for interpretation by the interviewed subject, for which the lay-interviewers were often unable to correct (Cooper et al., 1998; Wittchen, 1994). Therefore clinical reassessment was organised in the NEMESIS study (see below)

\section{Self-reported Hallucinatory Experiences and Delusional Ideation at baseline and $T$ I.}

We used the 17 core symptoms of the CIDI psychosis sections that assess delusional ideation (13 symptoms) and hallucinatory experience ( 4 symptoms). Ratings included: no symptom (rating "l"), not clinically relevant experience of psychosis (rating "2" symptom present but not clinically relevant, not bothered by it and does not seek help), symptom due to drugs (rating " 3 "), symptom due to somatic disease (rating "4"), true psychiatric symptom (rating "5") and finally "symptom" may have any reasonable explanation and has a possible basis in fact (rating "6") (van Os, Hanssen et al., 2000; van Os, Hanssen et al., 2001). Someone who hears voices or is convinced that controlled by higher powers or entities, as defined by the CIDI-item, without experiencing any distress or seeking help by a professional to relieve the disturbing influence of the symptom, is an example of a "2" score. A CIDI "5"score is present if someone seeks help by discussing it with a doctor, other professional or family. 
The assessment of psychotic symptoms by lay interviewers (e.g. in the CIDI) contained several limitations (Anthony et al., 1985; Cooper \& Collacott, 1994; Helzer et al., 1985). Therefore, all individuals who had at least one rating of " 5 " or "6" at baseline, were re-interviewed telephonically by experienced psychiatrists (hereafter: clinician). The Structured Clinical Interview for DSMIII-R (SCID), an instrument with proven reliability and validity in diagnosing schizophrenia (Spitzer, Williams, Gibbon, \& First, 1992) was used to guide the clinical re-assessment of the psychotic symptoms generated with ClDI. Assessment of the SCID by telephone showed good reliability (kappa 0.70) (Kobak, Taylor, Dottl, Greist, Jefferson, Burroughs, Mantle et al., 1997). CIDI ratings of " 5 " or " 6 " were corrected where necessary if there were discrepancies between the self-reports and the clinician"s findings. For example, an individuals with no rating of " 5 " on a particular CIDI psychosis item could receive such a rating on this item if the clinician detected the associated psychotic symptom. Alternatively, an individual with a rating of " 5 " on a particular CIDI psychosis item could lose this rating if the clinician did not concur, this rating was than changed into a CIDI "1"score. At baseline, ratings of "2" were not systematically checked for clinical validity (i.e. if it were truly a clinically not relevant experience) by the clinician. However, a rating of "2" would be changed to a " 5 " if the SCID interview indicated presence of psychosis on that item in question. A rating of "5" will hereafter be referred to as "Psychotic Symptom" and a rating of "2" will hereafter be referred to as "Non-clinical Self-reported Psychotic Experience". Out of a total of 479 individuals who at baseline were eligible for a clinical re-interview over the telephone, $226(47.2 \%$ ) were actually re-interviewed. At TI (the first follow-up round), a slightly different procedure was used, in that lay interviewers were trained to ask additional clinical questions in the case of suspected psychosis, which were later discussed with the team psychiatrist, followed by correction to the CIDI ratings where necessary. Both at baseline and T1, if possible DSM-III$\mathrm{R}$ diagnosis were based on corrected CIDI ratings.

\section{Definition of incident psychosis outcomes}

The longitudinal character of NEMESIS offered the possibility to identify incident cases of psychiatric disorder. In order to identify truly incident psychosis cases, the baseline and T1 interviews were used to exclude any lifetime and prevalent psychosis at the beginning of the study. The "double check" at baseline and TI ensured that even prevalent cases that had been missed at baseline interview could still be excluded at $\mathrm{T} 1$, thus making it possible to use the T2 assessment to identify strictly new psychosis onsets over a two-year period and reduce the risk of reversed causality with predictors. Therefore, individuals with lifetime CIDI diagnosis of any DSM-III-R affective or non-affective psychotic disorder at baseline $(n=107$ out of 7076$)$ and again at T1 ( $\mathrm{n}=20$ out of 5618) were excluded from further analyses. In addition, 
individuals with any self-reported psychotic experiences at baseline (CIDI rating of "2" or higher) who had not been re-interviewed at baseline by a clinician were also excluded $(n=1053)$. This was done to ensure that in the analyses, all subjects with reports of psychotic experiences at baseline had been the subject of clinical re-interview and could therefore be classified as either "RS" or "NRS" positive with regard to the presence of a Psychotic Symptom. One subject was excluded because of partial non-response. The number of remaining non-psychotic persons interviewed at both baseline and $\mathrm{T} 1$ was 4765 individuals. Of these, 4081 had been interviewed about presence of incident psychosis at T2. These 4081 constituted the final risk set.

\section{Psychosis outcomes at $T 2$}

At T2, all the subjects with non-organic psychotic symptoms (CIDI-ratings 2, 5 or 6) on any of the CIDI psychosis items were re-interviewed by a trained clinician, using the same procedure as at baseline. Additional clinical assessments were made on "unusual thought content" and "hallucinations" using the criteria for these two items on the Brief Psychiatric Rating Scale (BPRS) (Overall \& Gorham, 1962). The two BPRS symptoms ranged from 1 , "absent" to 7, "very severe". Ratings of 2-3 indicate non-pathological intensities of symptoms, 4-7 indicate a pathological intensity of symptoms (Lukoff et al., 1984). A rating of 4 or more on either of both items was labelled "BPRS pathology-level psychosis". Out of 220 eligible individuals with CIDI ratings of 2,5 or $6,74 \%(n=163)$ were re-interviewed.

Two different psychosis outcomes were used: a symptom-based outcome and a needs-based outcome. The symptom-based outcomes were BPRS pathology level psychosis was defined as the result based on symptom frequency and general dysfunction. The needs-based outcome was defined as the presence of BPRS-pathology score and the presence of need for care, with the emphasis on psychotic symptoms resulting in need and psychological distress, assessed during a consensus meeting attended by two psychiatrists and two psychologists, using criteria from the Camberwell Assessment of Need (CAN) (Slade, Phelan, Thornicroft, \& Parkman, 1996). The consensus meeting used information from the telephone interview, the SCID and the BPRS items. This resulted in a score of " 0 " when there was no need for care in relation to psychotic symptoms and "1" for probable or definite need for care in relation to psychotic symptoms. Validation of the needs-based diagnosis has been described in previous papers (Bak, Myin-Germeys et al., 2003; Hanssen et al., 2002; Krabbendam et al., 2002). The needs-based outcome was determined because DSM-III-R (American Psychiatric Association, 1987) allocated "patient-status" on the basis of symptom severity and dysfunction rather than clinical severity, expressed as a need for care which was regarded a better outcome measure not necessarily yielding overlap with symptom severity and dysfunction (Regier et al., 1998); (Spitzer, 1998). 
RS and NRS positive psychotic symptoms.

A recognised positive psychotic symptom (RS) was defined as: the presence of at least one psychotic symptom (CIDI "5"score) according the clinician at one of the CIDI psychosis items during the baseline interview. A non-recognised symptom (NRS) was defined as the presence of at least one self-reported psychotic symptom (CIDI " 5 "score) on any of the CIDl psychosis items at baseline but changed or declined by the clinician after reassessment at baseline.

\section{Analyses}

The analyses assessed the predictive value of RS and NRS positive psychotic symptoms at baseline for the two psychosis outcomes measures at T2. Risks were expressed as percentages, odds ratio's (OR) and the positive predictive values (PPV). Exact $p$-values and exact confidence intervals $(95 \%$ Confidence Intervals) were used throughout.

\section{Results}

RS and NRS positive symptoms

In the risk set of 4081 respondents, 80 individuals had a self-reported Psychotic Symptom (i.e. CIDI rating of "5"). Of these, only $15(19 \%)$ were confirmed as such by the clinician, whereas in 65 cases the CIDI " 5 "score was declined by the clinician. Two subjects had non-clinical psychotic experiences (CIDI rating of "2") but not reported by the subjects before. Out of the 12 subjects with at least one self-reported non-clinical experiences at baseline without any selfreported CIDI "5" symptom score, the rating was not changed after the reassessment by the clinician. Three subjects without any previous psychotic symptom rating received a CIDI rating of " 5 " after the clinical re-assessment.

Of the 65 not confirmed by the clinician, around half $(n=31,48 \%)$ had received ratings of non-clinical self-reported psychotic experience (i.e. CIDI rating of " 2 ") on other CIDI psychosis items, whereas 34 (52\%) had not had any other rating of non-clinical self-reported psychotic experience.

\section{Odds ratios and predictive values}

At $\mathrm{T} 2$, the risk set as defined above showed 13 new onsets of needs-based diagnosis of psychosis and 19 new onsets of BPRS pathology-level psychosis. RS was strongly associated with need for care based psychotic disorder at T2 $(\mathrm{OR}=46.5,95 \% \mathrm{Cl}: 4.6-238.9)$. However, $\mathrm{NRS}$ was also associated, albeit at only half the strength, with needs based psychotic disorder at $\mathrm{T} 2(\mathrm{OR}=24.4$, 95\% CI: 4.1-104.2) (Table 1). The same held for the other psychosis outcome of BPRS pathology level psychosis (Table 1). Positive predictive values (PPV) were calculated to assess the contribution of RS and NRS to the development of needs based psychotic disorder. RS performed relatively well, with PPV's of $11 \%$ for needs based psychotic disorder and $22 \%$ for BPRS pathology level 
psychosis (Table 1). NRS also had predictive power, although at a reduced level ( $5 \%$ for both outcomes).

Table 1. The relation between psychotic disorder and true and false positive symptoms expressed ass odds ratio and positive predictive value

\begin{tabular}{|c|c|c|c|c|}
\hline & $\begin{array}{l}\text { Reco } \\
\text { psych }\end{array}$ & $\begin{array}{l}\text { sed } \\
\text { c symptoms }\end{array}$ & $\begin{array}{l}\text { Non- } \\
\text { psyct }\end{array}$ & $\begin{array}{l}\text { ecognised } \\
\text { tic symptoms }\end{array}$ \\
\hline 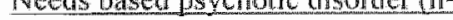 & & & & \\
\hline Odds ratio $(95 \% \mathrm{Cl})$ & 46.1 & $(4.6-236.5)$ & 27.5 & $(4.5-123.4)$ \\
\hline Positive predictive walue $(95 \% \mathrm{Cl})$ & $11 \%$ & $(10 \%-12 \%)$ & $5 \%$ & $(4 \%-5,3 \%)$ \\
\hline BPRS pathology level psychosis & & & & \\
\hline$(\mathrm{n}=19)$ & & & & \\
\hline Odds ratio $(95 \% \mathrm{Cl})$ & 77.1 & $(16.4-283.7)$ & 19.2 & $(3.3-76.9)$ \\
\hline Positive predictive value $(95 \% \mathrm{Cl})$ & $22 \%$ & $(21 \%-23 \%)$ & $5 \%$ & $(4 \%-5.3 \%)$ \\
\hline
\end{tabular}

Further analyses revealed that among the 65 individuals with NRS, none of the 34 who had no other ratings of Nonclinical Self-reported Psychotic Experience developed any of the psychosis outcomes at $\mathrm{T} 2$ (i.e. the positive predictive value in this group was zero), whereas 3 of the 31 who also had CIDI ratings of Nonclinical Self-reported Psychotic Experience met criteria for the two psychosis outcomes at T2 (PPV: 10\%, 95\% CI: 1\%-19\%). Even if the two subjects whose CIDI rating of " 5 " was changed in a CIDI rating of " 2 " after the clinician interview were excluded from the analyses, the PPV remained unchanged (PPV: 10\%, 95\% CI: 1\%-20\%).

\section{Discussion.}

As expected, RS appeared predictive of incident needs based psychotic disorder three years later. However, NSR also predicted needs based psychotic disorder development at $\mathrm{T} 2$ at a reduced, but still highly significant rate. Similar results were apparent RS and NRS in relation to T2 ratings of BPRS pathology level psychosis. The most salient finding, however, was that of those whose selfreported CIDI Psychotic Symptom (rating of "5") had been rejected by the clinicians, only those who had no additional Nonclinical Self-reported Psychotic Experiences had no increased risk for future need for care in the context of psychosis. Among the NRS's who did thave Nonclinical Self-reported Psychotic Experiences, the PPV $(10 \%)$ was nearly as high as those with RS (1. $1 \%)$. In other words, the clinicians' rejection appeared only valid if it concurred with the person's self report of more subtle psychotic experiences.

Several possible explanations can be brought to bear on these findings. It is likely that most of the 34 RS that had been re-rated as non-psychotic by the clinicians and had no Nonclinical Self-reported Psychotic Experiences represent cases of semantic confusion or other errors in understanding the CIDI question and/or the answer. For example, these may be individuals with a rating of " 5 " 
on one of the CIDI items measuring paranoid ideation, which are easilly misunderstood. With regard to the other 31 NRS subjects who also had Nonclinical Self reported Psychotic Experiences and did experience an increased risk of future need for care, the findings may indicate that the traditional clinical appraisal of psychotic symptoms may be not sensitive enough to pick up mental states that pose an increased risk for future psychotic disorder. In these cases, it would appear that enhanced sensitivity could be obtained if one relies on a combination of self-report and clinical assessment, rather than either one or the other in isolation. Otherwise, the number of psychotic experiences could have contributed to the PPV, which indicated that subjects with NRS and Nonclinical Self reported Psychotic Experiences were considered more psychotic than NRS alone.

\section{Limitations.}

The results should be interpreted in the light of several methodological limitations. First, the clinical re-interview rates for psychosis were incomplete at baseline and $\mathrm{T} 2$. The baseline interview and $\mathrm{T} 1$ interviews served primarily to identify prevalent cases of psychosis, so as to skew the sample of this study to incident cases of psychosis at T2. It is unlikely that, even with the interview limitations, a significant number of cases would not have been identified by repeated interviews at baseline and the confirmation one year later. Second, our diagnosis of psychotic disorder was based on clinical judgement of need for treatment by our panel, rather than by conventional categorical diagnostic criteria. However, we think that this may represent an advantage, as severity and dysfunction combined with need for care assessment in the context of early intervention in early psychosis, need for care diagnosis is a more relevant parameter than DSM classification per se. DSM does not contain needs assessment. Third, we have no data to examine the possibility that some individuals developed psychosis and need for care between T1 and T2, but recovered again by the time of the $T 2$ follow-up interview. Even if this had occurred, however, it is unlikely to have biased the findings. Fourth, we used a broad definition of psychosis including both non-affective and affective psychosis. Both, however, are suitable targets for early detection. Fifth, it is possible that some individuals who were actively psychotic when they were interviewed by the lay interviewer at baseline, had recovered or were less psychotic by the time the clinician rang them up. This, however, is unlikely, given the fact that the baseline CIDI and SICD interviews enquired after lifetime presence rather than current presence of symptoms. Finally, as in all large longitudinal population studies there was attrition from baseline to $T 2$. Previous work, however, has shown that the attrition in the sample was mostly non-differential and not related to mental health (de Graaf, Bijl, Smit, Ravelli, \& Vollebergh, 2000). That only half of the subjects eligible for clinical reinterview at baseline were actually assessed have hardly biased the findings, 
unless one assumes very complex and unlikely scenarios. For example, one scenario of differential attrition explaining the findings would be that among individuals with NRS and Nonclinical Self-reported Psychotic Experiences only those who were not bound to develop psychotic illness at $\mathrm{T} 2$ dropped out of the study whereas the reverse held for those with NRS and absence of Nonclinical Self-reported Psychotic Experiences. 


\section{References}

American Psychiatric Association, A. (1994). DSM-III-R. Diagnostic and Statistical Manual of Mental Disorders. Washington, DC: APA.

Andrews, G. (2000). Case ascertainment: the Composite International Diagnostic Interview. Aust N ZJ PSychiatry, 34 Suppl, S161-163.

Anthony, J. C., Folstein, M., Romanoski, A. J., Von Korff, M. R., Nestadt, G. R., Chahal, R., Merchant, A., Brown, C. H., Shapiro, S., Kramer, M., \& et al. (1985). Comparison of the lay Diagnostic Interview Schedule and a standardized psychiatric diagnosis. Experience in eastern Baltimore. Arch Gen Psychiatry, 42(7), 667-675.

Bak, M., Myin-Germeys, I., Hanssen, M., Bijl, R., Vollebergh, W., Delespaul, P., \& van Os, J. (2003). When does experience of psychosis result in a need for care? A prospective general population study. Schizophr Bull, 29(2), 349-358.

Bijl, R. V., Ravelli, A., \& van Zessen, G. (1998). Prevalence of psychiatric disorder in the generall population: results of The Netherlands Mental Health Survey and Incidence Study (NEMESIS). Soc Psychiatry Psychiar Epidemiol, 33(12), $587-595$.

Bijl, R. V., van Zessen, G., Ravelli, A., de Rijk, C., \& Langendoen, Y. (1998). The Netherlands Mental Health Survey and Incidence Study (NEMESIS): objectives and design. Soc Psychiatry Psychiatr Epidemiol, 33(12), 581-586.

Brugha, T. S., Jenkins, R., Taub, N., Meltzer, H., \& Bebbington, P. E. (2001). A general population comparison of the Composite International Diagnostic Interview (CIDI) and the Schedules for Clinical Assessment in Neuropsychiatry (SCAN). Psychol Med, 3t(6), 1001-1013.

Carr, V., Halpin, S., Lau, N., O'Brien, S., Beckmann, J., \& Lewin, T. (2000). A risk factor screening and assessment protocol for schizophremia and related psychosis. Aust N ZJ Psychiatry, 34 Suppl, S170-180.

Chapman, L. J., Chapman, J. P., Kwapil, T. R., Eckblad, M., \& Zinser, M. C. (1994). Putatively psychosis-prone subjects 10 years later. $J$ Abnorm Psychol, 103(2), 171-183.

Chapman, L. J., Edell, W. S., \& Chapman, J. P. (1980). Physical anhedonia, perceptual aberration, and psychosis proneness. Schizophr Bull, 6(4), 639-653.

Cooper, L., Peters, L., \& Andrews, G. (1998). Validity of the Composite International Diagnostic Interview (CIDI) psychosis module in a psychiatric setting. $d$ Psychiatr Res, 32(6), 361-368.

Cooper, S. A., \& Collacott, R. A. (1994). Clinical features and diagnostic criteria of depression in Down's syndrome. Br J Psychiatry, 165(3), 399-403.

de Graaf, R., Bijl, R. V., Smit, F., Ravelli, A., \& Vollebergh, W. A. (2000). Psychiatric and sociodemographic predictors of attrition in a longitudinal study: The Netherlands Mental Health Survey and Incidence Study (NEMESIS). Am J Epidemiol, 152(11), 1039-1047.

Eaton, W. W., Neufeld, K., Chen, L. S., \& Cai, G. (2000). A comparison of self-report and clinical diagnostic interviews for depression: diagnostic interview schedule and schedules for clinical assessment in neuropsychiatry in the Baltimore epidemiologic catchment area follow-up. Arch Gen Psychiatry, 57(3), 217-222.

Hanssen, M., Bak M., Bijl, R. V., Vollebergh, W., \& Os, J. v. (submitted). Outcome of selfreported psychotic experiences in the generela population. 
Helzer, J. E., Robins, L. M., McEvoy, L. T., Spitznagel, E. L., Stoltzman, R. K., Farmer, A. \& Brockington, I. F. (1985). A comparison of clinical and diagnostic interview schedule diagnoses. Physician reexamination of lay-interviewed cases in the general population. Arch Gen Psychiary, 42(7), 657-666.

Kobak, K. A., Taylor, L. H., Dottl, S. L., Greist, I. H., Jefferson, I. W., Burroughs, D., Mantle, J. M., Katzelnick, D. J., Norton, R.,Henk, H. J. \& Serlir, R. C. (1997). A computer-administered telephone interview to identify mental disorders. Jama, 278(11), 905-910.

Krabbendam, L. Janssen, I., Bak, M., Bijl, R. V., de, G. R., \& van, Os. J. (2002). Neuroticism and low self-esteem as risk factors for psychosis. Soc Psychiatry Psychiatr Epidemiol, 37(1), 1-6.

Kwapil, T. R., Miller, M. B., Zinser, M. C., Chapman, J., \& Chapman, L. J. (1997). Magical ideation and social anhedonia as predictors of psychosis proneness: a partial replication. I Abnorm Psychol, 106(3), 491-495.

Larsen, T. K., Frits, S., Haahr, U., Joa, L., Johannessen, J. O., Melle, I., Opjordsmoen, S., Simonsen, E., \& Vaglum, P. (2001). Early detection and intervention in first-episode schizophrenia: a critical review. Acta Psychiatr Scand, 103(5), $323-334$

Lukoff, D., Snyder, K., Ventura, J, \& Nuechterlein, K. H. (1984). Life events, familial stress, and coping in the developmental course of schizophrenia. Schizophr Bull, $10(2), 258-292$.

McGorry, P. D. (2000). The nature of schizophrenia: signposts to prevention. Aust $N Z J$ Psychiatry, 34 Suppl, \$14-21.

Overall, J. E, \& Gorham, D. (1962). The Brief Psychiatric Rating Scale. Psychological Reports, $10,799-812$.

Phillips, L. J., Yung, A. R., \& McGorry, P. D. (2000). Identification of young people at risk of psychosis: validation of Personal Assessment and Crisis Evaluation Clinic intake criteria. Aust N ZJ Psychiatry, 34 Suppl, S164-169.

Poulton, R., Caspi, A.. Moffitt. T. E.. Cannon. M., Murray , R., \& Harrington, H. (2000). Children's selfreported psychotic symptoms and adult schizophreniform disorder: a 15-year longitudinal study. Arch Gen Psychiatry, 57(11), 10531058.

Regier, D. A., Kaelber, C. T., Rae, D. S., Farmer, M. E., Knauper, B., Kessler, R. C., \& Norquist, G.S. (1998). Limitations of diagnostic criteria and assessment instruments for mental disorders. Implications for research and policy. Arch Gen Psychiatry. 55(2), 109-115.

Robins, L. N., Wing, J., Wittchen, H. U., Helzer, J. E., Babor, T. F., Burke, J., Farmer, A., Jablenski, A., Pickens, R., Regier, D. A., \& et al. (1988). The Composite International Diagnostic Interview. An epidemiologic Instrument suitable for use in conjunction with different diagnostic systems and in different cultures. Arch Gen Psychiatry, 45(12), 1069-1077.

Slade, M., Phelan, M., Thomicroft, G., \& Parkman, S. (1996). The Camberwell Assessment of Need (CAN): comparison of assessments by staff and patients of the needs of the severely mentally ill. Soc Psychiotry Psychiatr Epidemiol, $31(3-4), 109-113$.

Smeets, R. M. W., \& Dingenans, P. M. A. I. (1993). Composite International Diagnostic Interview (CIDI), version I.I (in Dutch). Amsterdam/Geneva: World Health Organization. 
Spitzer, R. L. (1998). Diagnosis and need for treatment are not the same. Arch Gen Psychiatry, 55(2), 120.

Spitzer, R. L., Williams, J. B., Gibbon, M., \& First, M. B. (1992). The Structured Clinical Interview for DSM-III-R (SCID). I: History, rationale, and description. Arch Gen Psychiatry, 49(8), 624-629.

van Os, J., Hanssen, M., Bijl, R. V., \& Ravelli, A. (2000). Strauss (1969) revisited: a psychosis continuum in the general population? Schizophr Res, 45(1-2), 11-20.

van Os, J., Hanssen, M., Bijl, R. V., \& Vollebergh, W. (2001). Prevalence of psychotic disorder and community level of psychotic symptoms: an urban-rural comparison. Arch Gen Psychiatry, 58(7), 663-668.

Wittchen, H. U. (1994). Reliability and validity studies of the WHO--Composite International Diagnostic Interview (CIDI): a critical review. J Psychiotr Res, 28(1), 57-84. 


\section{Chapter 6}

\section{When does experience of psychosis result in need for care? A prospective general population study}

Bak, M., Myin-Germeys, I., Hanssen, M., Bijl, R., Vollebergh, W., Delespaul, P., \& van Os, J. (2003). When does experience of psychosis result in a need for care? A prospective general population study. Schizophr Bull, $29(2), 349-358$. 


\section{Summary.}

Introduction. Not all individuals with experience of psychosis develop need for care.

Method. The present study investigated differences in coping strategies and associated levels of perceived control over psychotic symptoms, in relation to need for care status. The influence of coping on need for care was assessed in 47 individuals incident for psychosis in a general population sample of 4722 .

Results. Need for care was associated with severity of psychotic experiences rather than associated distress, mean level of control or average number of coping strategies used. Qualitative differences were apparent, however, in that those who resorted to the strategy of symptomatic coping (a coping strategy characterized by going along with and indulging in symptoms) experienced less control over their symptoms (OR $=0.79,95 \% \mathrm{Cl}$ : $0.63-0.98)$ and had a higher probability of need for care $(\mathrm{OR}=6.07,95 \% \mathrm{CI}: 1.94-18.95)$.

Conclusion. The results suggest that qualitative differences in self-initiated coping modify the risk for need for care and subsequent patient status in those who experience psychotic symptoms, and point to the possible importance of early coping-based interventions. 


\section{Introduction.}

Several population-based studies have found that the prevalence of psychotic symptoms is many times higher than the prevalence of affective and nonaffective psychotic disorders (Bentall \& Slade, 1985; Johns, Nazroo, Bebbington, \& Kuipers, 1998; Peters, Joseph, \& Garety, 1999; Tien, 1991; van Os, Hanssen et al., 2000; Verdoux, Maurice-Tison et al., 1998). Non-clinical experiences of psychotic symptoms are associated with clinical disorder crosssectionally (Eaton et al., 1991; Hanssen M., Bijl R.V., Vollebergh W., \& Os, 2003) and longitudinally (Chapman et al., 1994; Kwapil et al., 1997; Poulton et al., 2000), and may in fact be at the lower end of a continuum of psychosis of which clinical disorders form the extreme (Claridge, 1994; Strauss, 1969; van Os, Hanssen et al., 2001). Given the strong associations between experiences of psychotic symptoms in the general population and "cases" of psychotic disorder, it becomes important to understand what actually causes some individuals with psychotic experiences to develop a need for care (Johns \& van Os, 2001). There is evidence to suggest that it is not so much the implausibility of the psychotic experiences and the associated degree of conviction, but rather the degree of preoccupation and distress that may be related to need for care status (Bentall \& Slade, 1985; Garety \& Hemsley, 1994; Kendell, 1985; E. Peters et al., 1999; E. R. Peters et al., 1999; Young, Bentall, Slade, \& Dewey, 1986).

An important determinant of need for care status, in this respect, may be the level of functional coping that the person mobilises in the face of stressful (psychotic) experiences (Claridge, 1997; Lukoff et al., 1984; Nuechterlein \& Dawson, 1984; Romme \& Escher, 1989). It has been suggested that the level of depression and distress associated with symptoms is driven by appraisals of controllability and social rank (Birchwood \& Chadwick, 1997; Birchwood et al., 1993). Passive coping strategies such as isolating oneself or getting involved in non-specific activities, are reported to be unrelated to control experience, whereas symptomatic coping, characterized by going along with and indulging in the content of psychotic symptoms, diminishes the feeling of control (Bak et al., 2001 a; Carr, 1988). Active coping strategies, like problem solving, seeking help and distraction, on the other hand, are reported to generate control and improve general functioning in people with a diagnosis of schizophrenia (Bak et al., 2001b; Boschi et al., 2000; Falloon, 2000). Previous studies suggested that individuals with psychiatric disorders tend to use more passive coping strategies than healthy controls (van den Bosch \& Rombouts, 1997; Vollrath, Alnaes, \& Torgersen, 1994). People with schizophrenia, who represent the most deficient end of the continuum, display the least efficient coping strategies such as withdrawal and avoidance in dealing with stressors which results in poor control experiences (Hultman, Wieselgren, \& Ohman, 1997; Nicholson \& Neufeld, 1992; van den Bosch \& Rombouts, 1997). 
In the present study, a general population sample was followed to identify individuals who had at least one experience of a psychotic symptom and no previous diagnosis of any psychotic disorder. It was hypothesized that only a part of these individuals would display a need for care in relation to their psychotic symptoms. It was further hypothesised that need for care status would be associated with "symptomatic" coping strategies and less experience of control, whereas active coping strategies would reduce development of need for care status and increase the experience of control. To this end, a previously described method to assess coping with and experience of control over psychotic experiences was used (Bak et al, 2001 a, 200 l b).

\section{Methods}

Sample

The sample was formed as part of the Netherlands Mental Health Survey and Incidence Study (NEMESIS), a longitudinal study of the prevalence, incidence and consequences of psychiatric disorders in the Dutch general population (Bijl, Ravelli et al., 1998; Bijl, van Zessen et al., 1998). Subjects were interviewed on three occasions: in 1996 (T0), in 1997 (T1 - assessing the period between T0 and $\mathrm{T} 1$ ), and in 1999 (T2 - assessing the period between $\mathrm{T} 1$ and $\mathrm{T} 2$ ). A comprehensive description of the project objectives, sample procedure, response, diagnostic instrument, quality control procedures and analyses is provided in previous publications (Bijl, Ravelli et al., 1998; Bijl, van Zessen et al., 1998). NEMESIS is based on a multistage, stratified, random sampling procedure, in which 90 municipalities, a sample of private households within each municipality and members with the most recent birthday within each household were selected. Subjects were aged 18-64 years and sufficiently fluent in Dutch to be interviewed. Persons living in institutions, including those residing in psychiatric hospitals, were not included in the sampling frame.

\section{CIDI interviews and psychotic symptoms}

Subjects were interviewed face to face in their homes using the Composite International Diagnostic Interview (CIDI, version 1.1, computerised version (Smeets \& Dingemans, 1993), at T0 $(\mathrm{n}=7076)$, T1 $(\mathrm{n}=5618)$ and T2 $(\mathrm{n}=4848)$. The CIDI is a structured interview developed by the World Health Organization (WHO) on the basis of the Diagnostic Interview Schedule (DIS) (Robins, Helzer, Croughan, \& Ratcliff, 1981) and the Present State Examination (PSE) (Wing et al., 1974; Wing et al., 1977). It is designed for use by trained interviewers who are not clinicians, and the associated computer program yields DSM-III-R diagnoses. The CIDI psychosis section (G-section) consists of 17 psychosis items concerning delusions (13 items) and hallucinations (4 items): items G1-G13, G15, G16, G20 and G21. Each item is scored as one of six separate ratings: "I" no symptom; "2" symptom present but not clinically 
relevant (not bothered by it and not seeking help for it); "3" symptom is the result of drug use and "4" symptom is the result of somatic disease; "5" true psychiatric symptom; "6" interviewer is in doubt because there appears to be some plausible explanation for what appears to be a psychotic symptom.

\section{T2 assessment of incident cases of psychosis}

In order to identify incident cases of psychosis at $\mathrm{T} 2$, we used the following procedure. Individuals who had a diagnosis of any affective or non-affective psychotic disorder according to the DSM-III-R at T0 were excluded. In addition, those with such diagnoses at T1 were excluded to make sure that any prevalent psychosis cases that were missed at baseline were excluded. This resulted in the exclusion of 126 subjects leaving 4722 subjects at T2 (Fig. 1).

\section{Clinical re-interviews for psychotic symptoms at $T 2$}

The present study focused on subjects who had at least one experience of a psychotic symptom (score "2", "5", or "6") and no previous diagnosis of any psychotic disorder at $\mathrm{T} 2(\mathrm{n}=191)$. Because psychotic symptoms may be difficult to diagnose by lay interviewers, especially as regards their clinical relevance (Cooper \& Collacott, 1994; Helzer et al., 1985), clinical re-interviews were conducted over the telephone by an experienced clinician (psychiatrist, senior psychiatric trainee or psychologist). The re-interviews were conducted using questions from the Structured Clinical Interview for DSM-III-R (SCID-I), an instrument with proven reliability and validity in diagnosing schizophrenia, to enhance reliability of the re-assessment interview (Spitzer et al., 1992). If the CIDI rating of the clinician did not coincide with the rating of the lay interviewer, the rating of the lay interviewer was replaced with the rating of the clinician. These corrected CIDI ratings were then entered into the CIDI diagnostic program. The CIDI diagnoses of psychotic disorder and the presence of psychotic symptoms at $\mathrm{T} 2$ are thus based on the results of the clinical reinterview.

Telephone re-interviews were completed on $142(74.4 \%)$ of the 191 subjects (the 49 subjects who could not be re-interviewed were excluded from the analysis - see Fig. 1). In addition, 57 subjects were excluded from the analyses, because they had no CIDI ratings of " 2 " or " 5 "left after re-interview, resulting in a sample of 85 subjects (see Fig. 1 ).

The group that was not re-interviewed $(n=49)$ did not differ from the reinterviewed group $(\mathrm{n}=142)$ on the socio-demographic variables sex $(\mathrm{OR}=$ $1.13,95 \% \mathrm{CI}: .58,2.17)$, marital status $(\mathrm{OR}=0.89,95 \% \mathrm{Cl}: 0.44,1.82)$, employment $(\mathrm{OR}=1.04,95 \% \mathrm{CI}: 0.35,3.05)$, age (in 5 categories of $18-24,25$ $34,35-44,45-54,55-64$ years) $(\mathrm{OR}=1.02,95 \% \mathrm{Cl}: 0.78,1.34)$, and urbanization (five levels of urbanization defined following the standard classification of urbanization of place of residence according to the Dutch Central Bureau of Statistics, 1993; based on the density of addresses per square 
kilometre in an area, and classified as less than 500, 500-999, 1000-1499, 15002499, and 2500 or more) ( $O R=1.00,95 \% \mathrm{Cl}: 0.80,1.25$ ). Furthermore, no differences were found on previous psychiatric diagnoses (defined as any lifetime DSM-III-R Axis I diagnosis) at $\mathbb{T O}(\mathrm{OR}=1.30,95 \% \mathrm{CI}: 0.67,2.50)$ or $\mathrm{T} 1(\mathrm{OR}=1.02,95 \% \mathrm{Cl}: 0.49,2.14)$ or on the personality traits neuroticism (assessed with the 14-item Groningen Neuroticism Scale (Ormel, 1980) (OR = $0.99,95 \% \mathrm{Cl}: 0.93,1.05$ ), and mastery (assessed with the five item mastery scale (Pearlin \& Schooler, 1978) (OR $=0.97,95 \% \mathrm{CI}: 0.89,1.06)$.

\section{Brief Psychiatric Rating Scale}

The two items on positive psychotic symptoms of the Brief Psychiatric Rating Scale (BPRS; (Lukoff, Liberman, \& Nuechterlein, 1986), "unusual thought content" and "hallucinations" were additionally scored by the clinician at T2 (range: 1, "absent" to 7, "very severe"). Ratings of 2-3 indicate nonpathological intensities of symptoms, $4-7$ indicate a pathological intensity of symptoms in terms of severity and functional impairment (Lukoff et al., 1986).

\section{"Caseness" at T2}

In order to determine who, among the individuals with CIDI psychotic experiences at $\mathrm{T} 2$, was a case for treatment, we used the following a priori definition of "caseness". This definition allowed us to not only use classical criteria for allocation of patient status on the basis of functional impairment and severity (as for example in DSM), but additionally to use a clinical judgement of need for care, as recommend for case identification in the general population (Spitzer, 1998). Presence of severity and functional impairment was defined as a pathology-level score (see above) on the BPRS items unusual thought content and / or hallucinations (including one case who met this criterion just outside the 14-(lay period covered by the BPRS assessment).

Need for care was assessed as follows. During the interview by clinicians at T2, as much information as possible was gathered in the 22 areas of need as defined by the Camberwell Assessment of Need (CAN) (Slade et al., 1996), in particular needs in the areas of psychotic symptoms and psychological distress. After the interview, a consensus meeting was organized, attended by two psychologists and two psychiatrists, during which all available information on possible need for care was presented. The four clinicians reached a consensus regarding whether there was a need for mental health care, in particular need for care in relation to psychotic symptoms and psychological distress. Individuals discussed in the consensus meeting were thus categorized as i) no need for care, or ii) probable or definite need for care. Those who met both caseness criteria (BPRS pathology level and clinician consensus on probable/definite need for care) were defined as a case for treatment, hereafter referred to as "need for care status". 
Assessment of coping, distress and control

Coping, subjective distress with and perceived control over the psychotic experience were assessed using the Maastricht Assessment of Coping Strategies (MACS), a semi-structured interview administered by a clinician (Bak et al., $2001 \mathrm{a}, 200(\mathrm{~b})$. In the MACS, the assessment of control is used as a measurement of coping efficacy. We used the 7 positive symptoms from the extended version of the MACS that matched with the positive symptoms included in the CIDI G-section. The seven symptoms were suspiciousness, thought reading/broadcasting, passivity phenomena, thought insertion/interference, delusions of reference, hearing voices, and other hallucinations. During the MACS interview, the interviewer first described the symptom to the subject in a general way, as if other people might suffer from that specific symptom too. The interviewer then asked the subject whether this symptom might have been present, again repeating the same description and asking follow-up questions to clarify if necessary. If any of the seven MACS symptoms had been present, the subject was asked: (i) to indicate on a seven point Likert scale the degree of distress associated with the symptom, (ii) to name all the strategies used to alleviate distress with symptoms and (iii) to indicate on a seven-point Likert scale the degree of control experienced over the symptom. The coping strategies were assessed by asking standard questions about what the patient did or thought when faced with the symptom. All the strategies mentioned by the patient were scored in one of five domains of coping, based on the work by Carr (Carr, 1988). This method ensured that we gathered the most important, self-initiated coping strategies used by the patient. On the basis of extensive pilot interviews, definitions had been prepared for these five domains and their subcategories (see http:/www.macsinfo.homestead.com/index.html), and examples were given for different symptoms so as to guide the interviewer. The five domains of coping consisted of: (i) behavioural, (ii) social, (iii) cognitive, (iv) care and (v) symptomatic. The first four domains had 5, 2, 3 and 3 subcategories respectively, and the last consisted only of one item (see http://www macsinfo.homestead.com/index.html), so that patients' descriptions of coping mechanisms could be scored under any of 14 different items. In a previous study, factor analysis of the 14 coping strategies revealed an interpretable pattern of correlation yielding frve factors explaining $71 \%$ of the variance. The coping strategies distraction, problem solving and help-seeking clustered together in an active problem solving coping factor; the coping strategies prescribed medication, non-prescribed substances, and physical change clustered together in a passive illness behaviou* coping factor; the coping strategies shifted attention, socialisation, lask performance and indulgence clustered together in an active problem avoiding coping factor; the coping strategies isolation, non-specific activities and suppression clustered 
logether in a passive problem avolding coping factor, and the fifth factor was one on which only symptomatic behaviour (going along with the content of psychotic symptoms, like following orders from voices or keeping a knife to defend oneself against an imagined persecutor) loaded.

All 85 individuals were interviewed with the MACS, with the exception of two individuals who could not complete the interview (total: 83 individuals - see Fig. 1). The MACS assesses coping as a means to reduce distress associated with psychotic symptoms. According to this paradigm, coping only has meaning in the presence of a symptom generating at least minimal distress. Therefore, of the 83 interviewed individuals, only the individuals with symptom observations that were associated with at least minimal presence of symptom distress (i.e. score of 2 or higher on the Likert scale) were included in the analysis. A total of 47 individuals (need for care: $n=19$; no need for care: $n=28$ ) had at least one symptom observation associated with minimum distress (see Fig. 1).

Staristical analysis

Individual level

In the file of 47 person observations, logistic regressions were used to study the associations between need for care status and i) number of MACS symptoms present per subject (mean 1.9,

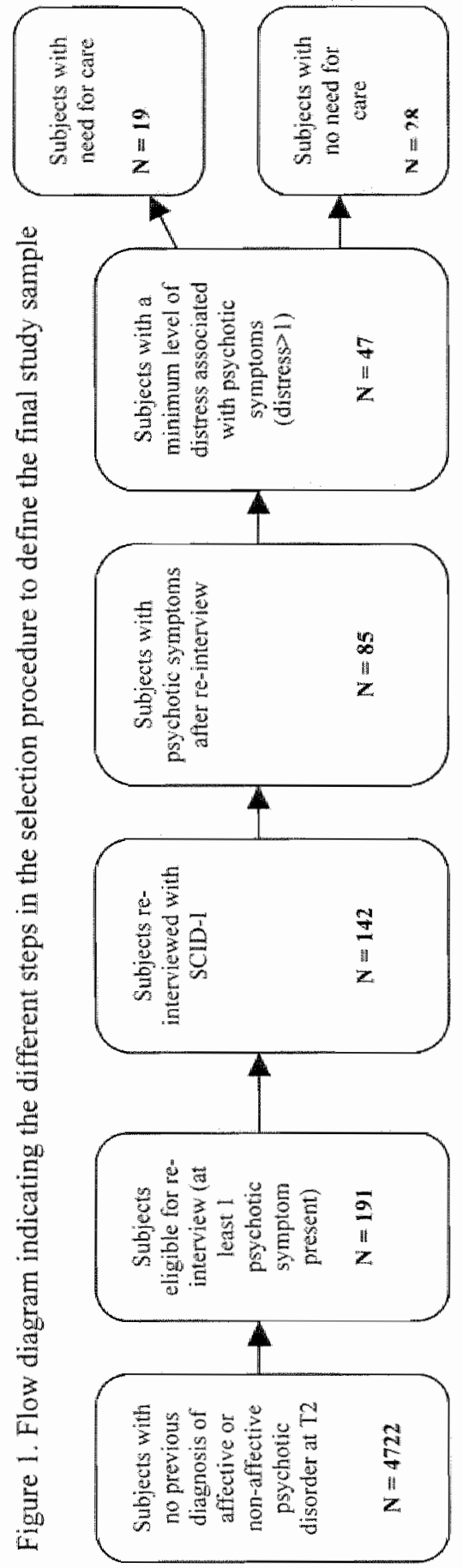


$\mathrm{SD}=1.0$, range 1-5), ii) mean distress score (for each subject, the average distress score per symptom present was calculated; mean $=3.8, \mathrm{SD}=1.9$, tange $1.25-7$ iii) mean number of coping strategies per subject (per subject, the average number of coping strategies per symptom present was calculated; mean $=1.8, \mathrm{SD}=1.1$, range $0-4$ ), iv) mean tevel of control (for each subject, the average control score per symptom present was calculated; mean $=3.4, \mathrm{SD}=$ 2.4 , range $1-7$ ) and $v$ ) intensity of psychotic symptomatology defined as the BPRS scores on unusual thought content (mean $3.2, \mathrm{SD}=1.6$ ) and hallucinatory behaviour (mean $=2.6, \mathrm{SD}=1.6)$.

\section{Coping observation level}

Analyses of coping were conducted with the STATA statistical program (Statacorp, 2001), and have been described before in detail (Bak et al., 2001a, 2001 b). A data file was constructed in which each of the 47 subjects included in the study contributed $14 \times 7=98$ observations: one for each of the different combinations of 14 original coping strategies and 7 symptoms of the MACS. These observations will hereafter be referred to as "coping observations". This was the most detailed level of analysis possible as the MACS assesses for each different symptom whether or not an individual uses any of the 14 coping strategies. Thus, for each of these 98 combinations patients could have a score of either 0 (indicating they did not use the coping strategy for the symptom) or 1 (indicating they did use the coping strategy for the symptom). The binary coping variable, indicating the presence or absence of coping, was the dependent variable in the analyses. Additional variables included coping type (the 5 coping factors as described above), need for care status $(1=$ need for care, $0=$ no need for care), level of control (scored on 7-point Likert scale), and level of distress (scored on 7-point Likert scale). The file thus contained 47 subjects $\times 98=4606$ observations. Of these, 938 were associated with at least minimum distress.

Effect sizes were expressed as odds ratios (OR) with a $95 \%$ confidence interval ( $95 \% \mathrm{Cl}$ ) from the logistic regression model predicting the presence of coping. Model contributions of independent variables and interactions were assessed by Wald test. The presence of coping was investigated in relation to coping type and need for care diagnosis along the lines of the hypotheses specified above, as was the relation between coping type and the experience of control. As obserwations were clustered within individuals, the CLUSTER and ROBUST options were used in the STATA logistic regression analyses (Bak et al., 200 Ia, $2001 \mathrm{~b}$ ). The CLUSTER option combined with the ROBUST option allows for the use of observations which are not independent within clusters (in this case: within individuals) and obtains the Huber/White/Sandwich estimator of variance instead of the traditional variance estimator. These procedures result in standard errors that are adjusted for clustering within persons. 


\section{Resulfs.}

\section{Individual level}

Need for care status was not associated with gender ( $\mathrm{OR}=0.4,95 \% \mathrm{CI}: 0.11$ 1.26) or age ( 5 categories: $\mathrm{OR}=0.96,95 \% \mathrm{CI}: 0.58-1.60$ ) at the individual level. Number of symptoms and both BPRS items discriminated between presence and absence of need for care when each was examined separately (Table 1). Mean level of distress, mean number of coping strategies used, and mean levell of control was not related to need for care status. When all were entered jointly in the equation, only BPRS unusual thought content and BPRS hallucinatory behaviour independently predicted need for care status (Table 1).

Table 1. Association between need for care status (no need for care: $n=28$, need for care: $n=19$ ) and independent variables.

Association with need for care status

\begin{tabular}{|c|c|c|c|c|c|c|}
\hline & Univariate & $x^{2}$ & $p$ & Multivariate & $\overline{x^{2}}$ & $\mathrm{P}$ \\
\hline $\begin{array}{l}\text { Total symptom score } \\
\text { (range: } 1-5 \text { ) }\end{array}$ & $\begin{array}{l}2.89 \\
(1.37,6.09)\end{array}$ & 7.76 & 0.005 & $\begin{array}{l}0.03 \\
(0.00,1.37)\end{array}$ & 3.23 & 0.072 \\
\hline $\begin{array}{l}\text { Mean distress score } \\
\text { (range: } 1.25-7 \text { ) }\end{array}$ & $\begin{array}{l}0.99 \\
(0.73,1.35)\end{array}$ & 0.00 & 0.956 & $\begin{array}{l}0.99 \\
(0.48,2.05)\end{array}$ & 0.00 & 0.98 \\
\hline $\begin{array}{l}\text { Mean coping score } \\
\text { (range: } 0-4)\end{array}$ & $\begin{array}{l}1.37 \\
(0.77,2.42)\end{array}$ & 1.14 & 0.286 & $\begin{array}{l}0.21 \\
(0.02,1.87)\end{array}$ & 1.94 & 0.164 \\
\hline $\begin{array}{l}\text { Mean control score } \\
\text { (range: } 1-7 \text { ) }\end{array}$ & $\begin{array}{l}0.96 \\
(0.75,1.24)\end{array}$ & 0.08 & 0.776 & $\begin{array}{l}1.32 \\
(0.71,2.47)\end{array}$ & 0.76 & 0.382 \\
\hline $\begin{array}{l}\text { BPRS "Lnustual } \\
\text { thought content" } \\
\text { (range: } 1-7 \text { ) }\end{array}$ & $\begin{array}{l}3.35 \\
(1.69,6.63)\end{array}$ & 12.05 & 0.001 & $\begin{array}{l}28.46 \\
(1.69 .480 .43)\end{array}$ & 5.39 & 0.02 \\
\hline $\begin{array}{l}\text { BPRS "hallucinatory } \\
\text { behaviour" } \\
\text { (range: } 1=6 \text { ) }\end{array}$ & $\begin{array}{l}2.53 \\
(1.52,4.2 \Downarrow)\end{array}$ & 12.65 & 0.0000 & $\begin{array}{l}20.93 \\
(1.51,290.03)\end{array}$ & 5.14 & 0.023 \\
\hline
\end{tabular}

\section{Coping observation level}

In the combined group of need for care and no need for care subjects, signilicant associations were apparent between the presence of coping and coping type (the 5 coping factors $-\chi^{2}=74.54$, $\mathrm{df}=4, \mathrm{p}<0.001$ ), indicating that different coping types were used with different frequencies. In both the need for care and the no need for care group, symptomatic coping was the most common strategy, followed by active problem solving and passive problem avoiding (Table 2). There was, however, a significant interaction between need for care status and coping type $\left(\chi^{2}=11.15, \mathrm{df}=4, P=0.025\right)$, also after correction for the two BPRS psychosis items $\left(\chi^{2}=10.88, \mathrm{df}=4, P=0.028\right)$. Examination of the relative distributions of coping type in both groups revealed that those with a need for care were much more likely to display symptomatic coping $(\mathrm{OR}=6.07$, $95 \% \mathrm{CI}: 1.94-18.95$ ), whereas the presence of the other four coping types was not different across the two groups (Table 2). 
Table 2. Presence of coping related to coping type and need for care status.

\begin{tabular}{|c|c|c|c|c|c|c|c|}
\hline \multirow[t]{2}{*}{$\begin{array}{l}\text { Coping } \\
\text { rype }\end{array}$} & \multicolumn{2}{|c|}{$\begin{array}{l}\text { No need for care } \\
\qquad(\mathrm{n}=28)\end{array}$} & \multicolumn{2}{|c|}{ Need for care $(n=19)$} & \multirow[t]{2}{*}{$x^{2}$} & \multirow[t]{2}{*}{ p } & \multirow[t]{2}{*}{$\begin{array}{c}\mathrm{OR} \\
(95 \% \mathrm{CD})\end{array}$} \\
\hline & $\begin{array}{l}\text { Coping } \\
\text { absent }\end{array}$ & $\begin{array}{l}\text { Coping } \\
\text { present }\end{array}$ & $\begin{array}{l}\text { Coping } \\
\text { absent }\end{array}$ & $\begin{array}{l}\text { Coping } \\
\text { present }\end{array}$ & & & \\
\hline $\begin{array}{l}\text { Active } \\
\text { problem } \\
\text { solving }\end{array}$ & $\begin{array}{l}91 \\
(84.26 \%)\end{array}$ & $\begin{array}{l}17 \\
(15.74 \%)\end{array}$ & $\begin{array}{l}69 \\
(74.19 \%)\end{array}$ & $\begin{array}{l}24 \\
(25.81 \%)\end{array}$ & 2.15 & 0.14 & $\begin{array}{l}1.86 \\
(0.81,4.27)\end{array}$ \\
\hline $\begin{array}{l}\text { Passive } \\
\text { illness }\end{array}$ & $\begin{array}{l}107 \\
(99.07 \%)\end{array}$ & $\begin{array}{l}1 \\
(0.93 \%)\end{array}$ & $\begin{array}{l}90 \\
(96,77 \%)\end{array}$ & $(3.23 \%)$ & 1.02 & 0.31 & $\begin{array}{l}3.57 \\
(0.30,42.03)\end{array}$ \\
\hline $\begin{array}{l}\text { Active } \\
\text { problem } \\
\text { awoiding }\end{array}$ & $\begin{array}{l}134 \\
(9306 \%)\end{array}$ & $\begin{array}{l}10 \\
(6.94 \%)\end{array}$ & $\begin{array}{l}117 \\
(94.35 \%)\end{array}$ & $\begin{array}{l}7 \\
(5.65 \%)\end{array}$ & 0.23 & 0.64 & $\begin{array}{l}0.80 \\
(0.32,2.00)\end{array}$ \\
\hline $\begin{array}{l}\text { Passive } \\
\text { problem }\end{array}$ & $\begin{array}{l}93 \\
(86.11 \%)\end{array}$ & $\begin{array}{l}15 \\
(13.89 \%)\end{array}$ & $\begin{array}{l}85 \\
(91.40 \%)\end{array}$ & $\begin{array}{l}8 \\
(8.60 \%)\end{array}$ & 1.44 & 0.23 & $\begin{array}{l}0.58 \\
(0.24 .1 .41)\end{array}$ \\
\hline avoiding & $\begin{array}{l}23 \\
(63.89 \%)\end{array}$ & $\begin{array}{l}13 \\
(36.11 \%)\end{array}$ & $\begin{array}{l}7(22.58 \\
46)\end{array}$ & $\begin{array}{l}24 \\
(77,42 \%)\end{array}$ & 9.62 & 0.002 & $\begin{array}{l}6.07 \\
(1.94 .18 .95)\end{array}$ \\
\hline Total & $\begin{array}{l}448 \\
(88.89 \%)\end{array}$ & $\begin{array}{l}56 \\
(11.11 \%)\end{array}$ & $\begin{array}{l}368 \\
(84.79 \%)\end{array}$ & $\begin{array}{l}66 \\
(15.21 \%)\end{array}$ & 3.40 & 0.06 & $\begin{array}{l}1.44 \\
(0.98,2.10)\end{array}$ \\
\hline
\end{tabular}

For example, the fifth row relates 10 "symptomatic coping". In those with no need for care, out of 36 possible symptomatic coping observations, coping was present in 13 observations $(36.11 \%)$. In subjects with need for care, out of 31 possible symptomatic coping olsserwations, coping was present $77.24 \%$ of the observations $(n=$ 24). The odds ratio of these iwo probabilities is 6.07 , indicating that those with need for care were 6.07 times more likely use symptomatic coping, where possible, compared to the other group.

The presence of coping was not associated with perceived control $(\mathrm{OR}=1.05$, $95 \% \mathrm{CI}: 0.97-1.13$ ) and this remained so after adjustment for distress $(\mathrm{OR}=1.05,95 \% \mathrm{Cl}: 0.98-1.12)$. However, the association between the presence of coping and experience of control differed as a function of coping type (coping type $x$ control interaction term: $x^{2}=19.24, \mathrm{~d} f=4, P<0.001$ ). Stratified analyses per coping type (Table 3) revealed that symptomalic coping was negatively associated with control ( $\mathrm{OR}=0.79 ; 95 \% \mathrm{Cl}: 0.63-0.98)$, whereas active problem solving was positively associated with experience of control $(\mathrm{OR}=1.28 ; 95 \% \mathrm{CI}: 1.10-1.49)$.

\section{Discussion}

Severity of psychotic experiences rather than mean level of distress, mean level of perceived control, and average amount of coping per se distinguished between those with and without need for care. Qualitative differences in the five main coping types were apparent, however, in that symptomatic coping was used more frequently in the need for care group. Symptomatic coping was associated with less, and active problem solving with more perceived control over the psychotic experience. 
Table 3 . Associaton between presence of coping and control, stratified by coping type

\begin{tabular}{lccc}
\hline & \multicolumn{3}{c}{ Association between coping and control } \\
\cline { 2 - 4 } & $\chi^{2}$ & $\mathrm{p}$ & OR $(95 \% \mathrm{Cl})$ \\
\hline Active problem solving & 9.73 & 0.002 & $1.28(1.10,1.49)$ \\
Passive illness behaviour & 0.43 & 0.51 & $1.18(0.72,1.92)$ \\
Active problem avoiding & 1.19 & 0.28 & $1.10(0.93,1.30)$ \\
Passive problem avoiding & 0.67 & 0.41 & $0.93(0.79,1.11)$ \\
Symptomatic & 4.53 & 0.03 & $0.79(0.63,0.98)$ \\
\hline
\end{tabular}

Interaction tem coping factor $x$ control: $\chi^{2}=19,24, \mathrm{df}=4, P<0,001$

The fact that average levels of distress and experienced control are not related to patient status seems counter-intuitive, but can be explained by the fact that average levels do not take into account the fact that different symptoms may be associated with different levels of distress and different coping mechanisms that differ in their effects on experience of control. The underlying dynamics between symptoms, distress and control was more accurately revealed by conducting analyses at the much more detailed level of coping per coping mechanism and per symptom. For example, a person may have several symptoms, for most of which he/she reports functional coping and high levels. of control. However, this subject might have one very distressing symptom, for which non-functional coping is used, resulting in low experience of control and need for care status. The mean level of control would be high for this subject, while he/she still would be in need for care.

It could be argued that the fact that symptomatic coping was more often used in the patient group may be simply the result of the patient group having more severe psychotic experiences. However, the interaction between need for care status and coping factor was not reduced and remained similarly highly significant after adjustment for both BPRS psychosis items. The use of coping strategies therefore differed between those with and without need for care independent of their differences in severity of symptoms. Additionally, it could be argued that symptomatic coping might have different effects in terms of experience of control in the group who develops need for care versus those who do not. However, a post-hoc analysis investigating the relation between coping strategy and experience of control in relation to need of care status revealed no significant association $\left(\mathrm{H}^{2}=1.56, \mathrm{p}=0.21\right)$, indicating that symptomatic coping resulted in a decrease in control in both groups.

The current findings suggest that a coping strategy characterized by going along with and indulging in symptoms, yielding less experience of control, discriminates between those with and those without need for care in the context of psychotic symptoms. These findings are in agreement with previous work by Birchwood and colleagues, who showed that anxiety and depression in relation to psychotic illness are associated with perceived controllability, and feelings of subordination to "omnipotent" voices (Birchwood \& Chadwick, 1997; Birchwood et al., 1993). A symptomatic coping strategy of going along with the content of psychotic experiences may give rise to low perceived controllability 
and depression and thus contribute to the development of need for care. Such a mechanism may also operate in individuals about to relapse with a psychotic episode, as evidenced by reports of an increase in depression and hallucinations in the month before relapse (Tarrier, Barrowclough, \& Barmrah, 1991).

Active coping, in agreement with the initial hypothesis, was positively associated with control. However, contrary to the initial hypothesis, no differences were found in the frequency of use of active coping between those with and without need for care.

\section{Methodological issues}

These results should be interpreted in the light of several potential limitations. The data were cross-sectional, so that no firm conclusions can be drawn about the direction of effects in associations between distress, coping and perceived control. Distress related to symptoms, coping and experience of symptom control are dynamic entities with within- and between day fluctuations that cannot be captured by a cross-sectional instrument (Delespaul, 1995; Sayer, Ritter, \& Gournay, 2000). Although it is therefore difficult to establish the true direction of effects in the association between distress, coping and control, the assumed effect of coping on control has face validity. A prospective study capturing the moment-to-moment variation of coping and control would be necessary to validate the present findings and establish the direction of effects. Such a study would be very difficult to carry out, however, given the problems of prospectively identifying individuals who will develop a need for care in relation to psychotic symptoms.

The interview was not ideal as assessments of coping and symptoms were carried out over the telephone, thus missing non-verbal expressions. Nevertheless, the results of the current investigation, especially as regards the negative association between symptomatic coping and control, and the positive association between active problem solving and control, was similar to previous face-to-face interview findings with the MACS in a sample of patients with psychotic illness (Bak et al., 2001a, 200 lb).

\section{Conclusion}

While accepting the above limitations, this study has strengths as well. As far as we are aware, it is the first to test the hypothesis of differences in coping between "patients" and "non-patients" in the context of psychotic symptoms in a longitudinal population-based study. Although the findings are a long way from contributing to efforts at early intervention (McGorry, Edwards, Mihalopoulos, Harrigan, \& Jackson, 1996), there is a suggestion that not just presence of psychotic experiences per se, but also the way individuals interact with these are important in producing need for care psychotic disorder. 


\section{References}

Bak, M., Van Der Spil, F., Gunther, N., Radstake, S., Delespaul, P., \& Van Os, J. (2001a). Maastricht Assessment of Coping Strategies (MACS-1): a brief instrument to assess coping with psychotic symptoms. Acra Psychiatr Scand, $103(6), 453-459$.

Bak, M. Van Der Spil, F., Gunther, N., Radstake, S., Delespaul, P., \& Van OS, J. (200 Ib). MACS-II: does coping enhance subjective control over psychotic symptoms? Acta Pychiatr Scand, 103(6), 460-464.

Bentall, R. P., \& Slade, P. D. (1985). Reality testing and auditory hallucinations: a signal detection analysis. BP J Clin Psychol, 24(Pt 3), 159-169.

Bijl, R. V., Ravelli, A., \& van Zessen, G. (1998). Prevalence of psychiatric disorden in the general population: results of The Netherlands Mental Health Survey and Incidence Study (NEMESIS). Soc Psychiatry Psychiatr Epidemiol, $33(12)$, $587-595$.

Bijl, R. V., van Zessen, G., Ravelli, A., de Rijk, C., \& Langendoen, Y. (1998). The Netherlands Mental Fealth Survey and Incidence Study (NEMESIS): objectives and design. Soc Psychiary Psychiatr Epidemiol, 33(12), 581-586.

Birchwood, M., \& Chadwick, P. (1997). The omnipotence of voices: testing the validity of a cognitive model. Psychol Med, 27(6), 1345-1353.

Birchwood, M., Mason, R., MacMillan, F., \& Healy, J. (1993). Depression, demoralization and control over psychotic illness: a comparison of depressed and non-depressed patients with a chronic psychosis. Psychol Med, 23(2), 387395.

Boschi, S., Adams, R. E., Bromet, E. J, Lavelle, J. E., Everett, E., \& Galambos, N. (2000). Coping with psychotic symptoms in the early phases of schizophrenia. Am J Orhopsychiatry, $70(2), 242-252$.

Carr, V. (1988). Patients' techniques for coping with schizophrenia: an exploratory study. Br J Med Psychol, 6I(Pt 4), 339-352.

Chapman, L. J., Chapman, J. P., Kwapil, T. R., Eckblad, M., \& Zinser, M. C. (1994). Putatively psychosis-prone subjects 10 years later. $J$ Abnorm Psychol 103(2), $171-183$.

Claridge, G. (1994). Single indicator of risk for schizophrenia: probable fact or likely myth? Schizoph" Bull, $20(1), 151-168$.

Claridge, G. (1997). Schizotypy. impications for illness and healh. Oxford: Oxford University Press.

Coopet, S. A., \& Collacolt, R. A. (1994). Clinical features and diagnostic criteria of depression in Down's syndrome. Br J Psychiatry. 165(3), 399-403.

Delespaul, P. A. E. G. (1995). Assessing Schizophenia in Daily Life: The Experience Sampling Method. Unpublished PhD Thesis, Maastricht University, Maastricht.

Eaton, W. W., Romanoski, A., Anthony, J. C., \& Nestadt, G. (1991). Screening for psychosis in the general population with a self-report interview. $J$ Nerv Ment $\mathrm{Dis}_{1}, 179(11), 689-693$.

Falloon, I. R. (2000). Problem solving as a core strategy in the prevention of schizophrenia and other mental disorders. Aust $N Z J$ Psychiamy, 34 Suppl, S. $85-190$.

Garety, P., \& Hemsley, D. (1994). Delusions. Investigations into the Psychology of Delusional Reasoning. Oxford: Oxford University Press. 
Hanssen M., Bijl R.V., Vollebergh W., \& Os, J. v. (2003). Self-reported psychotic experiences in the general population: a valid screening tool for DSM-III-R psychotic disorders?

Helzer, J. E., Robins, L. N., McEvoy, L. T., Spitznagel, E. L., Stoltzman, R. K., Farmer, A., \& Brockington, I. F. (1985). A comparison of clinical and diagnostic interview schedule diagnoses. Physician reexamination of lay-interviewed cases in the general population. Arch Gen Psychiaty, 42(7),657-666.

Hultman, C. M., Wieselgren, I. M., \& Ohman, A. (1997). Relationships between social support, social coping and life events in the relapse of schizophrenic patients. Scand J Pychol, 38(1), 3-13.

Johns, L. C., Nazroo, J. Y., Bebbington, P., \& Kuipers, E. (1998). Occurence of hallucinations in a community sample. Schizoph $R e s, 29,23$.

Johns, L. C., \& van Os, J. (2001). The continuity of psychotic experiences in the general population. Clin Psychol Rev, 21(8), 1125-1141.

Kendell, R. E. (1985). Schizophrenia. London: Basic Books.

Kwapil, T. R., Miller, M. B., Zinser, M. C., Chapman, J., \& Chapman, L. J. (1997). Magical ideation and social anhedonia as predictors of psychosis proneness: a partial replication. I Abnom Psychol, $106(3)$, 491-495.

Lukoff, D., Liberman, R. P., \& Nuechterlein, K. H. (1986). Symptom monitoring in the rehabilitation of schizophrenic patients. Schizophr Bull, 12(4), 578-602.

Lukoff, D., Snyder, K., Ventura, J., \& Nuechterlein, K. H. (1984). Life events, familial stress, and coping in the developmental course of schizophrenia. Schizophr Bull, $10(2), 258-292$.

McGorry, P. D., Edwards, J., Mihalopoulos, C., Harrigan, S. M., \& Jackson, H. J. (1996). EPPIC: an evolving system of early detection and optimal management. Schizophr Bull, 22(2), 305-326.

Nicholson, 1. R., \& Neufeld, R. W. (1992). A dynamic vulnerability perspective on stress and schizophrenia. Am J Orthopsychiatry, 62(1), 117-130.

Nuechterlein, K. H., \& Dawson, M. E. (1984). A heuristic vulnerability/stress model of schizophrenic episodes. Schizophr Buh, 10(2), 300-312.

Ormel, J. (1980). Maeite met Leven of een Moeilijk Leven? Groningen.

Pearlin, L. I., \& Schooter, C. (1978). The structure of coping. W Health Soc Bchav, $19(1), 2-21$.

Peters, E., Day, S., McKenna, J., \& Orbach, G. (1999). Delusional ideation in religious and psychotic populations. Br J Clin Psychol, 38(Pt 1), 83-96.

Peters, E. R., Joseph, S. A., \& Garety, P. A. (1999). Measurement of delusional ideation in the normal population: introducing the PDI (Peters et al. Delusions Inventory). Schizophr Bull, 25(3), 553-576.

Poulton, R., Caspi, A., Moffit, T. E., Cannon, M., Murray, R., \& Harrington, H. (2000). Children's self-reported psychotic symptoms and adult schizophreniform disorder: a 15-year longutudinal study. Arch Gen Psychiaty, 57(11), 10531058.

Robins, L. N., Helzer, J. E., Croughan, J., \& Ratcliff, K. S. (1981). National Institute of" Mental Health Diagnostic Interview Schedule. Its history, characteristics, and validity. Arch Gen Psychiary, 38(4), $381-389$.

Romme, M. A., \& Escher, A. D. (1989). Hearing voices. Schizoph Bull, 15(2), 209 216. 
Sayer, I., Ritter, S., \& Goumay, K. (2000). Beliefs about voices and their effects on coping strategies. I Adw Nurs, 3/(5), $1199-1205$.

Slade, M., Phelan, M., Thornictoft, G., \& Parkman, S. (1996). The Camberwell Assessment of Need (CAN): comparison of assessments by staff and patients of the needs of the severely mentally ill. Soc Psychiatry Psychiatr Epidemiol, $31(3-4), 109-113$.

Smeets, $\mathbb{R}$. M. W., \& Dingemans, P. M. A. J. (1993). Composite International Diagnostic Interview (CIDI), version 1.I (in Dutch). Amsterdam/Geneva: World Health Organization.

Spitzer , R. L. (1998). Diagnosis and need for treatment are not the same. Arch Gen Psychiatiy, $55(2), 120$.

Spitzer, R. L., Williams, I. B., Gibbon, M., \& Furst, M. B. (1992). The Structured Clinical Interview for DSM-III-R (SCID). I: History, rationale, and description. Arch Gen Psychiatry, 49(8), 624-629.

Statacorp. (2001). Statistical Software: release 7.: College Station, TX: Stata Corporation.

Strauss, J. S. (1969). Hallucinations and delusions as points on continua function. Rating scale evidence. Arch Gen Psychiatry, 2/(5), 581-586.

Tarrier, N., Barrowclough, C., \& Bamrah, J. S. (1991). Prodromal signs of relapse in schizophrenia. Soc Psychiatry Psychiar Epidemiol, 26(4), 157-161.

Tien, A. Y. (1991). Distributions of hallucinations in the population. Soc Psychiotry Psychiatr Epidemiol, 26(6), 287-292.

van den Bosch, R. J., \& Rombouts, R. P. (1997). Coping and cognition in schizophrenia and depression. Compr Psychiatry, 38(6), 341-344.

wan Os, J., Hanssen, M., Bijl, R. V., \& Ravelli, A. (2000). Strauss (1969) revisited: a psychosis continum in the general population? Schizophr Res, 45(1-2), 11-20.

van Os, J., Hanssen, M., Bijl, R. V., \& Vollebergh, W. (2001). Prevalence of psychotic disorder and community level of psychotic symptoms: an urban-rural comparison. Arch Gen Psychiatry, 58(7), 663-668.

Verdoux, H., Maurice-Tison, S., Gay, B., Van Os, J., Salamon, R., \& Bourgeois, M. L. (1998). A survey of delusional iceation in primary-care patients. Psychol Med. $28(1), 127-134$.

Vollnath, M., Alnaes, R., \& Torgersen, S. (1994). Coping and MCML-Il symptom scales, J Clin Psychol, 50(5), 727-736.

Wing, J. K., Cooper, J. E., \& Sartorius, N. (1974). The measurement and classificatoin of psychiatric symptoms. London: Cambridge University Press.

Wing, J. K., Nixon, J. M., Mann, S. A., \& Leff, J. P. (1977). Reliability of the PSE (ninth edition) used in a population study. Psychol Med.7(3), 505-516.

Young, H. F., Bentall, R. P., Slade, P. D., \& Dewey, M. E. (1986). Disposition towards hallucination, gender and EPQ scores: A brief report. Personality and Individual Differences., 7(2), 247-249. 


\section{Vignettes of cases indicating no need for care (A) and need for care (B) in this sample.}

\section{Case A}

Case A was a woman aged 58 years. She had been a widow since four years. During the clinical re-interview, she reported that she was hearing voices 2-3 times a week and that she had the feeling that some of her thoughts had predictive value. For example, she would be warning people of an unpleasant event about to befall them, and they would later tell her that what she predicted became true. Once (about a year before) she had an encounter with police officers at which moment she became convinced that her daughter would experience some accident in the near future. This also became true. During the interview, she mentioned that she regularly heard her deceased husband, whose remarks also have predictive value. She is convinced that some persons, like herself, are "media-mimical", or sensitive to picking up information from supernatural sources. She further stated that she was very sensitive and easily smelt all sorts of things, without a special meaning. She had a part-time job as a secretary. She has good friends and regularly looks after the two children of her daughter.

She was given a score of "2" (clinically non-relevant psychotic experience) on the category of miscellaneous delusions (magical thinking) (G13), acoustic experiences (G16) and hearing voices (G17). The BPRS ratings were, delusions ' 4' and hallucinations ' 3 '. We concluded that there was no need for care related to the psychotic experiences. The intensity and frequency appeared rather intense but no major impact on the subject's general functioning or her quality of life was apparent.

\section{Case B}

A man aged 28 years had been rated at the T2 interview with CIDI symptoms G6, G7 and G21, all rated as true psychotic symptoms (score "5"). During one and a half years he had been hearing and reading other people's thoughts and feelings. He was convinced that this was a common ability present in all people, but that he was special in that he had discovered how to actually make use of this gift. He had developed it to a higher level, so that he now was able now to open several chambers in his head, or make several internal connections in his brain. This enabled him to do several tasks at once, like watching television at three channels, reading a book page by just briefly looking at it, or listening to 3 records simultaneously. Sometimes he received a number from the television, which referred to a program he was intended to watch. Although he regarded his experiences as part of a gift, he was also worried, because he could not be certain whether someone else would read his thoughts or would be transmitting 
thoughts to him. He also sometimes experienced troublesome bodily sensations, like someone or something was grabbing at him. He described this experience as being immobilised and therefore unable to move, and attempted to push these sensations away using his brainpower. Because of this, he avoided public places and eye contact with other people. He found it impossible to work, although the would have liked to. He said he had no difficulties in taking care of his house and meals. He had some social contacts but no close friends, although would like to have a good friend. He preferred to live alone, because other people are very annoying.

He was given a "5" rating after clinical assessment for the symptom G6, G7 and G21.

The BPRS ratings were delusions ' 6 ' and hallucinations ' 4 '. He received a need for care diagnosis, because of the degree of the psychotic experiences and impact on needs and quality of life, such as avoiding social contact, not feeling able to work and his general isolation. 


\section{Chapter 7}

Do different psychotic experiences differentially predict need for care in the general population?

M. Bak, I. Myin-Germeys, Ph. Delespaul, W. Vollebergh, R. de Graaf, J. van Os Submitted for publication 


\begin{abstract}
Introduction. The pathway from sub-clinical psychotic experiences to need for care may depend on type of psychotic experience, level of associated distress and previous experience of psychosis.

Method. In a general population sample with no previous DSM-III-R psychotic disorder $(n=4722), 83$ subjects displayed at least one psychotic experience. Within the group of 83 , subjects with $(n=24)$ and without need for care $(n=59)$ were compared. Presence of psychotic experiences at younger ages had been assessed at earlier interviews.

Results. Of 7 different psychotic experiences, only Hearing Voices, Non-verbal Hallucinations and Passivity Phenomena discriminated between groups. These associations were largely explained by the distress associated with the psychotic experience, but whether individuals had had psychotic experiences at earlier ages did not matter.

Conclusions. Different psychotic experiences have different associations with need for care that tend to be mediated by distress. Longer prior exposure to psychosis may not influence the pathway from sub-clinical to clinical.
\end{abstract}

Keywords: psychosis, distress, single symptom, need for care, general population 


\section{Introduction.}

Several population-based studies have reported that the prevalence of subclinical psychotic experiences is many times higher than the prevalence of affective and non-affective psychotic disorders (Bentall \& Slade, 1985; Johns et al., 1998; E. R. Peters et al., 1999; Tien, 1991; Verdoux, Maurice-Tison et al., 1998). Sub-clinical experiences of psychosis are associated with clinical disorder cross-sectionally (Eaton et al., 1991; Hanssen et al., 2002) and longitudinally (Chapman et al., 1994; Kwapil et al., 1997; Poulton et al., 2000), and may in fact be at the lower end of a continuum of psychosis of which clinical disorders occupy the extreme (Claridge, 1994; Strauss, 1969; van Os, Hanssen et al., 2001).

Given the strong associations between sub-clinical psychotic experiences in the general population and "cases" of psychotic disorder, it becomes important to understand what actually causes some individuals with psychotic experiences to develop need for care (Johns \& van Os, 2001). Indirect factors such as general functioning, depression, neuroticism and self-esteem have been reported to be predictive of need for care in the context of psychosis. However, factors directly associated with the psychotic experiences, such as the degree of distress and the degree of previous exposure to experience of psychosis are also important, as both distress and behavioural sensitisation due to prior exposure can contribute to a poorer outcome of a given psychotic experience (Krabbendam, Hanssen, Bak, \& Van Os, 2003; Krabbendam et al., 2002; E. Peters et al., 1999; Pincus et al., 1998; Poulton et al., 2000; Ustun et al., 1998; van Os, Verdoux, MauriceTison et al., 1999). It has been suggested that the subsequent course of a psychotic experience in individuals not receiving treatment is worse for those who had prior exposure to psychosis (i.e. had longer duration of untreated psychosis) that in individuals without prior exposure, or only brief exposure (McGlashan, 1999).

With regard to these latter direct factors of distress and prior exposure to psychosis, however, it is not known whether the relationship between psychotic experiences and need for care is similar for different psychotic experiences, such as hallucinations and delusions, and whether the mediating role of, for example, distress operates in a similar fashion across these different symptom domains. In addition, whether or not prior exposure to psychosis in itself is causally related to more "toxic" outcomes remains controversial (Verdoux, Bergey et al., 1998). The single symptom research approach, both at the clinical and sub-clinical level, is a suitable method addressing pathopsychological mechanisms related to the ontogenesis and subsequent course of separate symptoms (Bentall, 1990; Costello, 1992; Garety et al., 2001; Mojtabai \& Rieder, 1998; Strauss, 1969). Therefore, the current study investigated, in a large general population sample, whether different sub-clinical psychotic experiences were associated differentially with need for care, and to what 
degree any association was differentially modified by distress and previous exposure to psychotic experiences.

\section{Method.}

\section{Sample}

The sample was part of the Netherlands Mental Health Survey and Incidence Study (NEMESIS), a longitudinal study of the prevalence, incidence and consequences of psychiatric disorders in the Dutch general population [Bijl, 1998 \#195; Bijl, 1998 \#196]. Subjects were interviewed on three occasions: in 1996 (T0), in 1997 ( $\mathrm{T} 1$ - assessing the period between T0 and T1), and in 1999 ( $\mathrm{T} 2$ - assessing the period between $\mathrm{T} 1$ and $\mathrm{T} 2$ ). A comprehensive description of the project objectives, sample procedure, response, diagnostic instruments, quality control procedures and analyses is provided in previous publications [Bijl, 1998 \#195; Bijl, 1998 \#196]. NEMESIS is based on a multistage, stratified, random sampling procedure, in which 90 municipalities, a sample of private households within each municipality and members with the most recent birthday within each household were selected. Subjects were aged 18-64 years and sufficiently fluent in Dutch to be interviewed. Persons living in institutions, including those residing in psychiatric hospitals, were not included in the sampling frame.

\section{CIDI interviews and psychotic symproms}

Subjects were interviewed face to face in their homes using the Composite International Diagnostic Interview (CIDI, version 1.1, computerised version (Smeets \& Dingemans, $\| 993)$, at T0 $(n=7076)$, T1 $(n=5618)$ and T2 $(n=4848)$. The CIDI is a structured interview developed by the World Health Organization (WHO) on the basis of the Diagnostic Interview Schedule (DIS) (Robins et al, 1981) and the Present State Examination (PSE) (Wing et al., 1974). It was designed for use by trained lay interviewers who are not clinicians, and the associated computer program yields DSM-III-R diagnoses. The CIDI psychosis section (G-section) consists of 17 psychosis items concerning delusions (13 items) and hallucinations ( 4 items): items G1-G13, G15, G16, G20 and G21. Each item is scored as one of six separate ratings: "I" no symptom; "2" symptom present but not clinically relevant (not bothered by it and not seeking help for it); "3" symptom is the result of drug use and "4" symptom is the result of somatic disease; "5" true psychiatric symptom; "6" interviewer is in doubt because there appears to be some plausible explanation for what appears to be a psychotic symptom.

\section{Exclusion of non-incident DSM-III-R diagnosis of psychosis at T2}

In order to be able to judge the unbiased relationship between psychotic symptoms and need for care at $\mathrm{T} 2$, individuals with previous established diagnoses of psychotic disorder (and, by inference, need for care) were 
excluded using the following procedure. Individuals who had a diagnosis of any affective or non-affective psychotic disorder according to the DSM-III-R at baseline were excluded. In addition, those with such diagnoses at TI were excluded to make sure that any prevalent cases with a diagnosis of psychosis that were missed at baseline were excluded. This resulted in the exclusion of 126 subjects leaving 4722 subjects in this risk set at T2 (Fig. 1)

\section{Clinical re-interviews for psychotic symptoms at $T 2$}

At $\mathrm{T} 2$, clinical re-interviews were carried out by a clinician for those who screened positive for one or more psychotic symptoms in the CIDI G-section, because psychotic symptoms may be difficult to diagnose by lay interviewers, especially as regards their clinical relevance (Cooper et al., 1998; Helzer et al., 1985). Only subjects who had at least one CIDI-rated experience of a functional psychotic symptom at T2 (CIDI score " 2 ", " 5 ", or "6") and no previous diagnosis of any psychotic disorder at T2 $(n=191)$ were eligible for clinical reinterview. Telephone re-interviews were completed on $142(74.4 \%)$ of the 191 subjects (the 49 subjects who could not be re-interviewed were also excluded from the analysis - see Fig. 1). The group that was not re-interviewed $(n=49)$ did not differ from the re-interviewed group $(\mathrm{n}=142)$ on the sociodemographic variables sex $(\mathrm{OR}=1.13,95 \% \mathrm{CI}: 0.58-2.17)$, marital status $(\mathrm{OR}$ $=0.89,95 \% \mathrm{CI}: 0.44-1.82)$, employment $(\mathrm{OR}=1.04,95 \% \mathrm{CI}: 0.35-3.05)$, age (in 5 categories of $18-24,25-34,35-44,45-54,55-64$ years $)(O R=1.02$, $95 \% \mathrm{Cl}: 0.78-1.34$ ), and urbanization (five levels of urbanization) (OR $=1.00$, $95 \% \mathrm{Cl}: 0.80-1.25)$. Furthermore, no differences were found on previous psychiatric diagnoses (defined as any lifetime DSM-III-R Axis I diagnosis) at $\mathrm{TO}(\mathrm{OR}=1.30,95 \% \mathrm{CI}: 0.67-2.50)$ or $\mathrm{T} 1(\mathrm{OR}=1.02,95 \% \mathrm{Cl}: 0.49-2.14)$.

Clinical re-interviews were conducted over the telephone by an experienced clinician (psychiatrist or psychologist). The re-interviews were conducted using questions from the Structured Clinical Interview for DSM-III-R (SCID-I), an instrument with proven reliability and validity in diagnosing schizophrenia, to enhance reliability of the re-assessment interview (Spitzer et al., 1992). If the CIDI rating of the clinician did not coincide with the rating of the lay interviewer, the rating of the lay interviewer was replaced with the rating of the clinician. After the re-assessment, 85 subjects thus had a CIDI score of " 2 " or "5".

Assessment of need for care at $T 2$

In order to determine who, among the individuals with CIDI psychotic experiences at $T 2$, was in need of care, we used the following a priori definition of "caseness". This definition allowed us to not only use classical criteria for allocation of patient status on the basis of functional impairment and severity of symptoms, but additionally to use a clinical judgement of need for care, as recommend for case identification in the general population (Spitzer, 1998). 
Presence of severity and functional impairment was defined as a pathologylevel score (score >3: Likert score 1. 7; (Lukoff et al., 1986)) on the BPRS items unusual thought content and / or hallucinations.

Need for care was assessed as follows. During the interview by clinicians at T2, as much information as possible was gathered in the 22 areas of need as defined by the Camberwell Assessment of Need (CAN) (Slade, 1996), in particular needs in the areas of psychotic symptoms and psychological distress. After the interview, a consensus meeting was organized, attended by two psychologists and two psychiatrists, during which all available information on possible need for care was presented. The four clinicians reached a consensus regarding whether there was a need for mental health care, in particular need for care in relation to psychotic symptoms and psychological distress. Individuals discussed in the consensus meeting were thus categorized as i) no need for care, or ii) probable or definite need for care. Those who met both "caseness" criteria (BPRS pathology level and clinician consensus on probable/definite need for care) were defined as a case with need for care, hereafter referred to as "need for care".

\section{Assessment of self-reported distress per symptom}

Self-reported distress associated with specific psychotic experiences was assessed using the Maastricht Assessment of Coping Strategies (MACS), a semi-structured interview to asses subjective experience of distress connected with psychotic symptoms, the coping strategies used and the resulting level of perceived control. This scale was administered over the telephone by a psychiatrist (MB) (Bak et al., 2001a, 2001b). We used the 7 positive symptoms from the extended version of the MACS that matched with the positive symptoms included in the CIDI G-section (see appendix). The seven symptoms were Suspiciousness, Thought Interference, Delusions of Reference, Passivity Phenomena, Thought Reading, Hearing Voices, and Non-verbal Hallucinations. During the MACS interview, the interviewer first described the symptom to the subject in a general way, as if other people might suffer from that specific symptom too. The interviewer then asked the subject whether this symptom might have been present, again repeating the same description and asking follow-up questions to clarify if necessary. The subject was then asked to indicate on a seven-point Likert scale the degree of distress associated with the symptom. In two subjects MACS data were incomplete, which resulted in a final research population of eighty three subjects (see figure)

\section{Statisfical analysis}

Logistic regression was used to study the association between need for care status (defined as $1=$ need for care, $0=$ no need for care) and 7 psychotic symptom ratings assessed with the MACS. The 7 symptoms were "Thought Insertion/interference" $(n=13)$, "Suspiciousness" $(n=34)$, "Delusions of 
Reference" $(\mathrm{n}=16)$, "Thought reading/broadcasting"( $\mathrm{n}=20)$, "Passivity Phenomena" $(\mathrm{n}=8)$, "Hearing voices" $(\mathrm{n}=28)$, and "Non-verbal Hallucinations" $(n=62)$. All symptoms were defined as $1=$ present or $0=$ not present. Analyses were conducted separately for each of the 7 symptoms.

The following covariates were included as possible mediators of the associations between symptoms and need for care: i) distress associated with the psychotic symptom, rated on a seven-point Likert scale, ii) previous exposure to psychotic symptoms, defined as presence of any "true psychotic symptom" (i.e. CIDI rating " 5 ") assessed with the $\mathrm{CIDI}$ at baseline and/or Tl.

Figure 1. Flow diagram of study sample

\begin{tabular}{|c|c|c|c|c|}
\hline $\begin{array}{l}\text { No } \\
\text { previous } \\
\text { diagnosis } \\
\text { of } \\
\text { psychotic } \\
\text { discorder at }\end{array}$ & $\begin{array}{l}\text { Subjects } \\
\text { aligible for } \\
\text { interview } \\
\text { who had a } \\
\text { least one } \\
\text { psychotic }\end{array}$ & $\begin{array}{l}\text { Subjects } \\
\text { re- } \\
\text { intervie } \\
\text { wed by } \\
\text { using } \\
\text { SCID-1 }\end{array}$ & $\begin{array}{l}\text { Subjects } \\
\text { with one or } \\
\text { more } \\
\text { psychotic } \\
\text { symptoms } \\
\text { after re- }\end{array}$ & $\begin{array}{l}\text { No need for } \\
\text { care } \\
\text { dingnosis } \\
\mathrm{N}=59\end{array}$ \\
\hline$N=4722$ & symptom & $N=142$ & $\begin{array}{l}\text { interview } \\
N=83 \\
\text { MACS }\end{array}$ & $\begin{array}{l}\text { Neted lor } \\
\text { care } \\
\text { diagnosis }\end{array}$ \\
\hline & & & assessed & $N=24$ \\
\hline
\end{tabular}

\section{Results}

Out of 83 subjects in this sample with a CIDI re-interview rating of " 2 " or " 5 " on at least one psychotic symptom and a complete MACS interview, 24 (29\%) subjects had a need for care. The remaining $59(71 \%)$ subjects experienced one or more psychotic experiences without a need for care (figure 1). Hearing Voices $(\mathrm{OR}=7.43: 95 \% \mathrm{CI} 2.41-22.85)$, Non-verbal Hallucinations $(\mathrm{OR}=2.88$ : $95 \% \mathrm{Cl} 1.04-7.97)$ and Passivity Phenomena ( $\mathrm{OR}=15.8: 95 \% \mathrm{Cl} 3.85-64.8)$ were all strongly associated with need for care. The remaining four symptoms, Thought Interference $(\mathrm{OR}=1.28: 95 \% \mathrm{Cl} \quad 0.38-4.71)$, Suspiciousness $(\mathrm{OR}=1.05: 95 \% \mathrm{Cl} 0.38-2.89)$, Thought Reading ( $\mathrm{OR}=2.67: 95 \% \mathrm{Cl} 0.50-$ 14.27) and Delusions of Reference $(\mathrm{OR}=2.32$ : $95 \% \mathrm{Cl} 0.63-8.51)$, were not significantly associated with need for care.

In a second analysis, we investigated whether the association between the various psychotic experiences and need for care was driven by the experience of associated distress. 
Table 1. Associations between the various symptoms and need for care, and association after adjustnent for the mediating factors

\begin{tabular}{|c|c|c|c|c|c|c|c|}
\hline & $\begin{array}{l}\text { Suspictols } \\
\text { ness }\end{array}$ & $\begin{array}{l}\text { Thoughol } \\
\text { inturreterence }\end{array}$ & $\begin{array}{l}\text { Defasiang of } \\
\text { Reference }\end{array}$ & Grandiosiy & $\begin{array}{l}\text { Passsivily } \\
\text { phentomenuat }\end{array}$ & $\begin{array}{l}\text { Hearing } \\
\text { Voicess }\end{array}$ & $\begin{array}{l}\text { Other } \\
\text { Hallucinations }\end{array}$ \\
\hline $\begin{array}{l}\text { Oddsg } \\
\text { Matia. }\end{array}$ & OR $205 \%$ & $\begin{array}{l}\text { OR } \\
09 \% 6 \mathrm{Cl}\end{array}$ & $\begin{array}{l}\text { OR } \\
(95 \% \mathrm{MC})\end{array}$ & $\begin{array}{l}\mathrm{OR} \\
95 \mathrm{6 \textrm {Ch }}\end{array}$ & $\begin{array}{l}\text { OR } \\
(95 \% \mathrm{~cm})\end{array}$ & $\begin{array}{l}9 \mathrm{OR} \\
95 \% \mathrm{Cl}\end{array}$ & $\begin{array}{l}\mathrm{OR} \\
95 \% \mathrm{Cl}\end{array}$ \\
\hline $\begin{array}{l}\text { Need for } \\
\text { care }\end{array}$ & $\begin{array}{l}1.05 \\
(0.38 \times 2.899)\end{array}$ & $\begin{array}{l}1.28 \\
(0.34-4.71)\end{array}$ & $\begin{array}{l}2.32 \\
(0.63-8.31)\end{array}$ & $\begin{array}{l}2.67 \\
(0.50-1427)\end{array}$ & $\begin{array}{l}15.79 \\
(3.85-64.82)\end{array}$ & $\begin{array}{l}7.43 \\
(2.41-22.85)\end{array}$ & $\begin{array}{l}2.80 \\
(1.04 .7971\end{array}$ \\
\hline $\begin{array}{l}\text { adjusted hor } \\
\text { al } \\
\text { sympotortus }\end{array}$ & $\begin{array}{l}4.0 \\
(0.95-16.81)\end{array}$ & $\begin{array}{l}0.24 \\
(0.01 \times 4.06\end{array}$ & $\begin{array}{l}3.34 \\
(0.48-33.07)\end{array}$ & $\begin{array}{l}3.50 \\
(0,27 \times 45.43)\end{array}$ & $\begin{array}{l}39.9 \\
(3.43 \times 465.61)\end{array}$ & $\begin{array}{l}9.68 \\
(2.15 \times 43.67)\end{array}$ & $\begin{array}{l}2.45 \\
(0.57 \sim 10.25)\end{array}$ \\
\hline $\begin{array}{l}\text { adjusted for } \\
\text { distress }\end{array}$ & $\begin{array}{l}0.82 \\
(0.00 \% 7.488\end{array}$ & $\begin{array}{l}0.18 \\
(0.01-3.73)\end{array}$ & " & $\begin{array}{l}2.24 \\
(0.16-31.76)\end{array}$ & $\begin{array}{l}5.59 \\
(0.32 .99), 065\end{array}$ & $\begin{array}{l}5.49 \\
(1.22-24.7 \llbracket)\end{array}$ & $\begin{array}{l}1.12 \\
(0.28-4.42)\end{array}$ \\
\hline $\begin{array}{l}\text { ajusted for } \\
\text { previous } \\
\text { hustory of } \\
\text { psychatic } \\
\text { syemploms }\end{array}$ & $\begin{array}{l}1.10 \\
(0.39-3.13)\end{array}$ & $\begin{array}{l}0.97 \\
(0.24-3.88)\end{array}$ & $\begin{array}{l}3.27 \\
(0.83-12.86)\end{array}$ & $\begin{array}{l}3.21 \\
(0.5 \% \cdot 18.26)\end{array}$ & $\begin{array}{l}15.99 \\
(3.72-68.76)\end{array}$ & $\begin{array}{l}6.09 \\
(1.91-19.43)\end{array}$ & $\begin{array}{l}2.34 \\
(0.81-6.73)\end{array}$ \\
\hline
\end{tabular}

The distribution of the distress scores were skewed for some symptoms (table 2 ), as indicated by substantial differences between the mean and median distress scores: Delusions of Reference $($ mean $=2, \mathrm{Sd}=1.86$, median $=1$ ), Thought Reading $($ mean $=1.6, \mathrm{Sd}=1.05$, median $=1)$, Hearing Voices $($ mean $=2.04, \mathrm{Sd}$ 1.89 , median $=1$ ) and Non-verbal Hallucinations (mean $=2.1, \mathrm{Sd}=1.73$, median = 1). For other symptoms, no such differences between mean and median were apparent: Passivity Phenomena (mean $=3.38, \mathrm{Sd}=2.33$, median $=$ 3.5) Suspiciousness $($ mean $=4.56, \mathrm{Sd}=1.91$, median $=4.5$ ), Thought Interference $($ mean $=2.15, \mathrm{Sd}=1.72$, median $=2$ ). Only for Suspiciousness, Passivity Phenomena and Thought Interference did a majority of subjects report a distress score higher than one ("no distress"). For the remaining 4 psychotic experiences, the majority did not report any distress in relation to the psychotic experience. When distress was added into the equations, the positive association between need for care and 'Non-verbal Hallucinations' $(\mathrm{OR}=1.12: 95 \% \mathrm{Cl} 0.28$ - 4.42) and "Passivity Phenomena" $(\mathrm{OR}=5.59: 95 \% \mathrm{Cl} 0.32-99.06)$ was greatly reduced and not statistically significant. This indicated that the association between these two psychotic experiences and need for care was largely driven by the amount of distress associated with these experiences. The association between need for care and Hearing Voices, however, remained large and significant $(\mathrm{OR}=5.49: 95 \% \mathrm{Cl} 1.22-24.70)$.

In a third analysis, it was investigated whether the association between need for care and psychotic experiences was driven by previous exposure to psychotic symptoms. The associations between need for care and Hearing Voices $(\mathrm{OR}=6.09: 95 \% \mathrm{Cl} 1.91-19.43)$ and Passivity Phenomena $(\mathrm{OR}=15.99: 95 \% \mathrm{CI}$ $3.71-68.76$ ) remained largely unchanged when previous exposure to psychotic 
symptoms was added to the model. This indicated that the association between these experiences and need for care was not due to previous experience of psychosis. The parameter of Non-verbal Hallucinations also remained essentially unchanged although it became statistically imprecise (OR $=2.80$ : $95 \%$ CI $0.90-8.71)$.

Table 2. Number of observations and distress distribution frequency scores in percentages, mean and median scores per symptom.

\begin{tabular}{|c|c|c|c|c|c|c|c|c|}
\hline & $\begin{array}{l}\text { Suspicious } \\
\text { ness }\end{array}$ & $\begin{array}{l}\text { Thought } \\
\text { Inter } \\
\text { ference }\end{array}$ & $\begin{array}{l}\text { Delusions } \\
\text { of } \\
\text { Reference }\end{array}$ & $\begin{array}{l}\text { Thoughtht } \\
\text { Reading }\end{array}$ & $\begin{array}{l}\text { Passivity } \\
\text { Phenomena }\end{array}$ & $\begin{array}{l}\text { Hearing } \\
\text { Voices }\end{array}$ & $\begin{array}{l}\text { Other } \\
\text { Halluc: } \\
\text { nations }\end{array}$ & Total \\
\hline $\begin{array}{l}\text { Number of } \\
\text { observations }\end{array}$ & 34 & 13 & 16 & 20 & 8 & 28 & 62 & 181 \\
\hline $\begin{array}{l}\text { Distress: \% } \\
\text { of } 1 \text { scores }\end{array}$ & 5.88 & 46.15 & 75.00 & 65.00 & 37.50 & 67.68 & 58.06 & 50.28 \\
\hline $\begin{array}{l}\text { Distress: } \% \\
\text { of }>1 \\
\text { scores }\end{array}$ & 94.12 & 53.85 & 25.00 & 35.00 & 62.50 & 32.32 & 41.94 & 49.72 \\
\hline $\begin{array}{l}\text { Distress } \\
\text { Mean (Sd) }\end{array}$ & $\begin{array}{l}4.65 \\
(1.91)\end{array}$ & $\begin{array}{l}2.15 \\
(1.72)\end{array}$ & $\begin{array}{l}2 \\
(1.86)\end{array}$ & $\begin{array}{l}1.60 \\
(1.04)\end{array}$ & $\begin{array}{l}3.38 \\
(2.33)\end{array}$ & $\begin{array}{l}2.04 \\
(1.90)\end{array}$ & $\begin{array}{l}2.10 \\
(1.73)\end{array}$ & $\begin{array}{l}2.56 \\
(2.03)\end{array}$ \\
\hline $\begin{array}{l}\text { Distress } \\
\text { Median }\end{array}$ & 4.5 & 2 & 1 & 1 & 5 & 1 & $\mathbb{1}$ & 1 \\
\hline
\end{tabular}

* Distress score of "I" indicates no distress

\section{Discussion.}

This study investigated the associations between various positive psychotic experiences and need for care in the general population. The seven MACSdefined psychotic experiences showed varying patterns of associations with need for care. Hearing Voices, Non-verbal hallucinations and Passivity Phenomena were significantly associated with need for care, while the four remaining symptoms; Suspiciousness, Thought Insertion, Delusions of Reference and Thought Reading showed no association with need for care, although the associations were directionally similar.

Why are some experiences not associated with need for care?

Studies that examine the outcome of psychotic experiences in terms of need for care and factors mediating this outcome are rare. It has been reported that some psychotic experiences may be more strongly associated with need for care than others, and psychotic experiences such as bizarre and paranoid delusions may have a poorer prognosis than others (Goldman, Hien, Haas, Sweeney, \& Frances, 1992; Nakaya, Kusumoto, Okada, \& Ohmori, 2002; Opjordsmoen \& Retterstol, 1991). Our findings suggest that hallucinatory experiences" and 
Passivity Phenomena are more strongly associated with need for care than others. Previous work has demonstrated that many psychotic experiences occur quite frequently in the general population(van Os, Hanssen ef al., 2000; van Os, Verdoux, Maurice-Tison et al., 1999), suggesting that absence of an association with need for care is in itself not a surprising finding. All psychotic experiences showed positive associations with needs for care, but onlly for hallucinatory experiences and Passivity Phenomena were significant. Hallucinatory experiences and passivity phenomena have in common that they are, contrary to delusions, experiences rather than ideas. One explanation, therefore, is that psychosis which is manifested at the level of experience may have a greater impact on the individual than psychosis manifested at the level of delusional ideation.

\section{Mediating role of distress}

In a previous general population study, patient status versus non-patient status in subjects with delusions was mediated by distress, preoccupation and conviction on the one hanc, and more indirect factors such as self-esteem, depression and anxiety on the other (Freeman et al., 2001; E. R. Peters et al., 1999). In the current study, the association between Passivity Phenomena and Non-verbal Hallucinations on the one hand and need for care on the other was greatly reduced after adjustment for distress, similarly indicating an important mediating role of distress. However, the cross-sectional association between Hearing Voices and need for care was not mediated by distress. Two explanations may be proposed. First, it may be that experience of Hearing Voices, even in individuals with need for care, are associated with little distress (Carter et al., 1996; Honig et al., 1998). Second, other, indirect factors may account for the lack of mediation by distress and may do so more with Hearing Voices than with other psychotic experiences. Previous studies have shown that Hearing Voices are not per se a sign of disorder (Asaad \& Shapiro, 1986; Romme, 1998; Romme \& Escher, 1989), but that need for care may arise as a consequence of a perceived "power" imbalance between the individual and the intrusive experience. (Birchwood, Meaden et al,, 2000; Morrison \& Baker, 2000). Indirect mediating factors, such as the level of co-morbid depression and delusional ideation may also play a crucial role in the outcome of voices (Krabbendam, Hanssen et al., 2003; Morrison \& Baker, 2000).

Other indirect mediating factors, such as neuroticism, low level of mastery and low self-esteem, have been reported to be associated with psychotic symptom formation and maintenance (Freeman \& Garety, 2003; Lysaker, Wilt, PlascakHallberg, Brenner, \& Clements, 2003; van Os, Park, \& Jones, 2001). The level of functional coping is another indirect factor related with psychosis formation and maintenance (Bak, Myin-Germeys et al., 2003). 
Mediating role of previous exposure to psychosis

Adjustment for previous exposure to psychosis revealed that associations between Hearing Voices, Passivity Phenomena, and Non-verbal Hallucinations on the one hand and need for care on the other remained essentially unchanged. As previous exposure to psychosis can be equated with longer duration of psychosis these fundings suggest that early psychosis with a longer prior duration does not in itself predict poorer outcome. Longer duration of psychosis has to date invariably been examined in individuals with established psychotic disorder who had already come to the attention of psychiatric services. The current study included individuals with psychosis independent of service contact and in this sample longer existence of psychosis did not predict poorer outcome in terms of need for care. Assessment of prior duration of psychosis in relation to outcome in a selected sample of service attendees may therefore give rise to confounds associated with both longer duration of "untreated" psychosis and poorer outcome such as high levels of negative symptoms and developmental cognitive delays.

\section{Limitations}

The results of this study should be interpreted in the light of several methodological limitations. The data were cross-sectional, so that no firm conclusions can be drawn about the direction of effects in associations between presence of psychosis, distress and need for care. Self-reported distress related to symptoms is a dynamic entity with within- and between day fluctuations that cannot be captured by a cross-sectional instrument (Delespaul, 1995; Sayer et al., 2000).

The interview was not ideal as confirmation assessment of CIDI-defined symptoms and the assessments of distress were carried out over the telephone, thus missing non-verbal expressions. Nevertheless, earlier studies using this method reported good reliability (Kobak, Taylor, Dottl, Greist, Jefferson, Burroughs, Katzelnick et al., 1997; Kobak, Taylor, Dottl, Greist, Jefferson, Burroughs, Mantle et al., 1997). 


\section{References.}

Asaad, G., \& Shapiro, B. (1986). Hallucinations: theoretical and clinical overview. Am J Psychiatry, 143(9), 1088-1097.

Bak, M., Myin-Germeys, I, Hanssen, M., Bijl, R., Vollebergh, W., Delespaul, P., \& van $O \mathrm{~S}_{2}$ J. (2003). When does experience of psychosis result in a need for care? A prospective general population study. Schizophr Bull, 29(2), 349-358.

Bak, M., Van Der Spil, F., Gunther, N., Radstake, S., Delespaul, P., \& Van Os, J. (2001a). Maastricht Assessment of Coping Strategies (MACS-1): a brief instrument to assess coping with psychotic symptoms. Acta Psychiatr Scand, $103(6), 453-459$.

Bak, M., Van Der Spil, F., Gunther, N., Radstake, S., Delespaul, P., \& Van Os, J. (200 lb). MACS-II: does coping enhance subjective control over psychotic symptoms? Acta Psychiatr Scand, 103(6), 460-464.

Bentall, R. (1990). Reconstructing Schizophrenia. London: Routledge.

Bentall, R. P., \& Slade, P. D. (1.985). Reality testing and auditory hallucinations: a signal detection analysis. Br J Clin Psychol, 24(Pt 3), 159-169.

Birchwood, M., Meaden, A., Trower, P., Gilbert, P., \& Plaistow, J. (2000). The power and omnipotence of voices: subordination and entrapment by voices and significant others. Psychol Med, 30(2), 337-344.

Carter, D. M., Mackinnon, A., \& Copolov, D. L. (1996). Patients" strategies for coping with auditory hallucinations. J Nerv Ment Dis, 184(3), 159-164.

Chapman, L. J., Chapman, J. P., Kwapil, T. R., Eckblad, M., \& Zinser, M. C. (1994). Putatively psychosis-prone subjects 10 years later. J Abnorm Psychol, I03(2), $171-183$.

Claridge, G. (1994). Single indicator of risk for schizophrenia: probable fact or likely myth? Schizophs Bull, 20(1), 151-168.

Cooper, L., Peters, L., \& Andrews, G. (1998). Validity of the Composite International Diagnostic Interview (CIDI) psychosis module in a psychiatric setting. $J$ Psychiatr Res, 32(6), 361-368.

Costello, C. G. (1992). Research on symptoms wersus research on syndromes. Arguments in favour of allocating more research time to the study of symptoms. Br J Psychiatry, 160, 304-308.

Delespaul, P. A. E. G. (1995). Assessing Schizophrenia in Daily Life: The Experience Sampling Method. Unpublished PhD Thesis, Maastricht University, Maastricht.

Eaton, W. W., Romanoski, A., Anthony, J. C., \& Nestadt, G. (1991). Screening for psychosis in the general population with a self-report interview. JNerv Ment Dis, $179(11), 689-693$.

Freeman, D., Garety, P. A. (2003). Connecting neurosis and psychosis: the direct influence of emotion on delusions and hallucinations. Behav Res Ther, 4/(8), 923-947.

Freeman, D., Garety, P. A., \& Kuipers, E. (2001). Persecutory delusions: developing the understanding of belief maintenance and emotional distress. Psychol Med, $3 /(7), 1293-1306$.

Garety, P. A., Kuipers, E., Fowler, D., Freeman, D., \& Bebbington, P. E. (2001). A cognitive model of the positive symptoms of psychosis. Psychol Med, $3 I(2)$, $189-195$. 
Goldman, D., Hien, D. A., Haas, G. L., Sweeney, J. A., \& Frances, A. J. (1992). Bizarre delusions and DSM-III-R schizophrenia. Am I Psychiatry. 149(4), 494-499.

Hanssen, M., Bak M., Bijl, R. V., Vollebergh, W., \& Os, J. v. (2002). Do self-reported psychotic experiences predict future clinical need? submitted.

Helzer, J. E., Robins, L. N., McEvoy, L. T', Spitznagel, E. L., Stoltzman, R. K., Farmer, A., \& Brockington, I. F. (1985). A comparison of clinical and diagnostic interview schedule diagnoses. Physician reexamination of lay-interviewed cases in the general population. Arch Gen Psychiatry, 42(7),657-666.

Honig, A., Romme, M. A., Ensink, B. J., Escher, S. D., Pennings, M. H., \& deVries, M. W. (1998). Auditory hallucinations: a comparison between patients and nonpatients. J Nerv Ment Dis, 186(10), 646-651.

Johns, L. C., Nazroo, J. Y., Bebbington, P., \& Kuipers, E. (1998). Occurence of hallucinations in a community sample. Schizophr Res $29,23$.

Johns, L. C., \& van Os, J. (2001). The contimuity of psychotic experiences in the general population. Clin Psychol Rev, 2I(8), 1125-1141.

Kobak, K. A., Taylor, L. H., Dottl, S. L., Greist, J. H., Jefferson, J. W., Burroughs, D., Katzelnick, D. J., \& Mandell, M. (1997), Computerized screening for psychiatric disorders in an outpatient community mental health clinic. Psychiatr Serv, 48(8), 1048-1057.

Kobak, K. A., Taylor, L. H., Dott, S. L., Greist, J. H., Jefferson, J. W., Burroughs, D., Mantle, J. M., Katzelnick, D. J., Norton, R., Henk, H. J., \& Serlin, R. C. (1997). A computer-administered telephone interview to identify mental disorders. Jama, 278(11), 905-910.

Krabbendam, L., Hanssen, M., Bak, M., \& Van Os, J. (2003). Psychotic features in the general population. Risk for what? In W. Gattaz \& H. Häfner (Eds.). In search for the causes of schizophrenia. Vol. in press.

Krabbendam, L., Janssen, 1., Bak, M., Bijl, R. V., de, G. R., \& van, O. J. (2002). Neuroticism and low sell-esteem as risk factors for psychosis. Soc Pychiatry Psychiatr Epidemiol, 37(1), 1-6.

Kwapil, T. R., Miller, M. B., Zinser, M. C., Chapman, J., \& Chapman, L. J. (1997). Magical ideation and social anhedonia as predictors of psychosis proneness: a partial replication. of Abnorm Psychol, $106(3), 491-495$

Lukof, D., Liberman, R. P., \& Nuechterlein, K. H. (1986). Symptom monitoring in the rehabilitation of schizophrenic patients. Schizophr Bull, 12(4), 578-602.

Lysaker, P. H., Wilt, M. A., Plascak-Hallberg, C. D., Brenner, C. A., \& Clements, C. A. (2003). Personality dimensions in schizophrenia: associations with symptoms and coping, J Nerv Men Dis, 19/(2), 80-86.

McGlashan, T. H. (1999). Duration of untreated psychosis in first-episode schizophrenia: marker or determinant of course? Biol Psychiary, 46(7), 899907.

Mojtabai. R., \& Rieder, R. O. (1998). Limitations of the symptom-oriented approach to psychatric research. Br.J Psychatry, 173, $198-202$.

Morrison, A. P., \& Baker, C. A. (2000). Intrusive thoughts and auditory hallucinations: a comparative study of intrusions in psychosis. Behow Res Ther. 38(11), 10971106.

Nakaya, M. Kusumoto, K., Okada, T., \& Ohmori, K. (2002). Bizarre delusions and DSM-IV schizophrenia. Psychiany Clin Nenrosci, 56(4), $391-395$. 
Opjordsmoen, $S_{\text {. \& }}$ Reterstol, N. (1991). Delusional disorder: the predictive validity of the concept. Acta Psychiart Scand, 84(3), $250-254$

Peters, E., Day, S. Mckenna, J., \& Orbach, G. (1999). Delusional ideation in religious and psychotic populations. Br J Clin Psychol, 38(Pt 1), 83-96.

Peters, E. R. Joseph., S. A., \& Garety, P. A. (1999). Measurement of delusional ideation in the nomal population: introducing the PDI (Peters et al. Delusions Inventory). Schizophr Bull, 25(3), 553-576.

Pincus, H. A., Zarin, D. A., \& First, M. (1998). "Clinical significance" and DSM-IV. Arch Gen Psychiatry, 55(12), 1145; discussion 1147-1148.

Poulton, R., Caspi, A., Moffitt, T. E., Cannon, M., Murray, R., \& Harrington, H. (2000). Children's self-reported psychotic symptoms and adult schizophreniform disorder: a 15 year longindinal study. Arch Gen Psychiatry, 57(11), 10531058.

Robins, L. N., Helzer, J. E., Croughan, J, \& Ratcliff, K. S. (1981). National Institute of Mentall Health Diagnostic lnterview Schedule. Its history, characteristics, and validity. Arch Gen Psychiarry $38(4), 381-389$.

Romme, M. (1998). Listening to the voice hearers. J Psychosoc Nurs Ment Heaith Serv, $36(9), 40-44$.

Romme, M. A., \& Escher, A. D. (1989). Hearing voices. Schizophr Bull, 15(2), 209 216.

Sayer, J., Ritter, S., \& Goumay, K. (2000). Beliefs about voices and their effects on coping strategies. $J$ Adv $N u r s, 3 /(5), 1199-1205$.

Slade, M. (1996). Assessing the needs of the severely mentally ill: cultural and professional differences. Int J Soc Psychiatry, 42(1), $1-9$.

Smeets, R. M. W., \& Dingemans, P. M. A. J. (1993). Composite Intemational Diagnostic Interview (CIDD), version l.I (in Dutch). Amsterdam/Geneva: World Health Organization.

Spitzer, R. L. ( 1998$)$. Diagnosis and need for treatment are not the same. Arch Gen Prychiatry, 55(2), 120.

Spitzer, R. L.., Willams, J. B., Gibbon, M., \& liirst, M. B. (1992). The Structured Clinical Interview for DSM-III-R (SCID). I: History, rationale, and description. Arch Gen Prychamy, 49(8), 624-629.

Strauss, J. S. (1969). Hallucinations and delusionss as points on continua function. Rating scale evidence. Arch Gen Psychiatry, 21(5), 581-586.

Tien, A. Y. (1991). Distributions of hallucinations in the population. Soc Psychiatry Pisychiar Epidemiol, 26(6), 287-292.

Ustun, T. B., Chatterji, S., \& Rehm, J. (1998). Limitations of diagnostic paradigm: it doesn't explain "need". Arch Gen Psychiaty. 55(12), 1145-1146; discussion $1147-1148$.

van Os, J., Hanssen, M., Bijl, R. V., \& Ravelli, A. (2000). Strauss (1969) revisited: a psychosis continuum in the general population? Schizophr Res, 45(1-2), 11-20.

Van Os, J., Hanssen, M., Bijl, R. V., \& Vollebergh, W. (2001). Prevalence of psychotic disorder and community level of psychotic symptoms: an urban-rural comparison. Arch Gen Psychiatry, 58(7), 663-668.

van Os, J. Park, S. B., \& Jones, P. B. (2001). Neuroticism, life events and mental health: evidence for person- enviromment correlation. Br J Psychatry Suppl, $40 . \mathrm{s} 72-77$. 
van Os, J., Verdoux, H., Maurice-Tison, S., Gay, B., Liraud, F., Salamon, R., \& Bourgeois, M. (1999). Self-reported psychosis-like symptoms and the contimum of psychosis. Soc Psychiatry Psychiatr Epidemiol, 34(9), 459-463.

Verdoux, H., Bergey, C., Assens, F., Abalan, F., Gonzales, B., Pauillac, P., Fournet, O., Liraud, F., Beaussier, J. P., Gaussares, C., Etchegarav, B., Bourgeois, M., \& Van Os, J. (1998). Prediction of duration of psychosis before admission. European Psychiatry, 13(7), 346-352.

Verdoux, H., Maurice-Tison, S., Gay, B., Van Os, J., Salamon, R., \& Bourgeois, M. L. (1998). A survey of delusional ideation in primary-care patients. Psychol Med, $28(1), 127-134$.

Wing, J. K., Cooper, J. E., \& Sartorius, N. (1974). The measurement and classificatoin of psychiatric symptoms. London: Cambridge University Press. 


\section{The seven MACS-defined items: description of symptoms, subjective recognition of presence, level of distress, coping assessment and perceived control.}

\section{Suspiciousness}

Somo people are convinced that other people want to ham them, that there is a conspiracy against them or that others are out to get them.

Regarding the conviction that other people want to ham you or that there is a conspiracy against you, I would like to ask you the following questions.

Have you had these experiences in the last week/month?

$>$ How distressing are these experiences?

$>$ In what ways do you try to influence or change these experiences?

- Can you tell me how much control you have over these experiences?

\section{Thought interference}

Some people have the experience that the thoughts in their head are not their own, or that their thoughts are being broadcasted so that others can pick them up or hear them, or that their thoughts are being taken away from their head.

Regarding the experience that the thoughts in your head are not your own, or that your thoughts are being broadcasted so that others can pick them up or hear them, or that your thoughts are being taken away from your head, I would like to ask you the following questions.

Have you had these experiences in the last week/month?

$>$ How distressing are these experiences?

In what ways do you try to influence or change these experiences?

- Can you tell me how much control you have over these experiences?

\section{Passivity phenomena}

Some people have the experience that what they feel, think or do is under the control of some outside force or agency that makes them feel, think or do something. "They feel controlled, and have the experience that it is actually not they who feel, think or do something.

Regarding the experience that that what you feel, think or do is under the control of some outside force or agency that makes you feel, think or do something, I would like to ask you the following questions.

- Have you had these experiences in the last week/month?

$>$ How distressing are these experiences?

$>$ In what ways do you try to influence or change these experiences?

$>$ Can you tell me how much control you have over these experiences? 


\section{Delusions of reference}

Some people have the experience that what happens around them, or what they see on TV or hear on the radio actually refers to themselves, in that it has some special personal significance or personal meaning. They may have the reeling that people in the street are talking about them, or laughing at them.

Regarding the experience that that what happens around you, or what you see on TV or hear on the radio, actually refers to yourself, in that it has some special personal significance or personal meaning, or the experience that people in the street are talking about you, or laughing at you, I would like to ask you the following questions.

Have you had these experiences last montli?

How distressing are these experiences?

In what ways do you try to influence or change these experiences?

Can you tell me how much control you have over these experiences?

\section{Grandiosity}

Some people are convinced they have special powers or abilities, that they have a special mission or merits because of their extraordinary talents or healing powers. They may be convinced that they are extremely famous, rich, noble or very important to society or God.

Regarding the experience or the idea you have special abilities or powers or extraordinary talents that set you apart from others, I would like to ask you the following questions.

Have you had these experiences in the last month?

How distressing are these experiences?

In what ways do you try to influence or change these experiences?

$>$ Can you tell me how much control you have over these experiences?

\section{Hearing voices}

Some people hear voices that their family and friends say they can't hear. The people themselves, however, actually hear these voices speaking to them, commenting on themor criticizing them.

Regarding the experience of hearing voices talking to you or about you that others say they can't hear, I would like to ask you the following questions.

Have you had these experiences in the last week/month?

How distressing are these experiences?

- In what ways do you try to influence or change these experiences?

Can you tell me how much control you have over these experiences? 


\section{Non-verbal hallucinatory experiences}

Sometimes people see, smell, taste or feel things that their family or friends say don't exist. For the people themselves, however, these experiences are real.

Regarding the experience you see, smell, taste or feel things that other people don't experience, I would like to ask you the following questions.

- Have you had these experiences in the last week/month?

How distressing are these experiences?

$>$ In what ways do you try to influence or change these experiences?

- Can you tell me how much control you have over these experiences? 


\section{Chapter 8}

Coping matters in psychosis 
Severe mental illness in general and psychotic illness in particular is difficult to treat and poses an important social and economic burden. Therefore, the idea to prevent the development of an illness, that is distressful and results in a need for care, is appealing. Despite a large body of knowledge on psychotic syndromes that is observed in mental health care, we still do not know much about psychotic experiences outside mental health care facilities. Subjects who report psychotic experiences may not have reached the level of clear-cut symptoms or have experiences that do not result in a need for care. However, a more profound understanding of development of psychotic experiences (but not illness) in the general population is important for prediction and possible prevention of the expression of full-blown symptoms, psychotic illnesses and the pathway through care. The studies presented in this dissertation explore the association between psychotic experiences and emergence of need for care. What are the characteristics that lead to a need for care in subjects in the early throws of psychotic experiences in the general population, the majority of whom never will need care? Why do people, who share the same phenomenology, differ in their need for care? What is the role of symptomassociated distress and symptom associated coping strategies? This dissertation explores the association between psychotic phenomenology, distress, coping and outcome in terms of need for care.

\section{Predictors of psychotic illness and need for care}

In the current diagnostic classification systems psychiatric disorders are considered present or absent (American Psychiatric Association, 1994). However, in "nature" such clear dichotomies do not exist (Khaw, 2001). Psychiatric disorders in general and psychotic disorders in particular are better conceptualised as distributed along a continuum. Arguments can be found in the observation that in the general population many more subjects have psychotic experiences than there are patients with psychosis known in the mental health system (Johns \& van Os, 2001; van Os, Hanssen et al., 2001). A real dichotomy would imply that the differences are qualitative, more than quantitative and that subjects with psychotic features in the general population are different, not associated with the clinical sample and not at risk. This is not the case (Delespaul \& van Os, 2003). There is a need for instruments that assess the continuum of psychosis including sub-threshold psychotic experiences (Chapman et al., 1994; Miller et al., 2002; Poulton et al., 2000) to explore the conditions that are conducive to the development of need for care (Brugha, 2002).

\section{General population data}

In a first study, the prevalence of psychotic experiences in the general population and its association to illness expression was assessed using data from 
the Dutch NEMESIS study - a large general population co-morbidity cohort. The main diagnostic instrument in this study is the Composite International Diagnostic Interview (CIDI). Data show that $17.5 \%$ of the subjects have at least one psychotic experience, but only $2.1 \%$ have a psychotic disorder (van $\mathrm{Os}$, Hanssen et al., 2000).

What are the characteristics of psychotic experiences that are part of a diagnosis and a need for care will grow over time? The CIDI is a self-assessment instrument, because trained lay interviewers collect the responses of the subjects. They do not make clinical evaluations. The reliability of self-report instruments is debated. Responses may be subject to momentary mood effects (Moum, 1988), "yea saying and nay saying" (Gove \& Geerken, 1977; Linden, Paulhus, \& Dobson, 1986), and social desirability (Ross \& Mirowsky, 1984). These are more pronounced when the self-reports are collected in an interview (Riessman, 1979). The weaknesses of self-reports affect assessments of psychotic experiences by misreporting occurrence and severity as well as the quality of the abnormal experiences (Danion, Gokalsing, Robert, MassinKrauss, \& Bacon, 2001; de Vries \& Delespaul, 1989; Liddle \& Barnes, 1988; McGorry \& McConville, 1999). Therefore, it seems necessary to crosscheck the CIDI self-reports by a clinician. The question is whether only clinicianconfirmed self-reported psychotic experiences predict future illness status and need for care.

\section{True clinician-confirmed symptoms or psychotic-like self-reports}

Subjects of the NEMESIS study were reassessed over three years with the CIDI. Subjects with a DSM-III-R diagnosis of psychosis at baseline were excluded. Subjects who developed a DSM-III-R psychotic disorder over time were incident cases. As expected, clinician-confirmed psychotic experiences (outside illness) at baseline were likely to have a psychotic disorder and need for care at follow-up. However, also unconfirmed self-reported psychotic experiences were associated with illness status and need for care. Clinicians, therefore, unjustly rejected subtle presentations of psychotic experiences as irrelevant (Chapter 5).

\section{Association of specific positive symptoms and need for care}

We found no association with thought interference, suspiciousness, thought reading and delusions of reference with need for care. In contrast, hearing voices, non-verbal hallucinations and passivity phenomena were associated with need for care. Previous studies have found that the level of distress mediated this association (Claridge et al., 1996; van Os, Verdouix, Bijl R.V. et al., 1999). After controlling for distress, the association between non-verbal hallucinations and passivity phenomena and need for care was not significant anymore. Hearing voices remained independently associated with need for care, even 
though most subjects who experienced voices did not experience distress (chapter 7 ).

\section{Coping as a mediating variable}

Current research shows that the emotional processes associated with the occurrence and maintenance of acoustic hallucinations are based on the appraisal of perceptions as threatening (Escher, Romme, Buiks, Delespaul, \& van Os, 2002; Escher, Romme, Buiks, Delespaul, \& Van Os, 2002). The origin is attributed to sources alien to the person. The anomalous experiences in psychosis-prone subjects precede this inner-outer confusion (Fowler, 2000). It may be a result of cognitive problems in self-monitoring or other informationprocessing deficits (Blackwood, Howard, Bentall, \& Murray, 2001). It may also result from emotional disturbances (Garety et al., 2001). These observations are reported in subjects with a diagnosis of schizophrenia, independent of the phase of illness (Birchwood, 2003; Morrison \& Baker, 2000). Subjects who hear voices in mental health treatment often report negative content and low selfesteem, reflecting presence of distress (Close \& Garety, 1998; Honig et al., 1998). The experience of distress in psychotic experiences seems a mediator for need for care (chapter 7), which is further increased in those subjects with hallucinations and co-morbid delusional ideations (Krabbendam, MyinGermeys, Hanssen, Bijl R.V. et al., 2003). Anxiety or distress alter the cognitive processing of individual psychotic experiences and therefore are conducive to maintaining psychotic beliefs (Freeman et al., 2001). Thus, distress is the result of psychotic experiences but also causes them (Freeman et al., 2001; Freeman, Garety, Kuipers, Fowler, \& Bebbington, 2002).

Anxiety, which may be regarded as an important feature of distress, occurs as the resultant of threat beliefs (Chadwick \& Birchwood, 1994), whereas depression is associated with negative beliefs about the power of the persecutors (Trower \& Chadwick, 1995). These psychological elaborations of experiences lie at the heart of the cognitive model of psychosis. Other factors such as cannabis misuse, urban environment or experiences of discrimination or trauma may play an additional mediating role in these distress-related negative appraisals and the resulting need for care (Janssen et al., 2003; Krabbendam, Myin-Germeys, Hanssen, de Graaf et al., 2003; van Os et al., 2002; van Os, Hanssen, Bak, Bijl, \& Vollebergh, 2003). In contrast, the presence of voices is not necessarily associated with distress and need for care in the general population (Romme \& Escher, 1994). As has been discussed, several factors mediate need for care. We will argue below that the level of functional of coping is another important factor, and explain why voice hearers without distress develop need for care. 


\section{Factors altering the experience of distress and influencing the pathways to need for care}

Psychosis-prone subjects are reported to be more sensitive to distress because they are more vulnerable to stress and may cope inadequately. The Mastricht Assessment of Coping Strategies (MACS) is a new method for assessing coping in subjects suffering from psychosis (Chapter 2). The MACS is based on concepts derived from the transactional coping model (Lazarus \& Folkman, 1984) and defines coping as: all the cognitive and behavioural conscious reactions that are used to adjust experienced distress. The MACS attempts to integrate aspects of theory pertaining to the cognitive model of psychosis on the one hand (Garety et al., 2001) and the transactional model of coping on the other. It assesses coping strategies associated with distress in the context of a single psychotic experience. Coping strategies are divided in five categories defined by Carr (1988): i) Behaviour control, ii) Socialisation, iii) Cognitive control, iv) Medical care and v) Symptomatic behaviour. In addition, the level of perceived control is included as a measurement of coping efficacy (Skinner, 1995).

The MACS is a valid instrument for coping assessment per symptom (Chapter 3). The self-report assessment used by the MACS is feasible and yields reliable reports of distress, perceived control and specific coping strategies. This was demonstrated in a group of subjects with a diagnosis of schizophrenia according DSM-IV (American Psychiatric Association, 1994). Depressive symptoms generated the highest number of coping strategies, followed by positive psychotic experiences (Carr, 1988; Middelboe \& Mortensen, 1997). No analyses of concurrent validity of MACS were carried out because other coping scales are not designed to assess coping at the level of experiences or symptoms.

\section{Coping Efficacy}

A positive association was found between active problem solving strategies and perceived control in subjects with a diagnosis of schizophrenia. Symptomatio coping behaviour has a negative association with perceived control (Carr, 1988; Middelboe \& Mortensen, 1997). No significant associations with perceived control were found for the three remaining coping domains. Parallels exist with other studies, in which problem solving was also reported as the most effective coping strategy (Takai et al., 1990; Tarrier, 1992). Passive or avoidant coping strategies were less effective and they were associated with increased distress and decreased general functioning. The negative direction of the avoidant strategies is in agreement with general reported and accepted results in coping research.

Unpublished data of the five symptom dimensions of the MACS show that different symptoms yield different numbers of coping strategies (Huistra, 2003). Depressive symptoms generate more active problem solving strategies, whereas 
positive symptoms generate predominantly active problem avoiding strategies. This is a replication of earlier work (Carr, 1988; Middelboe \& Mortensen, 1997). Compared with active problem solving, passive illness behaviour and passive problem avoiding are used significantly less in the depressive, negative and cognitive domains of symptomatology. The level of perceived control per symptom dimension does not differ significantly per coping type. In negative symptoms, active problem avoiding is associated to a lesser degree with perceived control than active problem solving. The number of subjects and coping strategies is rather small, which indicates that the results need to be interpreted with caution.

The difference of need for care between the various symptoms as described in chapter 7 , may be explained by differences in coping. Unpublished data show that two thirds of the Voice Hearers use symptomatic coping, which is associated with need for care. The other experiences show a more variable distribution of coping strategies.

\section{The main conclusions of these studies are:}

- Associations between psychotic experiences and need for care in a general population sample are mediated by distress and previous exposure to psychotic experiences, with the exception of Hearing Voices. Models of onset of psychosis need to take type and context of the psychotic experience into account (chapter 7 ).

- Traditional clinical evaluation of self-reported psychotic experiences is not effective in predicting future psychotic disorder in a general population sample. Relevant additional information is found in selfreported sub-clinical experiences. These should supplement clinicianassessed psychotic experiences in risk assessment (chapter 5).

- The MACS appears to be a reliable and valid instrument to assess coping in association with subjective distress at symptom level and to assess perceptions of control over psychotic experiences (chapter 3).

- Active problem solving has a positive association with perceived control whereas symptomatic behaviour has a negative association with perceived control (chapter 4 and 6 ).

- Qualitative differences in self-initiated coping, such as active problem solving versus symptomatic behaviour, modifies the risk for need for care and subsequent "patient" status in those who develop psychotic experiences in the general population (chapter 6).

\section{General discussion}

As suggested in our findings, not only psychiatric symptoms per se, but allso concurrent distress predicts clinical course and responsiveness to specific treatments (Regier, 2000). Distress experiences due to hallucinations or delusions differentiate patients from non-patients in the general population 
(Hanssen et al., 2003; E. Peters et al., 1999; Stefanis et al., 2002). Therefore, assessing emotional disturbances is important (Birchwood, 2003). Several factors mediate distress experiences. Neuroticism is a personality trait for anxiety proneness and autonomic lability (Ormel, Stewart, \& Sanderman, 1989). It is associated with psychosis independent from depression (Berenbaum \& Fujita, 1994; Gurrera, Nestor, \& O'Donnell, 2000; van Os, Park et al., 2001). Self-esteem is also relevant. It is associated with severity of the psychotic disorder in the general population (Brekke, Levin, Wolkon, Sobel, \& Slade, 1993; Hansson et al., 1999; Ritsner, Kurs et al., 2003) and with long term hospitalisation in patients with a diagnosis of schizophrenia (Close \& Garety, 1998). Neuroticism and low self-esteem are risk factors for the formation of psychosis-like symptoms in the general population, although the former has a stronger independent effect than the latter (Krabbendam et al., 2002). Both are associated with low levels of control and mastery and negatively affect subjective sense of well-being (Folkman, Lazarus, Gruen, \& DeLongis, 1986; Hansson et al., 1999). Subjects with a sense of mastery, low neuroticism and high self-esteem apply more effective coping strategies (Andres et al., 2000; Folkman \& Lazarus, 1988; Folkman \& Moskowitz, 2000; Jenner \& van de Willige, 2001; Skinner, 1996).

\section{Early intervention and coping}

Early recognition of symptoms at several levels may decrease duration of untreated psychosis (DUP) (Larsen et al., 2001). The study of paths leading to the development of distress and full-blown disorder and concurrent need for care can help to design preventive interventions. Considering the huge impact of schizophrenia these strategies are in dire need of development. Unfortunately, moving from clinical cases to general population detection schemes is often problematic. Due to the low prevalence of syndromes in the general population, the risk of false positive diagnosis and unnecessary treatment is high. This study has demonstrated that clinicians, who make assessments in the general population, disregard subjective reports of psychotic experiences that values the prediction of future need for care. Myin-Germeys and colleagues (MyinGermeys et al., 2000) describe the difference between externally observable and inner emotions in subjects suffering from schizophrenia. These emotions correlate with variation in presence and intensity of psychiatric symptoms (Delespaul, deVries, \& van Os, 2002). Therefore, distress is often not recognized. Missing these symptoms can lead to postponed treatment (Leon et al., 1997) and carries the risk of making treatment success less likely.

It is important to assess distress and the activation of coping strategies as well as their success in alleviating distress. Specific coping strategies, such as problem solving strategies or integration, reduce distress (Breier \& Strauss, 1983; Brenner et al., 1987; Dittmann \& Schuttler, 1990) and are associated with positive outcome, while 'sealing over" or passive and avoidant coping strategies 
are associated with negative prognosis (Jackson, Tait, Birchwood, \& Trower, 2002; McGlashan, 1975; Soskis \& Bowers, 1969). Can subjects suffering from schizophrenia learn more effective coping strategies? Several coping training programs show promising results (Andres et al., 2000; Schaub, Andres, Brenner, \& Donzel, 1997; Wykes et al., 1999). These programs promote the use of the most effective coping strategies (Böker et al., 1989; Hodel \& Brenner, 1996; Tarrier, 1992; Tarrier et al., 1993; Wiedl, 1997). The most promising programs combine cognitive behavioural therapy (CBT) with coping training (Jenner \& van de Willige, 2001; Jenner et al., 1998; Larsen, Bechdolf, \& Birchwood, 2003; Leclerc et al., 2000).

Coping assessment and therapy are part of first onset prevention programs. The Early Psychosis Prevention and intervention Programme (EPPIC, (Melbourne, Australia Herrmann-Doig, Maude, \& Edwards, 2003) or the Psychological First-episode Intervention Program (Tübingen, Germany Klingberg, Bucgkremer, \& Gaebel, 2002) use coping skills training.

\section{Future directions}

The present studies provide new insight in the association between psychotic experiences, distress, need for care and the mediating role of coping. Further prospective work will help to further clarify the pathway from psychotic experiences to a disorder that needs care. We will further elucidate the relevant parameters to optimise the design and the timing of appropriate interventions.

The MACS calls for some critique, because the assessment of coping is based on strategies subjects tell they use to minimize distress. It is unclear if these strategies are actually used and if the subjects' appreciation of their efficacy is adequate. Other critical issues are not unfamiliar to the bulk of the coping literature. A lot is known about stress (Lazarus, 1993), but not very much about coping (Folkman \& Greer, 2000). It is assumed that coping helps to alleviate stress, but evidence remains scarce (Coyne \& Racioppo, 2000; Snyder \& Dinoff, 1999). Finally, the MACS assumes that coping assessment is stable within a certain timeframe, while coping often is a dynamic process that changes over time and by situation (Folkman \& Moskowitz, 2000; Lazarus, 2000; Lazarus \& Folkman, 1984; Tennen et al., 2000). More knowledge about these issues is important to optimise treatments or treatment options.

Some of these remarks have inspired a study that has been initiated recently. To this end, the Experience Sampling Method (ESM) is being used (Delespaul, 1995). During six days at ten random moments subjects fill in a questionnaire. It assesses current mental state including psychotic experiences, and circumstantial assessments of coping (e.g. change of activity over time after distress). In addition subjects are asked if their actual activity, social context or cognitions are selected with the purpose to reduce distress. At the end of the week the MACS is assessed. This study will help further validate the MACS. Further, the study will describe the daily life reality of coping and possibly 
demonstrate its dynamic nature (see Coyne \& Racioppo, 2000; Lazarus, 1993; Stone et al., 1998).

Finally, some studies report that psychotic subjects use ineffective coping strategies because their problem solving skills are at stake due to neurocognitive deficits and personality styles like neuroticism (Corrigan \& Toomey, 1995; Penn et al., 1993; van den Bosch \& Rombouts, 1997). Experience of distress, however, is associated with the same factors: personality (Lysaker ef al., 2003; van den Bosch \& Rombouts, 1997) and neuro-cognitive variables (Amador \& Kronengold, 1998; Lysaker, Bryson, Lancaster, Evans, \& Bell, 2002; Schwartz, 1998a; van den Bosch et al., 1992). The cognitive psychological model of psychosis (Garety et al., 2001; Lysaker, Bryson, Marks, Tamasine, \& Bell, submitted; Lysaker et al., 2003) integrates these elements. Further research will therefore have to assess cognitive deficits and personality styles in order to evaluate the "trainability" of the coping skills assessed by the MACS. 


\section{References}

Amador, X.F, Kronengold, H. (1998). The Description and Meaning of Insight and Pschosis. In Annador X. F. \& D. A.S. (Eds.), Insight and Psychosis (pp. 15-32). New York: The Oxford University Press.

American Psychiatric Association, A. (1994). DSM-IV: Diagnostic and Statistical Manual of Menial Disorders. Washinton DC.: APA.

Andres, K., Pfammatter, M., Garst, F., Teschner, C., \& Brenner, H. D. (2000). Effects of a coping-orientated group therapy for schizophrenia and schizoaffective patients: a pilot study. Acta Psychiatr Scand, 101(4), 318-322.

Berenbaum, H., \& Fujita, F. (1994). Schizophrenia and personality: exploring the boundaries and connections between vulnerability and outcome. $J$ Abnorm Psychol, 103(11), 148-158.

Birchwood, M. (2003). Pathways to emotional dysfunction in first-episode psychosis. Br.J Psychiatry, 182, 373-375.

Blackwood, N. J., Howard, R. J., Bentall, R. P., \& Murray, R. M. (2001). Cognitive neuropsychiatric models of persecutory delusions. Am J Psychiatry, 158(4), $527-539$.

Böker, W., Brenuer, H. D., \& Wurgler, S. (1989). Vulnerability-linked deficiencies, psychopathology and coping behaviour of schizophrenics and their relatives. Br J Psychiatry Suppl(5), 128-135.

Breier, A., \& Strauss, J. S. (1983). Self-control in psychotic disordlers. Arch Gen Psychiary, 40(10), 1141-1145.

Brekke, J. S., Levin, S., Wolkon, G. H., Sobel, E., \& Slade, E. (1993). Psychosocial functioning and subjective experience in schizophrenia. Schizophr Bull, I9(3), 599-608.

Brenner, H. D., Boker, W., Muller, J., Spichtig, L., \& Wurgler, S. (1987). On autoprotective efforts of schizophrenics, neurotics and controls. Acta Psychiatr Scand, 75(4), 405-414.

Brugha, T. S. (2002). The end of the beginning: a requiem for the categorization of mental disonder. Psychological Medicine, 32(1149-1154).

Carr, V. (1988). Patients" techniques for coping with schizophrenia: an exploratory study. Br J Med Psychol, 6l(Pt 4), 339-352.

Chadwick, P... \& Birchwood, M. (1994). The omnipotence of woices. A cognitive approach to auditory hallucinations. Br.JPsychiatry, 164(2), 190-201.

Chapman, L. J., Chapman, J. P., Kwapil., T. R., Eckblad, M., \& Zinser, M. C. (1994). Putatively psychosis-prone subjects 10 years later. J Abnorm Psychol, 103(2), $171-183$.

Claridge, G., McCreery, C., Mason, O., Bentall, R., Boyle, G., Slade, P., \& Popplewell, D. (1996). The factor structure of "schizotypal" traits: a large replication study. Br J Clin Psychol, 35(Pt 1), 103-115.

Close, H., \& Garety, P. (1998). Cognitive assessment of voices: further developments in understanding the emotional impact of voices. Br J Clin Psychol, 37(Pt 2), 173-188.

Corrigan, P. W. \& Toomey, R. (1995). Interpersonal problem solving and information processing in schizophrenia. Schizophr Bull, 21(3), 395-403.

Coyne, J. C. \& Racioppo, M. W. (2000). Never the Twain shall meet? Closing the gap between coping research and clinical intervention research. Am Psychol, 55(6), $655-664$. 
Danion, J. M., Gokalsing, E., Robert, P., Massin-Krauss, M., Bacon, E. (2001). Defective relationship between subjective experience and behavior in schizoplirenia. Am J Psychiatmy, 158(12), 2064-2066.

de Vries, M. W., \& Delespaul, P. A. (1989). Time, context, and subjective experiences in schizophrenia. Schizoph Buh, 15(2), 233-244.

Delespaul, P., deVries, M., \& van Os, I. (2002). Determinants of occurrence and recovery from hallucinations in daily life. Soc Psychatry Psychior Epidemiol. $37(3), 97-104$.

Delespaul, P., \& van Os, J. (2003). Jaspers was right after all--delusions are distinct from normal beliefs. Against. Br J Psychiary. 183, 286.

Delespaul, P. A. E. G. (1995). Assessing Schizophrewia in Daily Life: The Experience Sampling Method. Unpublished PhD Thesis, Maastricht University, Maastricht.

Ditmann, J., \& Schuttler, R. (1990). Disease consciousness and coping strategies of patients with schizophrenic psychosis. Acta Psychiatr Scand.82(4), 318-322.

Escher, S., Romme, M., Buiks, A., Delespaul, P., \& van Os, J. (2002a). Formation of delusional ideation in adolescents hearing voices: a prospective study. $\mathrm{Am} \mathrm{J}$ Med Genet, 114(8), 913-920.

Escher, S., Romme, M., Buiks, A., Delespaul. P., \& Van Os, J. (2002b). Independent course of childhood auditory hallucinations: a sequential 3-yeai follow-up study. BrJ Psychiatry, 181(Suppl 43), S10-S18.

Folkman, S., \& Greer, S. (2000). Promoting psychological well-being in the face of serious illness: when theory, research and practice inform each other. Psychooncology, 9(1), 11-19.

Folkman, S., \& Lazarus, R. S. (1988). Coping as a mediator of emotion. J Pers Soc Psychol, 54(3), 466-475.

Folkman, S., Lazarus, R. S., Gruen, R. J., \& DeLongis, A. (1986). Appraisal, coping, health status, and psychological symptoms. I Pers Soc Psychol, $50(3), 571$ 579 .

Folkman, S., \& Moskowitz, J. T. (2000). Positive affect and the other side of coping. Am Psychol, 55(6), 64.7-654.

Fowler, D. (2000). Psychological formulation of early episodes of psychosis: a cognitive model. In M. Birchwood \& D. Fowler \& C. Jackson (Fds.), Eary intervention in psychosis: A gaide to concepts, evidence and interventions. (pp. 101-127). Chichester: Wiley.

Freeman, D., Garety, P. A., \& Kuipers, E. (2001). Persecutory delusions: developing the understanding of belief maintenance and emotional distress. Psychol Med. $3 /(7), 1293-1306$.

Freeman, D., Giarety, P. A., Kuipers, E., Fowler, D., \& Bebbington, P. E. (2002). A cognitive model of persecutory delusions. Br $/$ Clin Psychol, 41(Pt 4), 331 347.

Garety, P. A., Kuipers, E., Fowler, D., Freeman, D., \& Bebbington, P. E. (2001). A cognitive model of the positive symptoms of psychosis. Psychol Med, 3/(2), 189-195.

Gove, W. R., \& Geerken, M. R. (1977). Response bias in surveys of mental health: an empirical investigation. Ajs, 82(6), 1289-1317. 
Gurrera, R. J., Nestor, P. G., \& ODonnell, B. F. (2000). Personality traits in schizophrenia: comparison with a community sample. I Nerv Ment Dis, $188(1), 31-35$

Hanssen, M., Peeters, F., Krabbendam, L., Radstake, S., Verdow, H., \& Van Os, J. (2003). How psychotic are individuals with non-psychotic disorders? Soc Psychiatry Psychiar Epidemiol, 38(3), 149-154.

Mansson, L., Middelboe, T., Merinder, L., Bjarnason, O., Bengtsson-Tops, A., Nilsson, L., Sandlund, M., Sourander, A., Sorgaard, K. W., \& Vinding, H. (1999). Predictors of subjective quality of life in schizophrenic patients living in the community. A Nordic multicentre study. Int / Soc Psychiatry, 45(4), 247-258.

Hermann-Doig, T., Maude, D., \& Edwards, J. (2003). Systematic Treatment of Persistent Psychosis (STOPP). A psychological approach to facilitating recovery in young people with first-episode psychosis. London, Martin Dunitz.

Hodel, B., \& Brenner, H. D. (1996). [A training program for coping with maladaptive emotions of schizophrenic patients. Initial results and experiences]. Nervenarzt, 67(7), 564-571.

Honig, A., Romme, M. A., Ensink, B. I., Escher, S. D., Pennings, M. H., \& deVries, M. W. (1998). Auditory hallucinations: a comparison between patients and nompatients. J Nerv Ment Dis, 186(10), 646-651.

Huistra, K. (2003). Schizofrenie \& Coping. Het gebruik van coping strategieèn voor de symptomen van schizofrenie. Maastricht: Maastrich University.

Jackson, C., Tait, L., Birchwood, M., \& Trower, P. (2002, 25-28 September 2002). "Sealing-over": a psychological defence against the trawna of early psychosis? Paper presented at the 3rd Intemational Conference on Early Psychosis., Copenhagen, Denmark.

Janssen, I., Hanssen, M., Bak, M., Bijl, R. V., de Graat, R., Vollebergh, W., Mckenzie, $\mathrm{K}_{\text {, }, \text { \& van }} \mathrm{Os}_{\mathrm{s}} \mathbb{I}$. (2003). Discrimination and delusional ideation. $\mathrm{Br} J$ Psychiatry, $182,71-76$.

Jenner, J. A., \& van de Willige, G. (2001). HIT, hallucination focused integrative treatment as early intervention in psychotic adolescents with auditory hallucinations: a pilot study. Acta Psychiatr Scand 103(2), 148-152.

Jenner, J. A., wan de Willige, G., \& Wiersma, D. (1998). Effectiveness of cognitive therapy with coping training for persistent auditory hallucinations: a retrospective study of attenders of a psychiatric out-patient department. Acta Psychiar Scand, $98(5), 384-389$.

Johns, L. C. \& van Os, J. (2001). The continuity of psychotic experiences in the general population. Clin Psychol Rev, 21(8), 1125-1141.

Khaw, K. (2001). Health and disease are a continum. Drug and Therapeutics Bulletin, $39,47-57$.

Klingberg, S., Bucgkremer, G., \& Gaebel, W. (2002). Psychological intenentionsin first-episode schizophrenia first results of a German RCT. Paper presented at the 3rd International Conference on Early Psychosis., Copenhagen, Denmark.

Krabbendan, L., Janssen, I., Bak, M., Bijl, R. V., de, G. R. \& van, Os. J. (2002). Neuroticism and low self-esteem as risk factors for psychosis. Soc Psychiatry Psychion Epidemiol, 37(1), $1-6$.

Krabbendam, L., Myin-Germeys, I., Hanssen, M., Bijl R.V., de Graaf, R., Vollebergh, W. Bak, M., \& van Os, J. (2003). Hallucinatory experiences and onset of 
psychotic disorder: Evidence that the risk is mediated by delusion formation. submitred.

Krabbendam, L., Myin-Germeys, I., Hanssen, M., de Graaf, R., Vollebergh, W., \& vain Os, J. (2003). Depressed mood predicts onset of psychotic disorder individuals who report hallucinatory experiences. submitted.

Larsen, T. K., Bechdolf, A., \& Birchwood, M. (2003). The concept of schizophrenid. and phase-specific treatment: cognitive-behavioral treatment in pre-psychosis and in nonresponders. $J$ Am Acad Psychoanal, 3/(1), 209-228.

Larsen, T. K., Friis, S., Haahr, U., Joa, I., Johannessen, J. O., Melle, I., Opjordsmoen, S., Simonsen, E., \& Vaglum, P. (2001). Early detection and intervention in first-episode schizophrenia: a critical review, Acra Psychiatr Scand, 103(5), 323-334.

Lazarus, R. S. (1993). Coping theory and research: past, present, and future. Psychosom Med, 55(3), 234-247.

Lazarus, R. S. (2000). Toward a better research on stress and coping. American Psychologist, 55(6), 665-673.

Lazarus, R. S., \& Folkman, S. (1984). Stress, Appraisal and Coping. New York: Springer Verlag.

Leclerc, C., Lesage, A. D., Ricard, N., Lecomte, T., \& Cyr, M. (2000). Assessment of a new rehabilitative coping skills module for persons with schizophrenia. Am . Orthopsychiatry, 70(3), 380-388.

Leon, A. C., Portera, L., Olfson, M., Weissman, M. M. Kathol, R. G., Farber, L., Sheehan, D. V., \& Pleil, A. M. (1997). False positive results: a challenge for psychiatric screening in primary care. Am J Psychiatoy, 154(10), 1462-1464.

Liddle, P. F., \& Barnes, T. R. (1988). The subjective experience of deficits in schizophrenia. Compr Psychiary, 29(2), 157-164.

Linden, W., Paulhus, D. L., \& Dobson, K. S. (1986). Effects of response styles on the report of psychological and somatic distress. J Consult Clin Psychol, $54(3)$, 309-313.

Lysaker, P., Bryson, G., Marks, K. A., Tamasine, C. G., \& Bell, M. (in press). Coping style in schizophrenia: associations with neurocognitive deficits and personality.

Lysaker, P. H., Bryson, G. J., Lancaster, R. S., Evans, J. D., \& Bell, M. D. (2002). Insight in schizophrenia: associations with executive function and coping style. Schizophwenia Research, In Presis.

Lysaker, P. H., Wilt, M. A., Plascak-Hallberg, C. D., Brenner, C. A., \& Clements, C. A. (2003). Personality dimensions in schizophrenia: associations with symptoms and coping. I Nerv Ment Dis, $191(2), 80-86$.

McGlashan, T. H. (1975). Integration and sealing-over. Arch Gen Psychiatry, 32, 1269. 1272.

McGorry, P. D., \& MoConville, S. B. (1999). Insight in psychosis: an elusive target. Compr Psychiatry, 40(2), 131-142.

Middelboe, T., \& Mortensen, E. L. (1997). Coping strategies among the long-term mentally ill: categorization and clinical determinants. Acta Psychiatr Scand, 96(3), 188-1.94.

Miller, P., Byrne, M.y Hodges, A., Lawrie, S. M., Owens, D. G., \& Johnstone, E. C. (2002). Schizotypal components in people at high risk of developing 
schizophrenia: early findings from the Edinburgh High-Risk Study. $\mathrm{Br} J$ Psychiatry, 180(2), 179-184.

Morrison, A. P., \& Baker, C. A. (2000). Intrusive thoughts and auditory hallucinations: a comparative study of intrusions in psychosis. Behow Res Ther, 38(11), 10971106.

Moum, T. (1988). Yea saying and mood of the day effects in self-reported quality of life. Soc Indic Res, 20, $117-139$.

Myin-Germeys, I., Delespaul, P. A., \& deVries, M. W. (2000). Schizophrenia patients are more emotionally active than is assumed based on their behavior. Schizophr Bull, 26(4), 847-854.

Ormel, \&., Stewart, R., \& Sanderman, R. (1989). Personality as modifier of the life change-distress relationship. A longitudinal modelling approach. Soc Psychiarry Psychiar Epidemiol, 24(4), 187-195.

Penn, D. L., van der Does, A. J., Spaulding, W. D., Garbin, C. P., Linszen, D., \& Dingemans, P. (1993). Information processing and social cognitive problem solving in schizophrenia. Assessment of interrelationships and changes over time. J Nerv Ment Dis, 181(1), 13-20.

Peters, E., Day, S., McKenna, J., \& Orbach, G. (1999). Delusional ideation in religious and psychotic populations. BrJ Clin Psychol, 38(Pt 1), 83-96.

Poulton, R., Caspi, A., Moffit, T. E., Cannon, M., Murray, R., \& Harrington, H. (2000). Children's self-reported psychotic symptoms and adult schizophreniform disorder: a 15-year longitudinal study. Arch Gen Psychiarry, 57(11), 10531058.

Regier, D. A. (2000). Community diagnosis counts. Arch Gen Psychiatry, 57(3), 223224.

Riessman, C. K. (1979). Interviewer effects in psychiatric epidemiology: a study of medical and lay interviewers and their impact on reported symptoms. $A m J$ Public Health, 69(5), 485-491.

Ritsner, M., Kurs, R., Gibel, A., Hirschmann, S., Shinkarenko, E., \& Ratner, Y. (2003). Predictors of quality of life in major psychoses: a naturalistic follow-up study. $J$ Clin Psychiatry, 64(3), 308-315.

Ronme, M., \& Escher, S. (1994). Hearing voices. Bmj, 309(6955), 670.

Ross, C. E., \& Mirowsky, J. (1984). Socially-desirable response and acquiescence in a cross-cultural survey of mental health. J Heatth Soc Behov, 25(2), 189-197.

Schaub, A., Andres, K., Brenner, H. D., \& Donzel, G. (1997). Developing a group format for coping-oriented treatment programme for schizophrenic patients. In H. D. Brenner \& W. Böker \& R. Genner (Eds.), Towards a comprehensive therapy for schizophrenia (pp. 228-251). Seattle,: Hogrefe \& Huber,.

Schwartz, R. C. (1998). Insight and illness in chronic schizophrenia. Compr Psychiatry. $39(5), 249-254$

Skinner, E. A. (1995). Perceived control (Vol. 8). Thousand Oaks: Sage Publications.

Skinner, E. A. (1996). A guide to constructs of control. J Pers Soc Psychol, 7/(3), 549570.

Snyder, C. R., \& Dinoff, B. L. (1999). Coping: Where Have You Been? In C. R. Snyder (Ed.), Coping. The Psychology of What Works (pp. 3-20). New York: Oxford University Press.

Soskis, D. A., \& Bowers, M. B. (1969). The schizophrenic experience: A follow-up study of attitude and posthospital adjustment. J Nerv Ment Dis, 149, 443-449. 
Stefanis, N. C., Hanssen, M., Smirnis, N. K., Avramopoulos, D. A., Evdokimidis, I. K., Stefanis, C. N., Verdoux, H., \& Van, O. J. (2002). Evidence that three dimensions of psychosis have a distribution in the general population. Psychol Med, 32(2), 347-358.

Stone, A. A., Schwartz, J. E., Neale, J. M., Shiffman, S., Marco, C. A. Hickcox. M., Paty, J., Porter, L. S. \& Cruise, L. J. (1998). A comparison of coping assessed by ecological momentary assessment and retrospective recall. $J$ Pers Soc Psychol, 74(6), 1670-1680.

Takai, A., Uematsu, M., Kaiya, H. Inoue, M. \& Ueki, H. (1990). Coping styles to basic disorders anong schizoplurenics. Acta Psychiatr Scand, 82(4), 289-294.

Tarrier, N. (1992). Management and modification of residual positive psychotic symptoms. In M. Birchwood \& N. Tarrier (Eds.), Innowations in psychological managenent of schizophrenia. (pp. 147-169). Chichester: John Wiley \& Sons Ltd.

Tarrier, N., Sharpe, L., Beckett, R., Harwood, S., Baker, A., \& Yusopolf, L. (1993). A trial of two cognitive behavioural methods of treating drug-resistant residual psychotic symptoms in schizoplrenic patients. II. Treatment-specific changes in coping and problem-solving skills. Soc Psychiatry Psychiatr Epidemiol, $28(1), 5-10$.

Tennen, H., Affleck, G., Ameli, S., \& Carney, M. A. (2000). A daily process approach to coping. Linking theory, research, and practice. Am Psychol, 55(6), 626-636.

Trower, P., \& Chadwick, P. (1995). Pathways to defense of the self: A theory of two types of paranoia. Clinincal Psychology: Science and Practice, 2, 263-278.

van den Bosch, R. J., \& Rombouts, R. P. (1997). Coping and cognition in schizophrenia and depression. Compr Psychiatry, 38(6), 341-344.

van den Bosch, R. J., van Asma, M. J., Rombouts, R., \& Louwerens, J. W. (1992). Coping style and cognitive dysfunction in schizophrenic patients. $\mathrm{Br} J$ Psychiatry Suppl(18), 123-128.

van Os, J., Bak, M., Hanssen, M., Bijl, R. V., de Graaf, R., \& Verdoux, H. (2002). Cannabis use and psychosis: a longitudinal population-based study. Am .J Epidemiol. 156(4), 319-327.

van Os, J., Hanssen, M., Bak, M., Bijl, R. V., \& Vollebergh, W. (2003). Do urbanicity and familal liability coparticipate in causing psychosis? Am I Psychiary. $160(3), 477-482$.

van Os, J., Hanssen, M., Bijl, R. V., \& Ravelli, A. (2000). Strauss (1969) revisited: a psychosis continum in the general population? Schizoph Res, 45(1-2), 11-20.

van Os, J., Hanssen, M., Bijl, R. V., \& Vollebergh, W. (2004). Prevalence of psychotic disorder and community level of psychotic symptoms: an urban-rural comparison. Arch Gen Psychiairy, 58(7), $663-668$.

van Os, J., Park, S. B., \& Jones, P. B. (2001). Neuroticism, life events and mental health: evidence for person-environment correlation. Br J Psychiary Suppl, $40,572-77$.

van Os, J., Verdoux, H., Bijl R. V., \& Ravelli, A. (1999). Psychosis as an exireme of continuous wariation in dimensions of psychopathology. In $\mathrm{H}$. Hafner \& $W$ Gattaz (Eds.), Search for the Causes of Schizophrenia. (Vol. 4, pp. 59.79y. Berlin: Springer:

Wiedl, K. H. (1997). Coping-oriented therapy with schizophrenic patients: General guidelines, starting points and issues of evaluation. In H. D. Brenner \& W. 
Böker \& $\mathbb{R}$. Genner (Eds.), Towards a comprehensive therapy for schizophrenia (pp. 209-227). Seattle; Hogrefe \& Huber,

Wykes, T., Parr, A. M., \& Landau, S. (1999). Group treatment of auditory hallucinations. Exploratory study of effectiveness. Br J Psychiatry, 175,180 185. 
Chapter 9

Summary

Samenvatting. 
Psychotic syndromes are usually studied in mental health care facilities. Information about psychotic experiences outside the mental health services is rather limited. In the general population, psychotic experiences may not have developed into real symptoms, or the symptoms do not result in need for care. A more profound understanding of symptom development in the general population is important for prediction and possible prevention of the expression of full-blown psychotic illnesses and a pathway through care. Possibly, many people in the general population with real psychiatric symptoms have learned to adapt satisfactorily to their experiences, to minimize distress and avoid need for treatment. In other words, they may display an array of more or less appropriate coping strategies. The studies presented in this dissertation explore the relation between expression of psychotic experiences in general and expression of psychotic symptoms in the context of illness. It focuses on the relation between psychotic phenomenology, distress, coping and outcome in terms of need for care.

The prevalence of psychotic experiences in the general population and its relation to illness expression has been assessed using data from the Dutch NEMESIS study - a large general population co-morbidity cohort. The main diagnostic instrument in this study is the Composite International Diagnostic Interview (CIDI). The CIDI is a self-assessment instrument, Lay-interviewers record responses without any clinical interpretation. Self-reports of psychotic symptoms are valued as questionable, because of increased "false" positive results. Recent population-based studies, however, show that self-reported psychotic experiences predict the development of psychotic disorder in the short and long term. We have examined the predictive value of clinician Recognised Symptoms and clinician Non Recognised Symptoms in the NEMESIS study (chapter 5). Clinician Recognised Symptoms (but not illness) at baseline appear predictive of incident psychotic disorder resulting in need for care three years later. However, also Non Recognised Symptoms predict need for care at followup. Only the subgroup, whose self-reported psychotic experiences have been rejected as clinically irrelevant by the clinicians, but with attenuated psychotic experiences, has an increased risk for future need for care in the context of psychosis. Their Positive Predictive Value (PPV $=10 \%)$ is nearly as high as those of clinician Recognised Symptoms (PPV $=11 \%$ ).

Whether individuals with psychotic experiences develop a psychiatric illness resulting in a need for care may be mediated by several factors. In subjects with no history of psychosis, it is not the severity of psychotic experiences per se, but the level of distress and perceived control that distinguishes between those with and without a need for care (chapter 6). Thonght Interference, Suspiciousness, Grandiosity and Delusions of Reference, show no association with need for care, whereas Hearing Voices, Non-verbal Hallucinations and Passivity Phenomena are related to need for care (chapter 7). The associations for Nonverbal Hallucinations and Passivity Phenomena are largely explained by 
distress, but this is not the case for Hearing Voices. Models of onset of psychosis need to take type and context of the psychotic experience into account.

Different symptoms are associated with different levels of distress and specific coping mechanisms moderate the experience of control per symptom. The Maastricht Assessment of Coping Strategies (MACS) is designed to assess the spectrum of symptoms specific distress, coping and its resulting effect on perceived control. Data on reliability and validity are presented. Factor analysis of MACS items suggests that coping strategies can be summarized in five clinically relevant coping domains: active problem solving, passive illness behaviour, active problem aroiding, passive illness avoiding and symptomatic behoviour. The MACS has good to excellent intra class correlation coefficients for the various coping domains in subjects with a diagnosis of schizophrenia (chapter 3 ). They reliably describe (self-report) coping strategies for specific symptoms of psychosis and assess their effect.

The level of functional coping that a person mobilizes in the face of stressful. (psychotic) experiences may be an important determinant of need for care status (chapter 6). Qualitative differences in the five main coping domains are apparent. Subjects who experience control over symptoms use more active problem solving coping strategies (Chapter 4). Sympromatic coping is the most frequently used strategy. It is defined as going along with the content of the symptom and is negatively associated with control (chapter $4 \& 6$ ). This is clinically relevant, since dysfunctional coping may be replaced by more functional alternatives. A post-hoc analysis suggests that qualitative differences in self-initiated coping modify the risk of need for care and subsequent patient status in those who experience psychotic symptoms. It points to the importance of early coping-based interventions.

This dissertation shows that not psychiatric symptoms per se, but concurrent distress due to hallucinations or delusions differentiate patients from nonpatients in the general population. Coping can influence the distress generated by psychotic experiences. Subjects who apply more effective coping strategies do not need care. A successful treatment should take these observations into account and focus less on psychotic symptomatology per se and more on strategies that increase the perception control, to alleviate distress. 
Psychotische syndromen worden gewoonlijk binnen geestelijke gezondheidszorg instellingen bestudeerd. Kennis over psychotische ervaringen buiten de geestelijke gezondheidszorg is echter beperkt. Psychotische ervaringen hoeven zich hier niet ontwikkeld te hebben tot echte symptomen, of de symptomen resulteren niet in een zorgbehoefte. Een verdieping wan het begrip betreffende onze kennis over symptoomontwikkeling in de algemene bevolking is belangrijk voor de voorspelling en mogelijke preventie van psychotische stoornissen en de paden die tot zorg leiden. Het is mogelijk dat veel mensen in de algemene bevolking met echte psychiatrische symptomen geleerd hebben om op een bevredigende manier met hun ervaringen om te gaan en met de bij die ervaringen horende angst of spanning, waardoor behoefte aan behandeling vermeden wordt. Met andere woorden, ze vertonen mogelijk een scala aan meer functionele coping strategieẻn. De studies in deze dissertatie beschreven, onderzoeken de relatie tussen psychotische ervaringen in het algemeen en psychotische symptomen in het kader van ziekte. De primaire aandacht gaat uit naar de relatie tussen psychotische fenomenologie, angst/spanning ervaring, coping en zorgbehoefte.

De prevalentie van psychotische ervaringen in de algemene bevolking en de relatie met psychotische stoomis is onderzocht middels het gebruik van data van de Nederlandse NEMESIS studie, een groot co-morbiditeit onderzoek naar psychiatrische ziekten in de algemene bevolking. Het belangrijkste diagnostische instrument in deze studie is de Composite International Diagnostic Interview (CIDI). De CIDI is eigenlijk een zelfbeoordelingschaal, ondat leken interviewers de antwoorden van de subjecten zonder enige $\mathrm{k}$ linische interpretatie vastleggen. De waarde van zelfbeoordelingschalen wordt ter discussie gesteld, vanwege een verhoogd aantal fout positieve resultaten. Recente bevolkingsonderzoeken laten echter zien dat zelfrapportage van psychotische ervaringen de ontwikkeling van psychotische stoornissen zowel binnen de korte als de lange termijn voorspellen. De voorspellende waarde van door de clinicus herkende en door de clinicus niet herkende symptomen in de NEMESIS studie is in deze dissertatie onderzocht. De door de clinicus herkende symptomen (niet stoornis) van de basismeting van de NEMESIS studie blijken voorspellend te zijn voor incidente psychotische stoornissen die 3 jaar later tot zorg leiden (Hoofdstuk 5). Echter, niet door clinicus herkende psychotische symptomen blijken eveneens psychotische stoornissen gekarakteriseerd door zorgbehoefte te voorspellen. Maar het is alleen de subgroep van mensen met meerdere licht psychotische ervaringen, van wie de zelfgerapporteerde ervaringen door de clinicus zijn afgewezen, die een verhoogde kans heeft op toekomstige zorgbehoeften gerelateerd aan psychose. Hun positief voorspellende waarde ( $\mathrm{PVW}=10 \%$ ) is bijna even hoog als voor die van de door de clinicus herkende symptomen ( $P V W=11 \%$ ).

Of mensen met psychotische ervaringen een psychiatrische ziekte ontwikkelen die zorgbehoefte genereert, wordt door meerdere factoren gemediëerd. Bij 
subjecten zonder psychose in hun voorgeschiedenis, blijkt dat niet zozeer de ernst van de psychotische ervaringen, maar wel het niveau van angst/spanning en ervaren controle het verschil maken tussen aanwezigheid of afwezigheid van zorgbehoefte (Hoofdstuk 6). Gedachten beimwloeding, Achterdocht, Megalomanie en Betrekkingswanen laten geen associatie zien met zorgbehoefte, terwijl Stemmen Horen, Non-verbale Hallucinaties en Controle Erwaringen wel gerelateerd zijn met zorgbehoefte (Hoofdstuk 7). De associaties van zorgbehoefte met Non-verbale Hallucinaties en Controle Ervaringen worden grotendeels verklaard door angst/spanning, hetgeen niet het geval is voor Stemmen Horen. Modellen betreffende het ontstaan van psychose dienen dus rekening te houden met het type en de context van de psychotische ervaring.

Verschillende symptomen zijn geassocieerd met verschillende angst/spanning niveaus en specifieke coping strategieën die de controlle ervaring beïnvloeden. De Maastricht Assessment of Coping Strategies (MACS) is ontwikkeld on het spectrum van symptomen, en de symptoom gerelateerde angst/spanning, coping en controle ervaring vast te stellen. Data over betrouwbaarheid en validiteit worden gepresenteerd. Factor analyse van de MACS-items geeft aan dat de coping strategieën onderverdeeld kunnen worden in vijf klinisch relevante coping domeinen: actief probleem oplossende strategieën, passief ziekte gedrag. actief probleem vermijden, passief probleem vermijden en symptomatisch coping gedrag. De MACS heeft goede tot zeer goed intra-class correlatie coëfficiënten voor de verschillende coping domeinen in personen met de diagnose schizofrenie (Hoofdstuk 3). Deze patiënten beschrijven op een betrouwbare manier (zelfrapportage) coping strategieën voor specifieke symptoomgebieden van psychose en beoordelen de effectiviteit ervan.

Het niveau van functionele coping strategieèn ingezet door een persoon in het kader van stressvolle (psychotische) ervaringen, kunnen belangrijke determinanten zijn voor een zorgbehoefte status (Hoofdstuk 6). Kwalitatieve verschillen tussen de vijf coping domeinen zijn aanwezig. Subjecten die controle over symptomen ervaren, gebruiken meer probleem oplossende strategieën (Hoofdstuk 4). Symptomatisch coping gedrag is de meest gebruikte coping strategie. Dit wordt gedefinieerd als meegaan met de inhoud van het symptoom en is negatief geassocieerd met controle ervaring (Hoofdstukken $4 \&$ 6). Dit heeft klinisch grote betekenis, daar disfunctionele coping strategieèn vervangen kunnen worden door meer functionele alternatieve coping strategieën. Een post-hoc analyse geeft aan dat kwalitatieve verschillen tussen zelfgeïnitieerde coping strategieën het risico op zorgbehoefte en vervolgens patiënten status bij mensen met psychotische ervaringen beïnvloedt. Hiermee word tevens op het belang van vroege op coping gebaseerde interventies gewezen.

Deze dissertatie laat zien dat niet de psychiatrische symptomen, maar de aan de psychotische ervaringen (zoals hallucinaties en wanen) gerelateerde angst/spanning differentieert tussen patiënt of niet-patiënt zijn in de algemene 
bevolking. Coping heeft invloed op de angst/spamning die samenhangt met psychotische ervaringen. Mensen die meer effectieve coping strategieèn toepassen hebben geen zorgbehoefte. Een succesvolle behandeling dient met deze observaties rekening te houden, waarbij minder de focus ligt op de psychotische symptomatologie, maar de aandacht gericht wordt op strategieën die de controle ervaring verhogen en daardoor de angst/spanning reduceren. 


\section{Appendix}

Overview of coping with psychosis research 


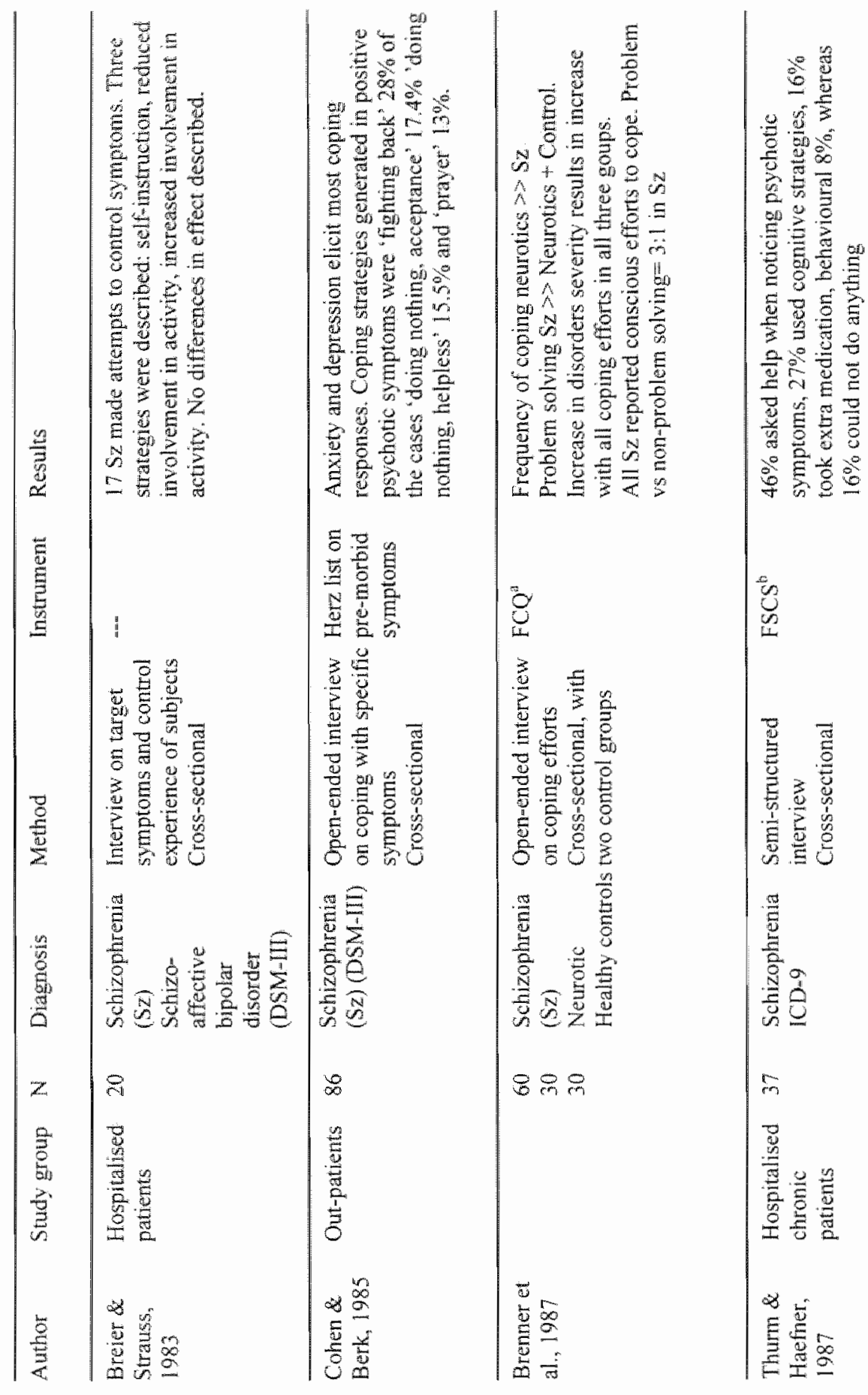




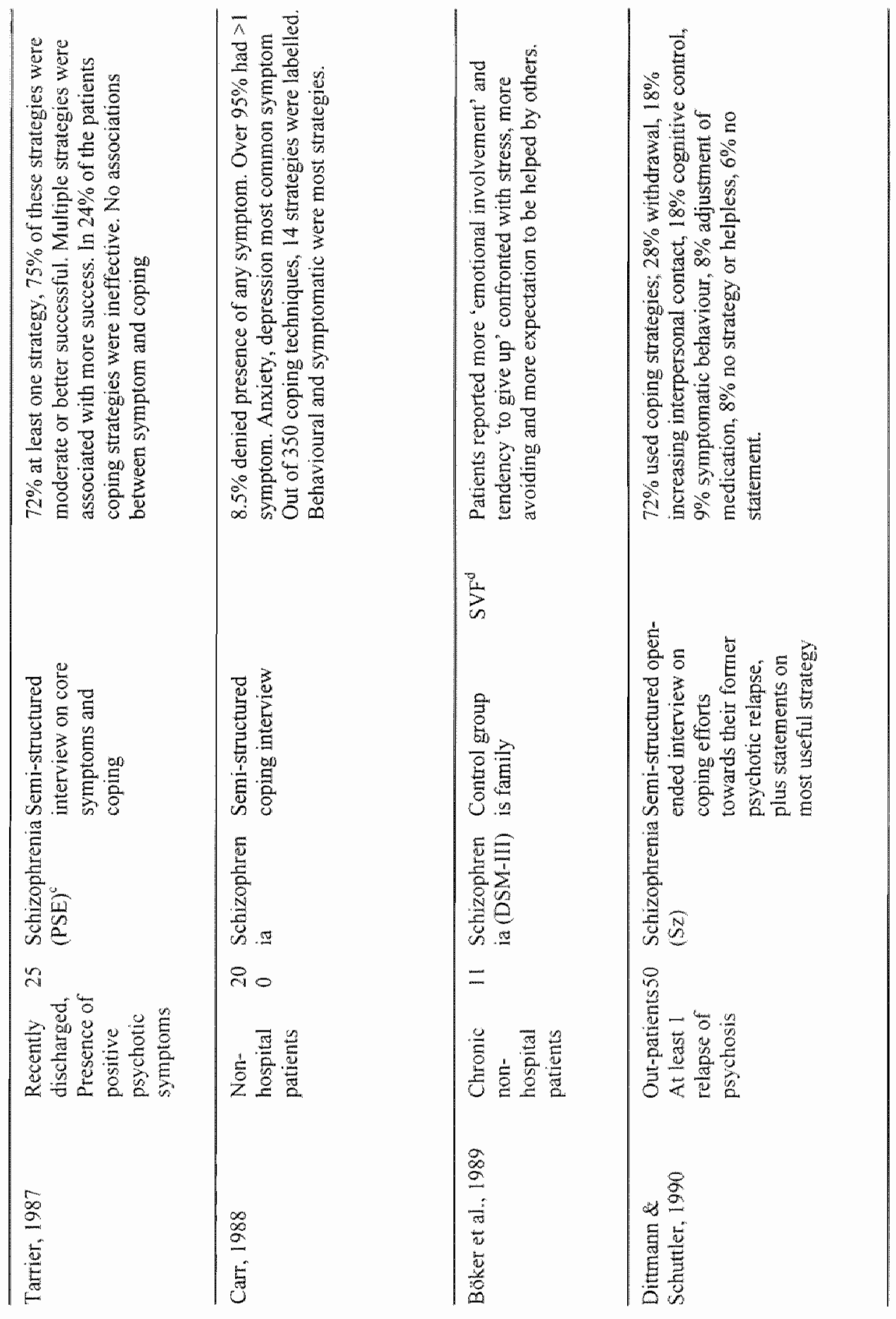




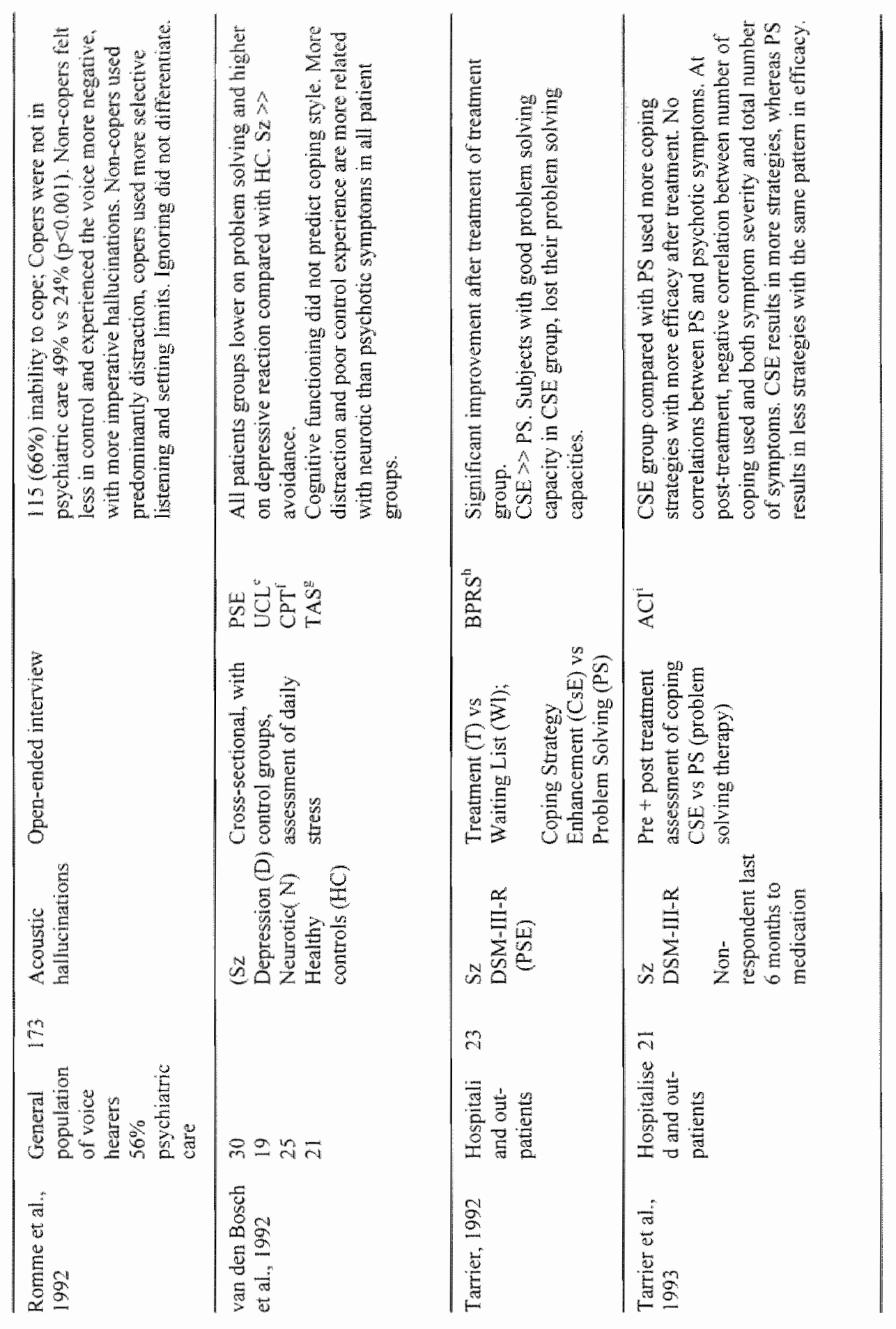




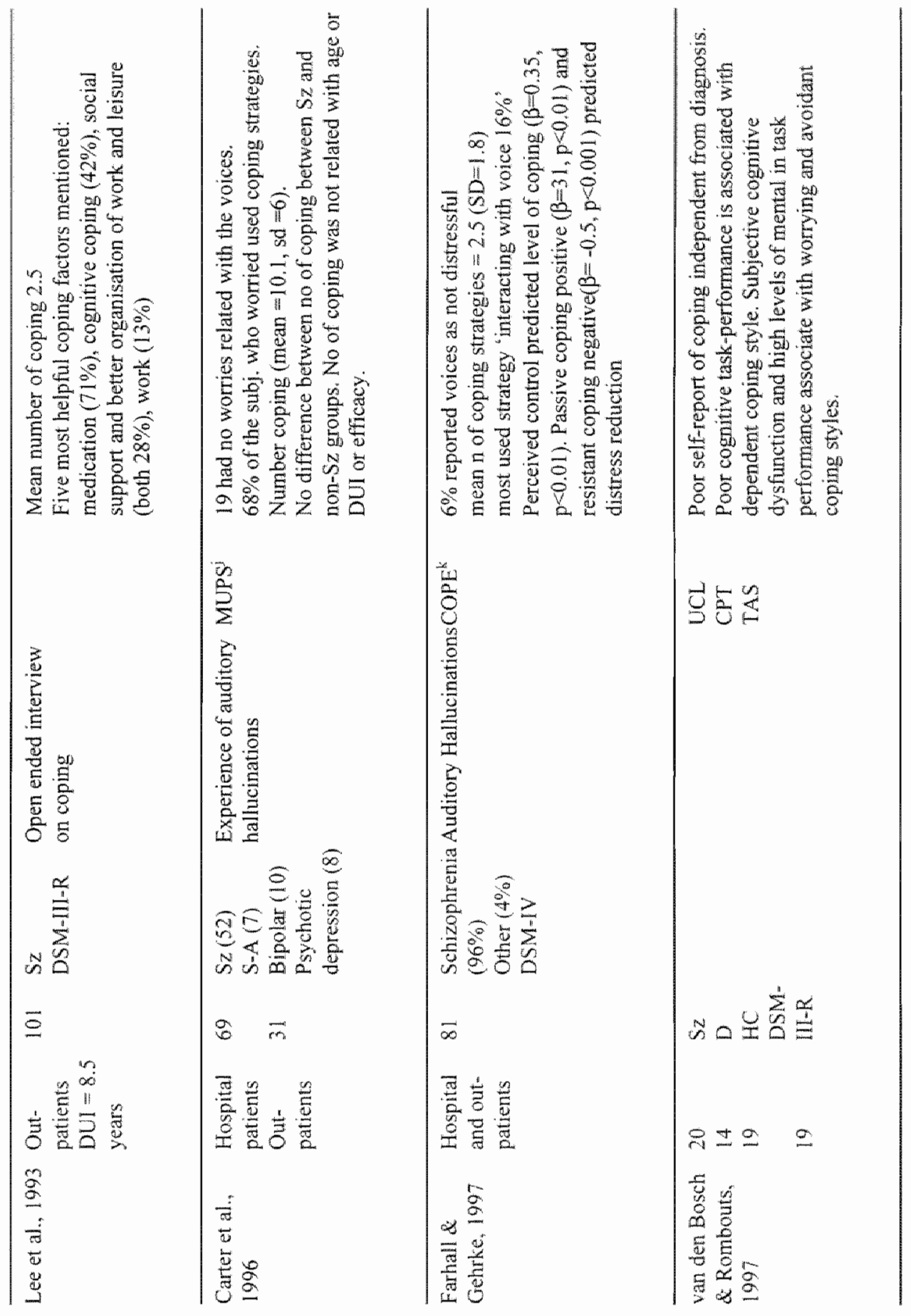




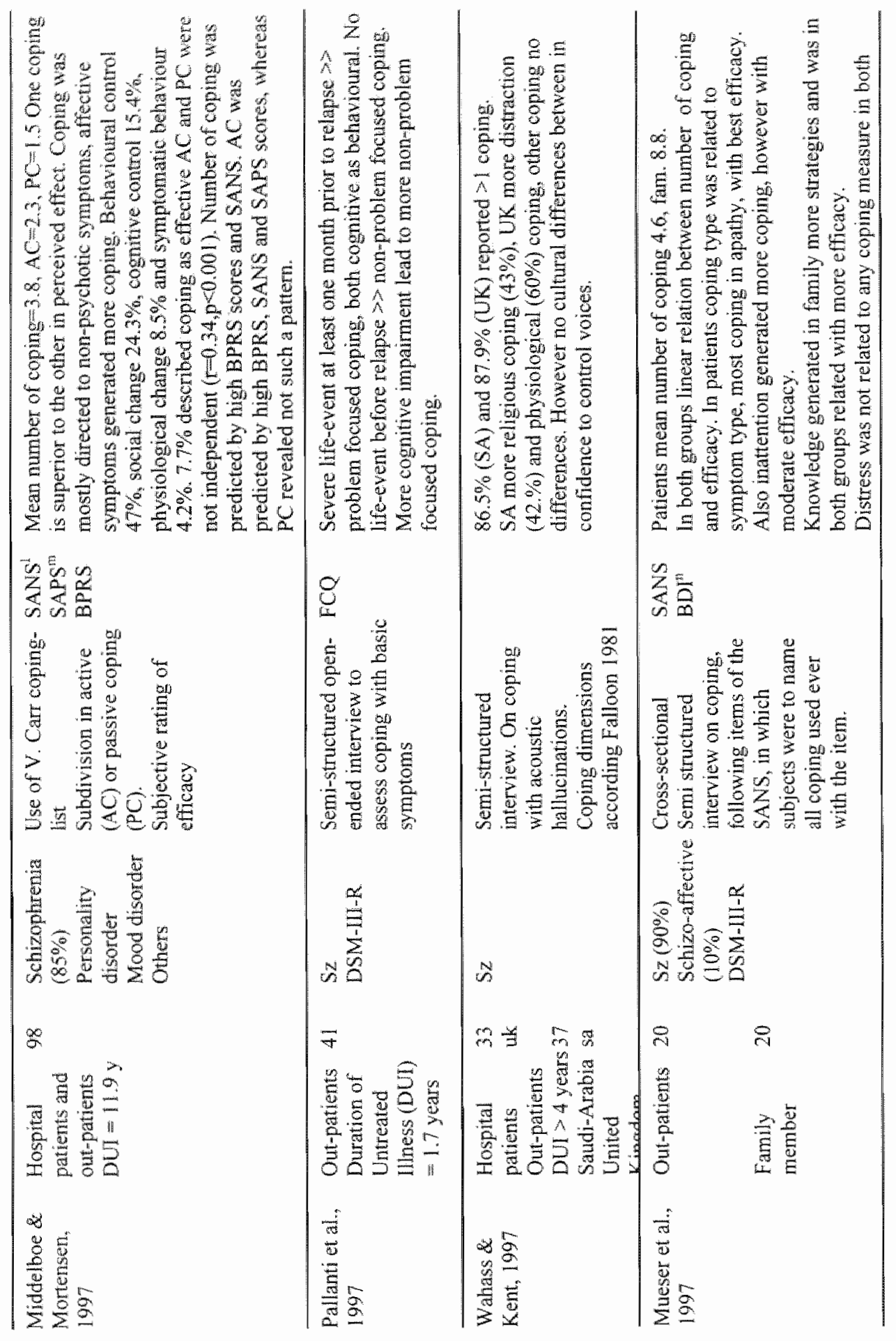




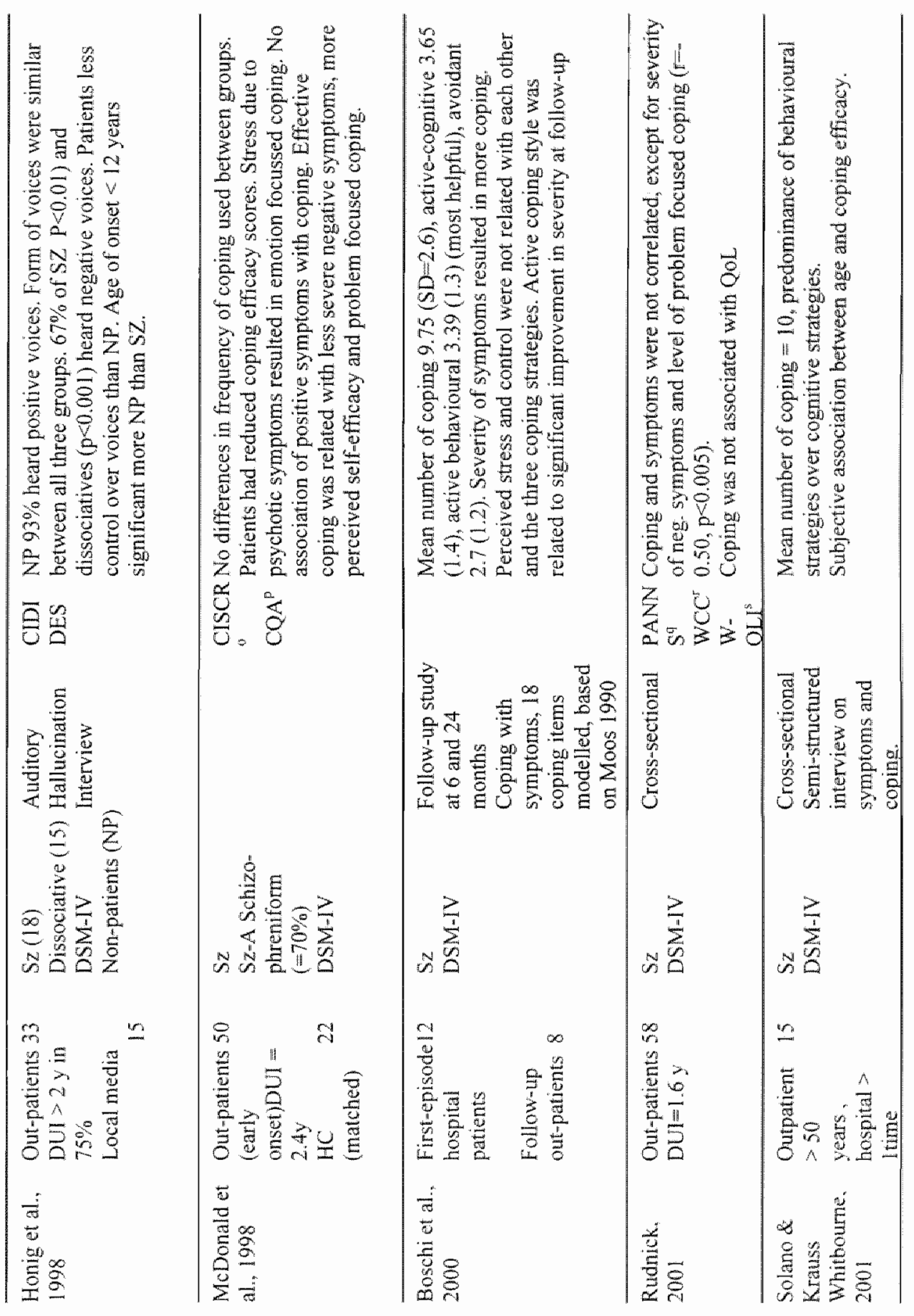




\begin{tabular}{|c|c|c|c|c|}
\hline 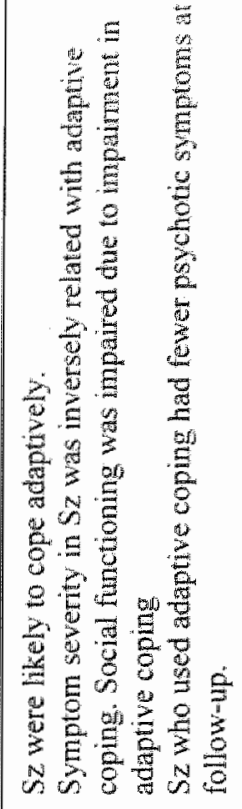 & 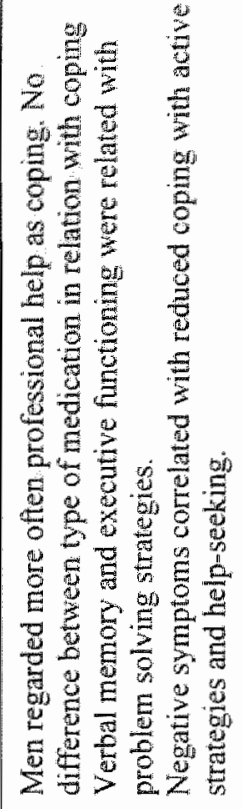 & 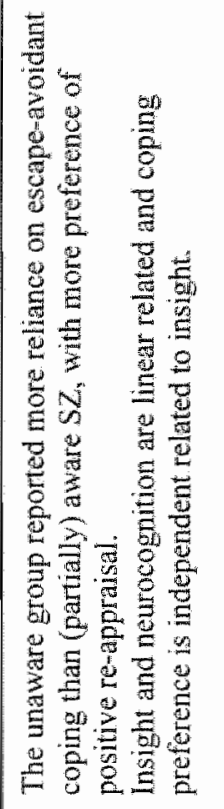 & 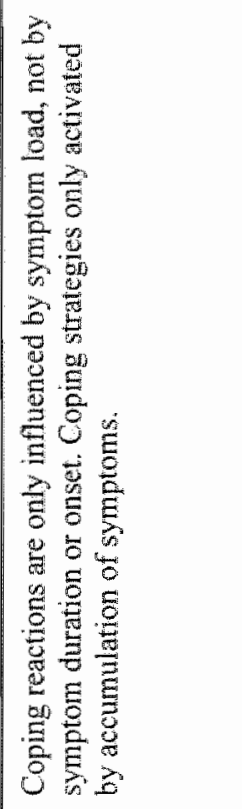 & 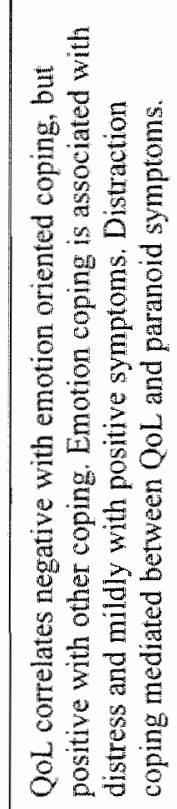 \\
\hline 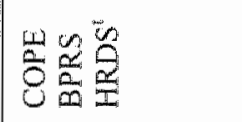 & 象舟员 & $\bigcup_{3} \sum_{\bar{m}}$ & & 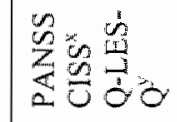 \\
\hline 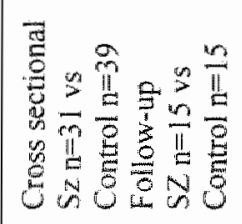 & 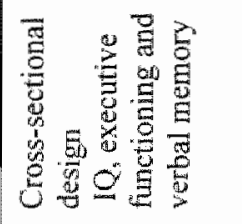 & 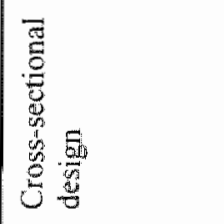 & 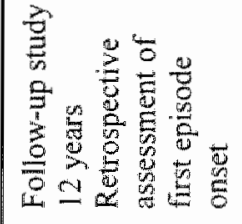 & 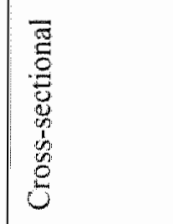 \\
\hline 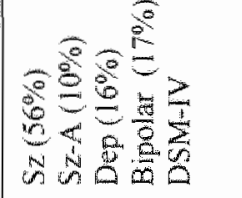 & $\sum_{n=0}^{7}$ & $\sum_{n}^{\frac{1}{2}}$ & 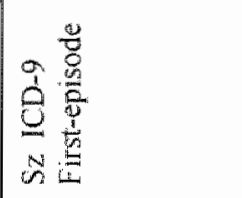 & $\sum_{n}^{2}$ \\
\hline & & $\Rightarrow$ & $\approx$ & $\bar{\square}$ \\
\hline 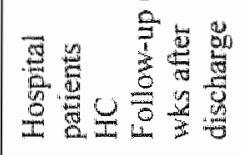 & 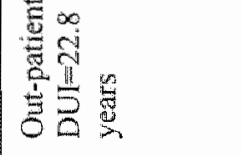 & 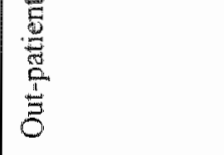 & 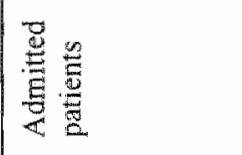 & 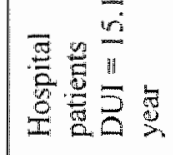 \\
\hline & 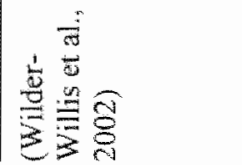 & 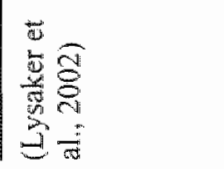 & | & 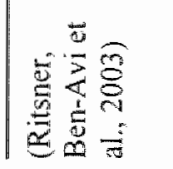 \\
\hline
\end{tabular}


a $\mathrm{FCQ}=$ Frankfurter Complaints Questonnaire (Sülwold, 1983)

bSCS = Frankfurter Selbstkonzeptskalen, Coping - Skala (Deusinger, 1986)

PSE $=$ Present State Examination (Wing et al., 1977)

d SVF $=$ Stress-Coping Questionnaire (Janke, Erdmann, \& Boucsein, 1984)

'UCL = Utrecht Coping List (Schreurs, van de Willige, Tellegen, \& Brosschot, 1988)

'CPT = Continuous Performance Test (Comblatt, Lenzenweger, \& Erlenmeyer-Kimling, 1989; Comblatt, Risch, Faris, Friedman, \& ErlenmeyerKimlling, 1988)

TAS = Test of Attentional Style

" BPRS = Brief Psychiatric rating Scale (Overall \& Gorham, 1962; Ventura, Green M.F., Shaner A., \& Liberman, 1993)

$\mathrm{ACl}=$ Antecent and Coping Interview (Tarrier, 1992)

; MUPS $=$ Mental Health Research Institute Unusual Perceptions Schedule (Carter, Mackinnon, Howard, Zeegers, \& Copolov, 1995)

* COPE $=$ Checklist of Coping Experiences (Carver et al., 1989)

1 SANS = Scale for the Assessment of Negative Symptoms (Andreasen, 1989)

m SAPS = Scale for the Assessment of Positive Symptoms (Andreasen, 1990)

"BDI = Beck Depression Inventory (Beck \& Beamesderfer, 1974)

${ }^{\circ}$ CISCR $=$ Critical Incident Stress and Coping Rating (Madden, James, Hayes, \&al., 1995)

p $\mathrm{CQA}=$ Coping Questionnaire for Adolescents (Madden, James, \& Paton, 1992)

${ }^{q}$ PANNS = Positive and Negative Symptom Scale (Kay et al., 1989)

WCC $=$ Ways of Coping Checklist (Lazarus \& Folkman, 1984)

"W-QLI = Wisconsin Quality of Life Index (Becker, Diamond, \& Sainfort, 1993)

' HRDS = Hamilton Depression Rating Scale (Miller, Bishop, Norman, \& Maddever, 1985)

"PVRQ = Personal Vision of Recovery Questionnaire (Ensfield, 1998)

" SUMD $=$ Scale to Assess Unawareness of Mental Illness (Amador et al., 1995)

" IKW = Interview zur Krankheitsbewältigung (Thurm \& Haefner, 1987)

${ }^{x}$ CISS = Coping Inventory for Stressful Situations (Parker \& Endler, 1990)

Y Q-LES-Q = Quality of Life Enjoyment and Satisfaction Questionnaire (Endicott, Nee, Harrison, \& Blumenthal, 1993) 


\section{References}

Amador, X., Flaum, M., Andreasen, N. C., Strauss, D. H., Yale, S. A., Clark, S., \& Gorman, J. M. (1995). A wareness of illness in schizophrenia and mood disorders. Arch Gen Psychiary, 51, $826-836$.

Andreaser, N. C. (1989). The Scale for the Assessment of Negative Symptoms (SANS): conceptual and theoretical foundations. Br J Psychicatry Suppl(7), 49-58.

Andreasen, N. C. (1990). Methods for assessing positive and negative symptoms. Mod Probl Pharmacopsychiatry, 24, 73-88.

Beck, A. T., \& Beamesderfer, A. (1974). Assessment of depression: the depression inventory. Mod Probl Pharmacopsychiary, 7(0), 151-169.

Becker, M., Diamond, R., \& Sainfort, F. (1993). A new patient focused index for measuring quality of life in persons with severe and persistent mental illness. Quality of Life Research, 2, 239.251.

Böker, W., Brenner, H. D., \& Wurgler, S. (1989). Vulnerability-linked deficiencies, psychopathology and coping behaviour of schizophrenics and their relatives. Br J Psychiatry Suppl(5), 128-135.

Boschi, S., Adams, R. E., Bromet, E. J., Lavelle, J, E., Everett, E., \& Galambos, N. (2000). Coping with psychotic symptoms in the early phases of schizophrenia. Am J Orthopsychiatry, 70(2), 242-252.

Breier, A., \& Strauss, J. S. (1983). Self-control in psychotic disorders. Arch Gen Psychiaty, 40(10), 1141-1145.

Brenner, H. D., Boker, W., Muller, J., Spichtig, L., \& Wurgler, S. (1987). On autoprotective efforts of schizophrenics, neurotics and controls. Acra Psychiatr Scand. 75(4), 405-414.

Carr, V. (1988). Patients' techniques for coping with schizophrenia: an exploratory study. BrJ Med Psychol, 6l(Pt 4), 339-352.

Carter, D. M., Mackinnon, A., Howard, S., Zeegers, T., \& Copolov, D. L. (1995). The development and reliability of the Mental Health Research Institute Unusual Perceptions Schedule (MUPS): an instrument to record auditory hallucinatory experience. Schizophr Res, 16(2), 157-165.

Carter, D. M., Mackinnon, A., \& Copolov, D. L. (1996). Patients' strategies for coping with auditory hallucinations. J Nerv Ment Dis, 184(3), 159-164.

Carver, C. S., Scheier, M. F., \& Weintraub, J. K. (1989). Assessing coping strategies: a theoretically based approach. J Pers Soc Psychol, 56(2), 267-283.

Cohen, L. J., \& Berk, L. A. (1985). Personal coping styles of schizophrenic outpatients. Hosp Community Psychiatry, 36(4), 407-410.

Deusinger, J. (1986). Frankfurter Selbstkonzept Skalen. Weinheim: Beltz.

Dittmann, J., \& Schuttler, R. (1990). Disease consciousness and coping strategies of patients with schizophrenic psychosis. Acta Psychiatr Scamd, 82(4), 318-322.

Dohrenwend, B. S., \& Dohrenwend, B. P. (1974). Stressfil Life Events: Their nature and Effects. New York: Wiley.

Endicott, J., Nee, J., Harrison, W., \& Blumenthal, R. (1993). Quality of life enjoyment and satisfaction questionnaire: A new measure. Psychopharmacology Bullitin, $29,321-326$.

Ensfield, L. B. (1998). The personal vision of recovery questionnaire. Disser, Abstr. Int: Sci. Engng, 59, 2416.

Farhall, J., \& Gehrke, M. (1997). Coping with hallucinations: exploring stress and coping framework. BrJ Clin Psychol, 36(Pt 2), 259-261. 
Honig, A., Romme, M. A., Ensink, B. J., Escher, S. D., Pennings, M. H. \& deVries, M. W. (1998). Auditory hallucinations: a comparison between patients and nonpatients. J Nerv Ment Dis, $186(10)$, 646-651.

Horan, W. P., \& Blanchard, J. J. (2003). Emotional responses to psychosocial stress in schizophrenia: the role of individual differences in alfective traits and coping. Schizophr Res, 60(2-3), 271-283.

Janke, W., Erdmann, G., \& Boucsein, W. (1984). Der Stresswerarbeitungsfragebogen $(S V F)$. Göttingen: Hogrefe.

Janssen, I., Hanssen, M., Bak, M., Bijl, R. V., de Graaf, R., Vollebergh, W., McKenzie, $\mathrm{K}$., \& van Os, J. (2003). Discrimination and delusional ideation. Br J Psychiatry, 182, 71-76.

Kay, S. R., Opler, L. A., \& Lindenmayer, J. P. (1989). The Positive and Negative Syndrome Scale (PANSS): rationale and standardisation. Br.J Psychiatry Suppl(7), 59-67.

Lazarus, R. S., \& Folkman, S. (1984). Stress, Appraisal and Coping. New York: Springer Verlag.

Lee, P. W., Lieh-Mak, F., Yu, K. K., \& Spinks, J. A. (1993). Coping strategies of schizophrenic patients and their relationship to outcone. Br,J Psychiarry, 163 , $177-182$.

Lysaker, P. H., Bryson, G. J., Lancaster, R. S., Evans, J. D., \& Bell, M. D. (2002). Insight in schizophrenia: associations with executive function and coping style. Schizophrenia Research, In Press.

Lysaker, P. H., Wilt, M. A., Plascak-Hallberg, C. D., Brenner, C. A., \& Clements, C. A. (2003). Personallity dimensions in schizophrenia: associations with symptoms and coping. J Nerv Ment Dis, 191(2), 80-86.

Madden, C., James, J., Hayes, R. L., \& al., e. (1995). A Coping Skills Training Programme (Coping with Stress). Melbourne: La Trobe University.

Madden, C., James, J., \& Paton, A. (1992). A Coping Skills Training Programme (Skills) for Adolescents. Melbourne: La Trobe University.

Maurer, K, \& Häfner, H. (2002). Coping and social support as protective factors. In H. Häfner (Ed.), Risk and Protective Factors in Schizophrenia. (pp. $303-320$ ). Darmstadt: Steinkopff.

McDonald, E. M., Pica, S., McDonald, S., Hayes, R. L., \& Baglioni, A. J., Jr. (1998). Stress and coping in early psychosis. Role of symptoms, self-efficacy, and social support in coping with stress. Br J Psychiary Suppl, 172(33), 122-127.

Meyer B. (2001). Coping with severe mentall illness: relations of the Brief COPE wilh symptoms, functioning and well-being. Journal of Psychopathology and Behavioural Assessment, 23(4).

Middelboe, T., \& Mortensen, E. L. (1997). Coping strategies among the long-term mentally ill: categorization and clinical determinants. Acka Psychiar Scand, $96(3), 188-194$.

Miller, I. W., Bishop, S., Norman, W. H., \& Maddever, H. (1985). The modified Hamilton Rating Scale for Depression: Relaibility and Validity. Psychiary Research, $14(131-142)$.

Mueser, K. T., Valentiner, D. P., \& Agresta, J. (1997). Coping with negative symptoms of schizophrenia: patient and family perspectives. Schizophr Bull, 23(2), 329. 339. 
Overall, J. E. \& Gorham, D. (1962). The Brief Psychiatric Rating Scale. Psychological Reports, $10,799-812$.

Pallanti, S., Quercioli, L, \& Pazzagli, A. (1997). Relapse in young paranoid schizophrenic patients: a prospective study of stressfull life events, P300 measures, and coping. Am I Psychiaty, 154(6), 792-798.

Parker, J. D., \& Endler, N. S. (1990). Multidimensional assessment of coping: A critical evaluation. I Pers Soc Psychol, 58, 844-854.

Ritsner, M., Ben-Avi, I., Ponizovsky, A., Timinsky, I., Bistrow, E., \& Modai, I. (2003). Quality of life and coping with schizophrenia symptoms. Qual Life Res" $12(1)$, $1-9$.

Romme, M. A., Honig, A., Noorthoom, E. O., \& Escher, A. D. (1992). Coping with hearing voices: an emancipatory approach. BrJ Psychiath, 161, 99-103.

Rudnick, A. (2001). The impact of coping on the relation between symptoms and quality of life in schizophrenia. Psychiatry, 64(4), 304-308.

Schreurs, P. J.G., van de Willige, G., Tellegen, B., \& Brosschot, J. F. (1988). De Urechtse Coping Lijst: UCL. Handleiding. Lisse. Swets en Zeitlinger.

Solano, N. H., \& Krauss Whitbourne, S. (2001). Coping with schizophrenia: Patterns in later adulthood. Int. J. Aging and Human Development, 53(1), 1-10.

Sillwold, L. (1983). Schizophrenie. Stuttgart: Kohlhammer.

Tarrier, N. (1987). An investigation of residual psychotic symptoms in discharged schizophrenic patients. Br.J Clin Psychol, 26(Pt 2), 141-143.

Tarrier, N. (1992). Management and modification of residual positive psychotic symptoms. In $\mathbb{N}$. Tarrier (Ed.), Innovarions in psychological management of schizophrenia. (pp. 147-169). Chichester: John Wiley \& Sons Ltd.

Tarrier, N., Sharpe, L., Beckett, R., Harwood, S., Baker, A., \& Yusopoff, L. (1993). A trial of two cognitive behavioural methods of treating drug-resistant residual psychotic symptoms in schizophrenic patients. II. Treatment- specific changes. in coping and problem-solving skills. Soc Psychiatry Psychiatr Epidemiol. $28(1), 5-10$.

Thurm, 1., \& Haeliner, H. (1987). Perceived vulnerability, relapse risk and coping in schizophrenia. An explorative study. Eur Arch Psychiatry Newrol Sci, 237(1), $46-53$.

van den Bosch, R. J., \& Rombouts, R. P. (1997). Coping and cognition in schizophrenia and depression. Compr Psychiomry, 38(6), 341-344.

van den Bosch, R. I., van Asma, M. J., Rombouts, R., \& Louwerens, J. W. (1992). Coping style and cognitive dysfunction in schizophrenic patients. $\mathrm{Br} J$ Psychiatry Suppl(18), 123-128.

Ventura, J., Green M.F., Shaner A., \& Liberman, R. P. (1993). Training and Quality Assurance with the Brief Psychiatric Rating Scale: 'the drift Busters". International Jownal of Methods in Psycharmic Research, 3, 221-244.

Wahass, S., \& Kent, G. (1997), Coping with auditory hallucinations: a cross-cultural comparison between westem (British) and non-western (Saudi Arabian) patients. J Nerw Ment Dis, 185(11),664-668.

Wiadl, K. H., \& Schöttner, B. (1989). Die Bewältigung einer schizophrenen Erkrankung (11): weiter fürlurende Forschungsansätze. Zeitschxift für Klinische Psychologie, Psychopathologie und Psychotherapie., 37, 317 - 340.

Wiedl, K. H., \& Rauh, D. A. (1991). Ein halbstrukturiertes Tagebuch als Zugang zur Krankheitsverarbeitung schizophrener Patienten. In M. Perrez (Ed.), Jahrbuch 
der Medizinischen Psychologie: Belastungswerambeinng im Zusammenhang mit Erkrankwngen. Göttingen: Hogrefe.

Wiedl, K. H. (1992). Assessment of coping with schizophrenia. Stressors, appraisals, and coping behaviour. Br J Psychatry Suppl(18), 114-122.

Wilder-Willis, K. E., Shear, P. K., Steffen, J. J., \& Borkin, J. (2002). The relationship between cognitive dysfunction and coping abilities in schizophrenia. Schizoph $\operatorname{Res}_{x} 55(3), 259-267$.

Wing, J. K., Nixon, J. M., Mann, S. A., \& Leff, J. P. (1977). Reliability of the PSE (ninth edition) used in a population study. Psychol Med, 7(3), 505-5 6. 


\section{Dankwoord}

Het behoeft geen nader betoog dat promotieonderzoek teamsport is. Dit promotietraject is daarvan een voorbeeld. I $\mathrm{k}$ wil daarom allen danken die aan de totstandkoming van dit proefschrift hebben bijgedragen. Het was voor mij overigens de enige denkbare strategie om dit promotietraject aan te gaan en tot een goed einde te brengen

Alle patiënten die mijn pad hebben gekruist, die actief geparticipeerd hebben in onderzoek, of bereid waren vragenlijsten en ideeën kritisch te toetsen, will ik danken. Van hen heb ik geleerd dat de onderzoeksvragen die van belang zijn, een zorgbehoefte moeten dienen en pas dan op wederzijds enthousiasme kunnen rekenen. Monique Gerrits ik wil je bijzonder danken voor je actieve participatie als ervaringsdeskundige en het feit dat ik je persoonlijke geschenk mocht gebruiken als kaft van dit boekje.

Temidden van een langdurige en complexe reorganisatie binnen PMS Vijverdal, met veel veranderingen, personele wisselingen en onzekerheden, ondervond ik veel steun van verpleging en collegae, in het bijzonder de kernkliniek en psycope. Zij hielden mij op het rechte pad als ik weer eens tegelijk met zorg, organisatie, onderwijs en onderzoek dacht bezig te moeten zijn. Vooral 04 en later O8-III, tegenwoordig KK 3-4-6 bleek een stabiele factor en een tweede thuis walar het goed toeven is. Door drie keer een aantal maanden waar te nemen op KK2 (O3-III), kreeg ik er een goed omsloten vluchthaven bij. Zeker ook door Min, Leon en Mario, Anky, Sandra, Wim, Roel, Benjamin en Wilma en alle andere verpleegkundigen en Saïd.

Met het ontstaan van psycope werd mijn scope verbreed en werd transmuraal werken het motto. Er was veel onduidelijk, behalve dat tomeloze inzet en enthousiasme tot mooie dingen leiden. Met plezier denk ik terug aan alle bijeenkomsten en het wederzijdse respect. Marcel Hilwig en Dirk Corstens en alle andere psycopisten: laten we door gaan. Frans Dullens en voorheen Jan Bosma effenen de moeilijk begaanbare paden. Het is een genoegen met jullie te werken. Bijzondere dank aan Psycope team II, Gerard, Wiel, Monique, Lucia, Esmée, Frank, Frank, Philippe de verschillende AGIO's, Fred en Lilian

Rob Havermans bedankt voor de gezamenlijkheid waarmee we stand hebben weten te houden in de alsmaar veranderende omstandigheden, hoge zorgdruk en matje verwikkeld in promotie perikelen. Jean-Paul Glaser je ondersteunt in vele opzichten. Detlef Petry wil ik danken als grondlegger van mijn idealen. Je gedrevenheid en idealisme zijn zeer inspirerend en troostend. Dank ook aan Henk Milius, je was er verantwoordelijk voor dat ik met Jim van Os in contact 
kwam en door het onderzoek werd gegrepen. Voor iemand die absoluut geen route kaart kan lezen en geen oriëntatievermogen heeft weet Marie-Anne Haenen de weg binnen de GGZ goed te vinden en inzichtelijk te maken. Een open deur, dropjes en een dosis relativerende humor helpen echt. Wil Brauers, voor mij ben je die betrouwbare dwarsliggende rots in de branding, met het hart de op juiste plaats. Alle AGIO's die geduldig en met kritische noot mijn "wijsheden" aanhoorden.

De MACS was nooit zover gekomen als Steven Radstake en Giovanni Poddighe mij tijdens de stage sociale psychiatrie niet de ruimte hadden gegeven om bij $\mathrm{Jim}$ onderzoek te doen en om het idee coping systematisch in kaart te brengen verder uit werken. Farida van der Spil, jij hebt me bij de start van het traject fantastisch op weg geholpen. Het ontstaan van de MACS en het uitvoeren van de eerste studies, én de evaluatie van NEMESIS zouden zonder jou niet zo goed verlopen zijn. Manon Hanssen, dank voor de wijze waarop je samen met mij de NEMESIS data hebt verwerkt en de discussies die vruchtbaar bleken. Nicole Gunther, je verheft de lach tot kunst. En Ilse Janssen en Nele Jacobs vormden gezellige gesprekspartners. Desirée Nijst je hebt een goede engelse vertaling van de MACS gemaakt. Dit heeft zelfs geleid tot gebruik in Canada, Engeland, China en Japan. Ger Driessen, dankzij jou ben ik genezen van mijn computer fobie. Marjan Drukker, je stille kracht is merkbaar in dit proefschift, omdat je alle vragen en praktische narigheden die mij schier onoverkomelijk leken tot eenvoudige probleempjes wist te reduceren. Moeder Drukker bedankt voor alle correcties. Karola Huistra, ondat je altijd die ene vraag weet te stellen waardoor ik even moet zwijgen. Lydia Krabbendam, het is prettig reizen en discussiëren en overnachten in het "Vondelpark" en samenwerken. Natuurlijk wil ik alle anderen leden van de sectie sociale psychiatrie en psychiatrische epidemiologie danken, voor de zeer sociale wijze waarop jullie mij hebben opgenomen. Jullie zijn het bewijs dat sfeer en productie positief causaal zijn geassocieerd. Rob Bijl, Ron de Graaf en Wilma Vollebergh wil ik danken voor het bieden van de mogelijkheden binnen de NEMESIS studie.

Frank van Dael, psychiater, nog niet zolang psycope teamlid, onderzoeker en pretig gestoord. Gelijkenissen die wij delen, en daarom ben ik vereerd dat je mijn paranimf wilt zijn.

Inez Myin-Germeys, co-promotor, je was en bent van onschatbare waarde voor de kritische analyse van teksten en data, denk aan het zg. tweetjes en vijfjes artikel, dat er nooit is gekomen, maar waardoor de basis werd gelegd voor een high level samenwerking.

Philippe Delespaul, co-promotor en goede collega, mijn dank is groot. We delen dezelfde passie voor mensen bij wie de zorg complex en langdurig is. Ik bewonder je kennis en mathematisch integratief vermogen binnen een abstract realistisch denkkader. Je bent een trouwe en vriendelijke gids, waarvoor ik je bijzonder wil danken. I hoop dat we nog lang een team zullen blijven. 
De gedrevenheid en passie waarmee Jim van Os werkt, zijn zo sprankelend en bruisend dat je wordt meegezogen in zijn tomeloze energie. $1 \mathrm{k}$ heb je leren kennen als een katalysator, als iemand die stimuleert, zelf laat ploeteren, bijstuurt, van kritiek en tegenargumenten houdt, geniet van prestaties van anderen of anderen deelgenoot laat zijn van je eigen prestaties, en die trots is. Waar voor mij twijfel en onzekerheden een zekerheid zijn in het vak, zijn ze voor jou bronnen voor onderzoek. Je hebt me geleerd om kritisch nieuwsgierig te zijn, om de kracht van wetenschap alsook de beperkingen te begrijpen en te waarderen.

Een promotieonderzoek pleegt een aanslag op vrienden en familie. Dat jullie er nog zijn zegt genoeg. Joost, Karin en Robertjan mooi dat jullie er nog zijn voor: mij. Robertjan ik ben trots dat je weer achter me wilt staan nu als paranimf. Hans, dank voor je luisterend professionele oor en ontwapende glimlach. Dory bedankt voor je gastvrijheid thuis en op Vlie, en samen met Ruth voor alle verhaaltjes voor Emma en Jonas.

Frederique en Eleonore, al ben ik niet altijd even toegankelijk, het is goed jullie als zussen te hebben.

$\mathrm{Pa}$ en $\mathrm{Ma}$, zonder jullie was dit proefschrift er helemaal niet geweest. Ongeacht de oppositie, je eigen dwarse weg gaan en deze afmaken zonder dat tijd een rol speelt, en er zijn. Opah en Omah met liefde en dank.

Emma en Jonas, het lijkt voor jullie de gewoonste zaak dat ik er weer eens niet was of met mijn hoofd in de wolken liep. Want pappa is een praat dokter en hij schrijft verhaaltjes. Ik wil wat vaker met jullie ouwehoeren en schrijven.

Lidwien, dank voor je steun, je stimulans om door te gaan, het tijdig remmen en gas geven en het creëren van een thuis. Het is niet gemakkelijk geweest, de donkere wolken zijn overgedreven. Ik wil met jou oud worden. 


\section{Curriculum Vitea}

Maarten Bak werd geboren op 13-01-1963 en groeide op in Merkelbeek. Na het afronden van het VWO-A aan het Serviam Lyceum te Sittard in 1983, werd hij vrachtwagenchauffeur bij de Koninklijke Artillerie. Tijdens de dienstperiode deed hij staatsexamen scheikunde. In 1984 begon hij de studie geneeskunst aan de Rijksuniversiteit Limburg (tegenwoordig Universiteit Maastricht). Aan het einde van de opleiding tot basisarts, volbracht hij ruim twee maanden keuzestage psychiatrie in Exeter (Engeland). Aansluitend startte hij in 1991 als AGNIO op de PAAZ in Sittard. Vervolgens werkte hij van 1992 tot aan de start van opleiding tot psychiater in 1994 als AGNIO op de afd. rehabilitatie bij D. Petry in PMS Vijverdal. Gedurende de opleiding begon hij met onderzoek bij prof. dr. J. van Os.

Vanaf 1999 werkt hij als Universitair Docent verbonden binnen de vakgroep Psychiatrie en Neuropsychologie aan de Universiteit Maastricht. De zorgtaak als psychiater ligt binnen de kernkiniek van PMS Vijverdal met als aandachtsgebied psychotische stoomissen en "Severe Mental Illness". Hij is nauw betrokken bij de opstart en implementatie van het transmurale zorgprogramma "Psycope". Ten behoeve van het Psychose Protocol te Maastricht traint hij, samen met Ph. Delespaul en anderen, zorgverleners in de BPRS (Briel Pstychiatric Rating Scale) en de CAN (Camberwell Assessment of Need). Tevens is hij onbezoldigd consulent psychiatrie bij MEE voorheen SPeD (Sociaal Pedagogische Dienst) te Maastricht. Het resultaat van het wetenschappelijk onderzoek dat hij de laatste vijf jaar heeft verricht, is vervat in deze dissertatie.

Maarten Bak is gehuwd met Lidwien en vader van Emma en Jonas. 


\section{List of publications.}

Alphen, P. J. M., \& Bak, M. (1994). Wat te doen na een suicide poging? Patient Care, $10,70-77$.

Bak, M., Delespaul, P., Hanssen, M., de Graaf, R., Vollebergh, W., \& van Os, J. (2003). How false are "false" positive psychotic symptoms? Sichizoph" Res, 62(1-2), 187-189.

Bak, M., Delespaul, P., Hanssen, M., de Graaf, R., Vollebergh, W., \& van Os, J. (2004). Voorspellende waarde van door clinici erkende en niet-erkende positieve psychotische symptomen: een rospectieve studie in de algemene bevolking. Tijdschrift voor Psychiatrie. 46 (5), 285 - 293.

Bak M., I. Myin-Germeys, Ph. Delespaul, W. Vollebergh, R. de Graaf, J. van Os. Do different psychotic experiences differentially predict need for care in the general population? Submitted for publication

Bak, M., Drukker, M., Os, J. v., \& Delespaul, P. (submitted). Symptoms of manic and excitement dimensions rather than positive dimensions predict hospital admission in patients with a psychotic disorder.

Bak, M., Myin-Germeys, I., Hanssen, M., Bijl, R., Vollebergh, W., Delespaul, P., \& van Os, J. (2003). When does experience of psychosis result in a need for care? A prospective general population study. Schizoph" Bull, $29(2), 349-358$.

Bak, M., Radstake, S., \& van Os, J. (1999). Consultatie aan huisartsen ter detectie van zorgmijdende mensen met een psychose. $M G v_{1}$ 12(12811289).

Bak, M., van der Spil, F., Gunther, N., Radstake, S., Delespaul, P., \& van Os, J. (2001a). Maastricht Assessment of Coping Strategies (MACS-1): a brief instrument to assess coping with psychotic symptoms. Acta Psychiatr Scand. 103(6), 453-459.

Bak, M., van der Spil, F., Gunther, N., Radstake, S., Delespaul, P., \& van Os, J. (2001b). MACS-II: does coping enhance subjective control over psychotic symptoms? Acta Psychiatr Scand, 103(6), 460-464.

Delespaul, P., Bak M., \& Van Os, J. (2002). Handleiding Maastrichtse Psychoseprotocol (2e edition ed.). Maastricht: Maastricht University.

Driessen, G., Gunther, N., Bak, M., van Sambeek, M., \& van Os, J. (1998).

Characteristics of early- and late-diagnosed schizophrenia: implications for first-episode studies. Schizophr Res, 33(1-2), $27-34$.

Drukker, M., Bak, M., Driessen, G., Os, J. v., \& Delespaul, P. (submitted). Is zorbehoefte gemeten met de "Camberwell Assessment of Need" vragenlijst een voorspeller voor (verandering in) zorgbehoefte?

Haack, M. J., Bak, M. L., Beurskens, R., Maes, M., Stolk, L. M., \& Delespaul, P. A. (2003). Toxic rise of clozapine plasma concentrations in relation to inflammation. Eur Neuropsychopharmacol, 13(5), 381-385. 
Hanssen, M., Bak M., Bijl, R. V., Vollebergh, W., \& Os, J. v. (2004). Outcome of self-reported psychotic experiences in the general population: a prospective study. submitted.

Janssen, I., Hanssen, M., Bak, M., Bijl, R. V., De Graaf, R., Vollebergh, W., McKenzie, K., \& Van Os, J. (2003). Discrimination and delusional ideation. BrJ Psychiatry, 182(1), 71-76.

Janssen, I., Krabbendam, L., Bak, M., Hanssen, M., Vollebergh, W., de Graaf, R., \& van Os, J. (2004). Childhood abuse as a risk factor for psychotic experiences. Acta Psychiatr Scand 109(1), 38-45.

Krabbendam, L., Hanssen, M., Bak, M., \& Van Os, J. (2003). Psychotic features in the general population. Riskfactors for what? In W. Gattaz \& H. Häfner (Eds.), In search for the causes of schizophrenia. Darmstadt: Steinkopff Verlag.

Krabbendam, L., Janssen, I., Bak, M., Bijl, R. V., de Graaf, R., \& van Os, J. (2002). Neuroticism and low self-esteem as risk factors for psychosis. Soc Psychiatry Psychiatr Epidemiol, 37(1), 1-6.

Krabbendam, L., Myin-Germeys, I., Hanssen, M., Bijl R.V., de Graaf, R., Vollebergh, W., Bak, M., \& van Os, J. (2003). Hallucinatory experiences and onset of psychotic disorder: Evidence that the risk is mediated by delusion formation. submitted.

van Diest, R., Bak, M., Schruers, K., van Dalen, J., Scherpbier, A., \& van der Vleuten, C. (2003). Problem based learning at Maastricht University: Evaluation of psychiatric education with the progress test. Medizinische Ausbildung., 20, 197-201.

van Diest, R., van Dalen, J., Bak, M., Schruers, K., van der Vleuten, C., Muijtens, A., \& Scherpbier, A. (submitted). Growth of knowledge in Psychiatry and Behavioural Sciences in a Problem-Based learning Curriculum. Medical Education.

van Os, J., Bak, M., Hanssen, M., Bijl, R. V., de Graaf, R., \& Verdoux, H. (2002). Cannabis use and psychosis: a longitudinal population-based study. Am J Epidemiol, 156(4), 319-327.

van Os, J., Delespaul, P., Radstake, S., Hilwig, M., Bak, M., \& Driessen, G. (2001). Kernparameters ter evaluatie van een zorgpromma van psychotische patiënten. $M G v, 10$.

van Os, J., Hanssen, M., Bak, M., Bijl, R. V., \& Vollebergh, W. (2003). Do urbanicity and familial liability coparticipate in causing psychosis? $A m$ J Psychiatry. $160(3), 477-482$.

van Os, J., Janssen, 1., Hanssen, M., Bak, M., Myin-Germeys, I., Marcelis, M., Bijl, R., Vollebergh, W., \& Delespaul, P. (2002). Cognitive epidemiology: psychological and social risk mechanisms for psychosis. In H. Häfner (Ed.), Risk and protective factors in schizophrenia. Towards a conceptual model of the disease process. Darmstadt: Steinkopff Verlag. 